\title{
The Effect of Bypass Nozzle Exit Area on Fan Aerodynamic Performance and Noise in a Model Turbofan Simulator
}

Christopher E. Hughes, Gary G. Podboy, Richard P. Woodward, and Robert J. Jeracki

Glenn Research Center, Cleveland, Ohio 


\section{NASA STI Program . . . in Profile}

Since its founding, NASA has been dedicated to the advancement of aeronautics and space science. The NASA Scientific and Technical Information (STI) program plays a key part in helping NASA maintain this important role.

The NASA STI Program operates under the auspices of the Agency Chief Information Officer. It collects, organizes, provides for archiving, and disseminates NASA's STI. The NASA STI program provides access to the NASA Aeronautics and Space Database and its public interface, the NASA Technical Reports Server, thus providing one of the largest collections of aeronautical and space science STI in the world. Results are published in both non-NASA channels and by NASA in the NASA STI Report Series, which includes the following report types:

- TECHNICAL PUBLICATION. Reports of completed research or a major significant phase of research that present the results of NASA programs and include extensive data or theoretical analysis. Includes compilations of significant scientific and technical data and information deemed to be of continuing reference value. NASA counterpart of peer-reviewed formal professional papers but has less stringent limitations on manuscript length and extent of graphic presentations.

- TECHNICAL MEMORANDUM. Scientific and technical findings that are preliminary or of specialized interest, e.g., quick release reports, working papers, and bibliographies that contain minimal annotation. Does not contain extensive analysis.

- CONTRACTOR REPORT. Scientific and technical findings by NASA-sponsored contractors and grantees.
- CONFERENCE PUBLICATION. Collected papers from scientific and technical conferences, symposia, seminars, or other meetings sponsored or cosponsored by NASA.

- SPECIAL PUBLICATION. Scientific, technical, or historical information from NASA programs, projects, and missions, often concerned with subjects having substantial public interest.

- TECHNICAL TRANSLATION. Englishlanguage translations of foreign scientific and technical material pertinent to NASA's mission.

Specialized services also include creating custom thesauri, building customized databases, organizing and publishing research results.

For more information about the NASA STI program, see the following:

- Access the NASA STI program home page at http://www.sti.nasa.gov

- E-mail your question to help@sti.nasa.gov

- Fax your question to the NASA STI Information Desk at 443-757-5803

- Phone the NASA STI Information Desk at 443-757-5802

- Write to: STI Information Desk NASA Center for AeroSpace Information 7115 Standard Drive Hanover, MD 21076-1320 


\section{The Effect of Bypass Nozzle Exit Area on Fan Aerodynamic Performance and Noise in a Model Turbofan Simulator}

Christopher E. Hughes, Gary G. Podboy, Richard P. Woodward, and Robert J. Jeracki Glenn Research Center, Cleveland, Ohio

Prepared for the

Turbo Expo 2005

sponsored by the American Society of Mechanical Engineers

Reno, Nevada, June 6-9, 2005

National Aeronautics and

Space Administration

Glenn Research Center

Cleveland, Ohio 44135 
Level of Review: This material has been technically reviewed by technical management.

Available from

NASA Center for Aerospace Information 7115 Standard Drive

Hanover, MD 21076-1320
National Technical Information Service 5301 Shawnee Road Alexandria, VA 22312

Available electronically at http://www.sti.nasa.gov 


\title{
The Effect of Bypass Nozzle Exit Area on Fan Aerodynamic Performance and Noise in a Model Turbofan Simulator
}

\author{
Christopher E. Hughes, Gary G. Podboy, Richard P. Woodward, and Robert J. Jeracki \\ National Aeronautics and Space Administration \\ Glenn Research Center \\ Cleveland, Ohio 44135
}

\begin{abstract}
The design of effective new technologies to reduce aircraft propulsion noise is dependent on identifying and understanding the noise sources and noise generation mechanisms in the modern turbofan engine, as well as determining their contribution to the overall aircraft noise signature. Therefore, a comprehensive aeroacoustic wind tunnel test program was conducted called the Fan Broadband Source Diagnostic Test as part of the NASA Quiet Aircraft Technology program. The test was performed in the anechoic NASA Glenn 9- by 15-Foot Low Speed Wind Tunnel using a $1 / 5$ scale model turbofan simulator which represented a current generation, medium pressure ratio, high bypass turbofan aircraft engine. The investigation focused on simulating in model scale only the bypass section of the turbofan engine. The test objectives were to: identify the noise sources within the model and determine their noise level; investigate several component design technologies by determining their impact on the aerodynamic and acoustic performance of the fan stage; and conduct detailed flow diagnostics within the fan flow field to characterize the physics of the noise generation mechanisms in a turbofan model. This report discusses results obtained for one aspect of the Source Diagnostic Test that investigated the effect of the bypass or fan nozzle exit area on the bypass stage aerodynamic performance, specifically the fan and outlet guide vanes or stators, as well as the farfield acoustic noise level. The aerodynamic performance, farfield acoustics, and Laser Doppler Velocimeter flow diagnostic results are presented for the fan and four different fixed-area bypass nozzle configurations. The nozzles simulated fixed engine operating lines and encompassed the fan stage operating envelope from near stall to cruise. One nozzle was selected as a baseline reference, representing the nozzle area which would achieve the design point operating conditions and fan stage performance. The total area change from the smallest to the largest nozzle was 12.9 percent of the baseline nozzle area.

The results will show that there are significant changes in aerodynamic performance and farfield acoustics as the fan nozzle area is increased. The weight flow through the fan model increased between 7 and 9 percent, the fan and stage pressure dropped between 8 and 10 percent, and the adiabatic efficiency increased between 2 and 3 percent - the magnitude of the change dependent on the fan speed. Results from force
\end{abstract}

balance measurements of fan and outlet guide vane thrust will show that as the nozzle exit area is increased the combined thrust of the fan and outlet guide vanes together also increases, between 2 and 3.5 percent, mainly due to the increase in lift from the outlet guide vanes. In terms of farfield acoustics, the overall sound power level produced by the fan stage dropped nearly linearly between $1 \mathrm{~dB}$ at takeoff condition and $3.5 \mathrm{~dB}$ at approach condition, mainly due to a decrease in the broadband noise levels. Finally, fan swirl angle survey and Laser Doppler Velocimeter mean velocity and turbulence data obtained in the fan wake will show that the swirl angles and turbulence levels within the wake decrease as the fan nozzle area increases, which helps to explain the drop in the fan broadband noise at all fan speeds.

\section{Nomenclature}

$\begin{array}{ll}\mathrm{A} & \text { Cross sectional area, } \mathrm{in}^{2} \\ \mathrm{c} & \text { Airfoil chord, in } \\ \mathrm{M} & \text { Mach number } \\ \mathrm{N} & \text { Mechanical fan rotational speed, } \mathrm{rpm} \\ \mathrm{N}_{\mathrm{c}} & \text { Corrected fan speed, } \frac{\mathrm{N}}{\sqrt{\theta}} \\ & \\ \mathrm{NP}_{\mathrm{c}} & \text { Percent of corrected fan design speed, } \frac{\mathrm{N}_{\mathrm{c}}}{\mathrm{N}_{\mathrm{dp}}} \cdot 100, \\ & \text { percent } \\ \mathrm{P} & \begin{array}{l}\text { Pressure, psia } \\ \mathrm{R}\end{array} \\ \mathrm{T} & \text { Gas constant, } 53.35 \mathrm{ft} \mathrm{lb}_{\mathrm{f}} / \mathrm{lb}_{\mathrm{m}}{ }^{\circ} \mathrm{R} \\ \mathrm{t} & \text { Airfoil thickness, in } \\ \gamma & \text { Specific heat ratio, } 1.4 \\ \delta & \text { Pressure correction to standard day conditions, } \\ & \quad \mathrm{P}_{\mathrm{t}, \mathrm{o}} \\ & 14.696\end{array}$

Adiabatic efficiency, $\frac{\left(\mathrm{P}_{\mathrm{t}} / \mathrm{P}_{\mathrm{t}, \mathrm{o}}\right)^{\frac{\gamma-1}{\gamma}}-1}{\left(\mathrm{~T}_{\mathrm{t}} / \mathrm{T}_{\mathrm{t}, \mathrm{o}}\right)^{-1}}$

$\theta$ Temperature correction to standard day conditions, $\frac{\mathrm{T}_{\mathrm{t}, \mathrm{o}}}{518.67}$ 
$\omega$

Weight flow rate,

$A_{b m} \sqrt{\frac{\gamma}{R}} \frac{P_{t, b m}}{\sqrt{T_{t, b m}}} \frac{M_{b m}}{\left(1+\frac{\gamma-1}{2} M_{b m}^{2}\right)^{\frac{\gamma+1}{2(\gamma-1)}}}, l_{b_{m} / s e c}$

$\omega_{\mathrm{c}} \quad$ Corrected weight flow rate, $\omega \frac{\sqrt{\theta}}{\delta}, \mathrm{lb}_{\mathrm{m}} / \mathrm{sec}$

$\Theta \quad$ Acoustic angle, deg

\section{Subscripts}

$\begin{array}{ll}\text { ae } & \text { Adiabatic efficiency } \\ \text { bm } & \text { Bellmouth inlet condition } \\ \text { c } & \text { Corrected condition } \\ \text { dp } & \text { Design point } \\ \text { em } & \text { Emission } \\ \mathrm{f} & \text { Fan value } \\ \mathrm{f} & \text { Force } \\ \text { geom } & \text { Geometric } \\ \mathrm{m} & \text { Mass } \\ \mathrm{o} & \text { Freestream condition } \\ \mathrm{s} & \text { Static condition } \\ \mathrm{s} & \text { Stage value } \\ \mathrm{t} & \text { Total condition }\end{array}$

\section{Introduction}

In recent years, commercial aircraft noise has become a major concern for aircraft owners and airport operators. The increased frequency of takeoffs and landings has produced an increasing number of complaints from local residents. The Federal Aviation Administration in the United States and the International Civil Aviation Organization, the international organization that coordinates environmental noise issues, have responded to these complaints by issuing increasingly more stringent noise regulations and curtailed flight operations for aircraft, forcing aircraft and engine manufacturers to pursue quieter aircraft designs. With the support of Congress, NASA and the U.S. aircraft and engine manufacturing companies have joined to cooperatively investigate high-risk technologies for reducing aircraft noise through programs such as the NASA Advanced Subsonic Technology (refs. 1 to 4) and Quiet Aircraft Technology Programs.

As part of an overall NASA effort to reduce aircraft noise, technical programs were initiated starting in 1989 with the major U.S. aircraft manufacturers to investigate noise reduction technologies. As part of this effort, NASA established aggressive goals to reduce the noise signature of then 1992 technology turbofan engines by 6 EPNdB (Effective Perceived Noise $\mathrm{dB}$ ) by the year 2000. Engine studies were conducted across a wide range of engine and aircraft operating cycles to identify and quantify the benefit of potential noise reduction concepts. Several noise reduction technology concepts were investigated using scale model wind tunnel testing of turbofan engine simulators, and the noise reduction potential successfully demonstrated in most cases (refs. 5 to 10). However, new noise reduction standards and new noise reduction program goals were aggressively pushing the technology. The goals of the NASA Quiet Aircraft Technology Program, the follow-on the Advanced Subsonic Technology program, sought to reduce turbofan noise by another 4 EPNdB by 2006, using 1997 High Bypass turbofan engine technology as the baseline. This new level of noise reduction technology would require novel technical approaches.

Therefore, in order to more fully understand the noise sources and noise generation mechanisms in a modern turbofan engine and be able to properly guide further noise reduction technology development, a comprehensive scale model wind tunnel test of a turbofan simulator was planned, called the "Fan Broadband Source Diagnostic Test," or just Source Diagnostic Test. The test was a cooperative effort between NASA and General Electric Aircraft Engines. It was a two-phase experimental investigation conducted in the NASA Glenn anechoic 9- by 15-Foot Low Speed Wind Tunnel to identify and understand the noise source mechanisms within a turbofan engine and determine their individual contributions to the overall engine system noise signature. For this test, the bypass stage portion of a medium pressure ratio, high bypass ratio turbofan engine was simulated in approximately $1 / 5$ model scale. The fan model consisted of a 22 in., 22-blade, wide-chord fan, an outlet guide vane or stator assembly, and a simulated flight-type nacelle which included a fixed area nozzle and an inner flowpath contour simulating the outer core cowling. The emphasis for this test was placed only on simulating the bypass stage portion of the engine, not the booster core or power stage, eliminating the possibility of contaminating the fan noise field with the noise from a simulated core. Likewise, to minimize the noise contamination sources within the fan model, the outlet guide vanes were used to support the nacelle, eliminating any struts or pylons from the flowpath. The fan model was powered by the NASA Glenn Ultra High Bypass Drive Rig propulsion simulator. In order to simulate aircraft flight effects during takeoff roll, approach and landing phases, wind tunnel velocities up to Mach number 0.10 were provided during acoustic testing.

The Source Diagnostic Test had several technical objectives, both acoustic and aerodynamic. The first phase of testing, completed in 2000, verified the usability of the proposed fan as a baseline for future technology development. The aerodynamic performance and farfield acoustics of the fan were measured. In addition, the effect of the number of outlet guide vanes used, as well as the effect of aft radial sweep and chord length, on the aerodynamic performance and noise level of the fan model was investigated with three different outlet guide vane designs (ref. 11). The overall test had several areas of investigation including acoustic mode measurements using sensors located on the inner surface of the fan duct, spinning mode 
measurements using a rotating acoustic rake in both the inlet and the nozzle, unsteady surface pressure measurements on two different types of outlet guide vanes, and detailed flow diagnostic measurements using laser doppler velocimetry and hot-wire anemometry. Some results from this phase of the test can be found in references 12 to 16 . Also, the first rotor alone testing in a wind tunnel using realistic fan geometry was accomplished (ref. 14) This part of the testing was important for understanding the contribution of the fan noise sources to the overall engine system noise.

In phase two, completed in 2003, the same fan model components (including the baseline fan and outlet guide vanes (OGVs)) were used to determine the effect of fan tip clearance and bypass nozzle exit area on the aerodynamic performance and noise. Previous research has been conducted to determine the effect of nozzle area on fan performance and noise (refs. 17 to 21). However, this work was performed using then current technology that, while not directly applicable to current generation turbofans, did provide invaluable direction and guidance for future areas of noise reduction research. In addition, the previous investigations were conducted using a more component riglike research apparatus. The results presented in this paper have a direct relationship with current technology, which can be scaled directly to full scale application. In addition, a comprehensive set of flow diagnostic surveys using Laser Doppler and Particle Image Velocimetry were performed to measure the unsteady velocity and turbulence components within the internal model flowfield. These data allow a better understanding of the flow physics and how it interacts with the model hardware, leading to identifying and understanding the mechanisms that produce noise within the model.

This paper will discuss the results of an investigation to determine the effect of the bypass nozzle exit area on the fan bypass stage aerodynamic and acoustic performance. Four different nozzle area geometries were designed and fabricated for use with a baseline fan and outlet guide vanes. The total area change investigated was 12.9 percent of the baseline nozzle area, which was the original Source Diagnostic Test Phase One fan nozzle, designed to achieve optimum fan stage performance at the design point conditions. Relative to the baseline nozzle, one smaller nozzle and two larger nozzle areas were tested. The aerodynamic performance of the fan and OGVs with each of the four nozzle configurations will be discussed in terms of fan and stage pressure, temperature and adiabatic efficiency maps including radial profiles downstream of the fan. Farfield acoustics for the fan model with three nozzle configurations (the baseline nozzle and the two larger area nozzles) will be provided in terms of reduction of overall sound power level noise at various fan speeds. Finally, flow diagnostics will be shown which will describe the mean velocity and turbulence components in the fan wake for three of the nozzles for several fan speeds in order to show the changes in these components with increasing nozzle area and their relationship to the farfield acoustics.

\section{Research Apparatus}

\section{NASA Glenn Research Center 9- By 15-Foot Low Speed Wind Tunnel}

The 9- by 15-Foot Low Speed Wind Tunnel (9x15) is an anechoic wind tunnel facility located at the NASA Glenn Research Center in Cleveland, Ohio. The facility is operated as an open loop, continuous flow wind tunnel at atmospheric pressure conditions. The test section is located in the return leg of the NASA Glenn 8- by 6-Foot Supersonic Wind Tunnel flow circuit. The two wind tunnels share a common airflow drive system. The 9x15 wind tunnel is capable of producing Mach numbers 0.0 to 0.23 (ref. 22) in the test section. Static propulsion system performance testing is also conducted in this facility. Flow conditioning upstream of the test section allows the facility to produce very low freestream turbulence and distortion levels, making it ideal for acoustic testing of propulsion systems (ref. 23). The test section surfaces are covered with boxes filled with an acoustic treatment material that is capable of absorbing sound reflections down to $250 \mathrm{~Hz}$ (refs. 24 to 26). Figure 1 is an overview of the wind tunnel circuit. Figures $2 \mathrm{a}$ and $\mathrm{b}$ provide an overhead view drawing of the 9x15 test section and the location of the installed research hardware and instrumentation for aerodynamic performance and farfield acoustic configurations.

\section{Turbofan Propulsion Simulator}

A propulsion simulator called the NASA Glenn Ultra High Bypass (UHB) Drive Rig was used to power the model fan test article. Details about the UHB Drive Rig can be obtained from a report documenting the General Electric Aircraft Engines (GEAE) Universal Propulsion Simulator (ref. 27), which is very similar to the NASA Glenn UHB Drive Rig simulator. A four-stage air turbine generates the power that is supplied to the fan model through a common shaft connection. The air turbine is driven by high pressure (up to $350 \mathrm{psi}$ ), high temperature (up to $550^{\circ} \mathrm{F}$ ) air that is supplied to it from tubes running through a support strut that mounts the UHB Drive Rig in the wind tunnel test section. The UHB Drive Rig can generate a maximum of 5,000 shaft horsepower at $16,850 \mathrm{rpm}$. Figure 3 provides a cutaway view of the UHB Drive Rig and a table of maximum performance parameters.

\section{Fan Module}

The research model, or fan module, used was a 1/5-scale model representation of the bypass stage of a current generation high bypass turbofan aircraft engine. The fan module was designed and built by GEAE with partial funding under contract to NASA Glenn. Only the bypass section of the engine was simulated in order to ensure that the fan model noise field was not contaminated by noise from a core section simulator. The fan module consisted of the fan, 
the outlet guide vanes (OGVs) and a flight-type nacelle. The nacelle included a flight-type inlet, a cowl and a fixed-area, flight-type bypass exhaust nozzle. In order to minimize adding additional noise sources within the model, the OGVs were designed to provide structural support for the nacelle, thereby eliminating the need for struts normally present in a turbofan engine. In addition, neither pylon nor bifurcations were simulated in the model. Figure 4 shows a cutaway view of the fan module in the flight configuration, showing the location of various model components.

The fan used for this test was 22 in. in diameter and had 22 individual, wide-chord, titanium blades. In combination with the 54 vane baseline OGVs, the fan model had a stage design point pressure ratio of 1.47 at a model corrected speed of $12,657 \mathrm{NP}_{\mathrm{c}}$, corresponding to a design point fan tip speed of $1,215 \mathrm{ft} / \mathrm{s}$. Table 1 provides a summary of the design parameters for the fan. The fan was a scale model designed and previously tested by GEAE, who designated the fan as "R4." The fan was originally designed to operate in conjunction with a powered core simulator. As a result, the performance level at its design point could not be achieved in this test since this installation did not include a core simulation. However, since this fan was meant to be representative of current technology, the performance compromise was deemed to be acceptable for this test. The fan was tested with a rubstrip casing that was designed for a .020 in. fan blade tip clearance at the fan design point $(100 \%$ corrected fan speed, or 12,657 $\mathrm{NP}_{\mathrm{c}}$ ). This clearance was selected as representative of a turbofan engine which had undergone many takeoff and landing cycles, and therefore could potentially be the noisiest configuration. In addition, this tip clearance minimized the chance of a fan rub event during testing, thus insuring a clean and uniform flowpath contour at the fan tip. This was important for obtaining uncontaminated acoustic data and LDV fan wake flow diagnostic survey data, since a discontinuity in the flowpath after a rub would alter the tip flowfield.

There were four fixed-area fan nozzles designed for testing. Typically, fixed-area, "flight-type" engine nozzles are sized so the engine can achieve maximum efficiency at cruise conditions. For this test, a baseline nozzle and three additional fan nozzles were included which allowed the fixed operating line to be varied across the fan and stage operating maps. The purpose of the additional fan nozzles was to determine the effect of reducing the fan blade loading on the fan module acoustics. The four fan nozzles were: 1), a Baseline (BL) nozzle, typically used as the nozzle for all acoustic testing, and designed to achieve minimum pressure losses across the OGVs and maximum efficiency at the design point (normally, cruise conditions); 2), a Low Flow (LF) nozzle, which reduced the fan exit area by 2 percent compared with the BL nozzle and the maximum fan weight flow by 2.5 percent at the fan design speed; 3), a Design Point (DP) nozzle, which increased the fan exit area 5.4 percent and the maximum weight flow by 5 percent; and 4), a High Flow (HF) nozzle that increased the fan exit area
10.9 percent and the maximum weight flow by 7.5 percent. The size for the additional nozzles was determined using previous fan performance results (ref. 11) and isentropic flow relationships in an iterative spreadsheet program. A plot of the four flight-type fan nozzle geometries is shown in figure 5. Table 3 lists the design parameters for the four fan nozzles.

To establish the fan and OGV performance, the fan module installation included a uniform-inflow bellmouth inlet and either the fixed-area flight-type nozzle or a Variable area Fan Exit Nozzle (VFEN). The fixed area nozzle was used to obtain the fan performance on a representative operating line for a turbofan engine installation, at sea level conditions. The VFEN was used to obtain fan and stage performance across a range of fan speed operating conditions and simulated aircraft flight conditions. It consisted of a series of trapezoidal-shaped plates, each with a central radial pivot, arranged circumferentially in an annular duct. The plates moved in pairs in opposing directions to one another, like double doors. The fan operating point was changed by varying the exit area, and therefore the back pressure on the fan and weight flow through the fan stage, while at a constant fan speed. Changing the fan back pressure simulates a change in the aircraft flight speed and altitude. In figure $6 a$, photographs of the fan module in the aerodynamic performance configuration while installed in the $9 \times 15$ wind tunnel test section are shown. Figure $6 \mathrm{~b}$ is a close-up view of the VFEN arrangement.

\section{Laser Doppler Velocimetry}

In order to conduct the LDV wake survey it was necessary to place part of the LDV system inside the test section of the wind tunnel. Figure $7 \mathrm{a}$ shows a photograph of the LDV traverse system located on the side of the fan model. The traverse was used to move the LDV probe volume radially and axially relative to the model. The LDV system optics are located behind the cylindrical shield shown in the photo. This shield was installed to keep the tunnel flow from striking the optics.

Figure $7 \mathrm{~b}$ shows a photograph taken with the cylindrical shield removed. In this photo the fiber optic cables used to deliver the laser beams into the tunnel, the transmitting optics used to direct the beams into the model, and one set of receiving optics can be seen. The LDV system is a fourbeam, two-color, backscatter system which allows the measurement of two components of velocity simultaneously. Two green beams were used to measure the axial component of velocity, while two blue beams allowed the measurement of the tangential component. The photo provided in figure $7 \mathrm{~b}$ shows one of two optical arrangements used during the test. As pictured, only one component of velocity could be measured at a time. Initially, another optical arrangement, one employing two sets of receiving optics (one above and one below the transmitting optics) was used to conduct the wake surveys. During the initial surveys it was possible to 
measure both the axial and tangential velocity components simultaneously.

The LDV flow diagnostic wake surveys were conducted with bellmouth inlet installed on the model. The bellmouth inlet provided essentially the same flow into the fan as the flight inlet, but allowed the tunnel to be run at a lower speed. This provided the following benefits: 1) the test was conducted at a lower cost and 2) the LDV system components mounted in the test section were subjected to lighter air loads. The test section Mach number during the LDV testing was approximately 0.05 . Two windows installed in the side of the model permitted optical access to the internal flow. These two windows are shown in the photograph of figure $8 \mathrm{~b}$. The downstream window shown at the left was used to acquire the wake surveys. These windows, made of $0.1 \mathrm{in}$. thick sodium alumino silicate, were slumped in a furnace to have the same shape as the inner contour of the model.

In order to acquire LDV data at the axial location corresponding to the leading edge of the Baseline stators, a different set of OGVs were installed in the fan module. This alternate set consisted of 26 vanes, each with $30^{\circ}$ of leading edge radial sweep. The increase in the axial length between the fan trailing edge and the OGV leading edge provided by the swept OGVs allowed a large downstream LDV window to be used, which in turn allowed the Baseline OGV leading edge axial location to be viewed by the LDV system. Test results previously obtained for the fan module during the Source Diagnostic Test Phase 1 have shown that the fan and stage performance were relatively unaffected by replacing the Baseline OGVs with the swept OGVs (ref. 11).

\section{Research Instrumentation}

\section{Aerodynamic}

Freestream conditions in the wind tunnel were determined using a ceiling mounted pitot-static rake with thermocouples located near the entrance to the test section. Fan inlet conditions to the bellmouth were determined using a floor mounted, cruciform-shaped rake located near the fan centerline and upstream of the bellmouth inlet. Total pressure and total temperature conditions upstream of the fan and within the fan stream tube were measured using this rake. The fan weight flow was determined using static pressure measurements obtained within the bellmouth inlet and a flow correlation function which related the average of the bellmouth static pressures to the fan weight flow.

Fan and stage performance were determined using fixed total pressure/total temperature rakes mounted behind the fan and OGVs. Fan performance was obtained using three rakes and stage performance was obtained with seven rakes. Each rake consisted of seven measurement sensors, and each sensor contained a total pressure probe and a total temperature probe co-located within an aspirated stagnation tube. The sensors on each rake were located radially in such a way as to provide flow conditions at the center of equal areas. In addition, surface mounted static pressures were located at several axial locations in the fan module for calculating internal velocities. During the fixed operating line testing with the fixed area nozzle installed, only fan performance could be measured, since the stage performance rakes could only be installed in the model with the VFEN in place. A complete description of the aerodynamic performance instrumentation used in this test can be found in reference 11 .

Forces produced by the fan and OGV were measured using two different types of force balances. Thrust and torque produced by the fan was measured with a two-component rotating force balance. Signals from this balance were transmitted to the data system using a 104 channel slip ring system internal to the UHB Drive Rig. Thrust and drag forces produced by the OGVs (including the nacelle and inner flowpath hardware downstream of the fan) were measured using a six-component static force balance mounted directly on the UHB Drive Rig. Signals were sent directly to the data system through wiring channels located in a fairing mounted in front of the Drive Rig strut. Figure 4 shows the location of the balances and their physical relationship to the fan module components. The accuracy of the measured thrust is $\pm 10 \mathrm{lbf}$, or \pm 0.25 percent of the full scale measurement range (4000 lbf) of the combined balances. A complete description of the force balance components and technique used in measuring performance of turbofan simulators in wind tunnel testing at Glenn using can be found in reference 28 .

\section{Acoustic}

Figure $8 \mathrm{a}$ is a photograph of the fan module in the acoustic, flight-type configuration installed in the $9 \times 15$. In figure $8 \mathrm{~b}$, the downstream fixed microphones and sideline traversing microphone probe can be seen to the left of the fan model.

Sideline acoustic data were acquired with a computercontrolled translating microphone probe and with three aft microphone assemblies mounted to the tunnel floor. The translating microphone probe acquired data at 48 sideline geometric angles from $27.2^{\circ}$ to $134.6^{\circ}$ relative to the fan rotor plane. The translating probe traverse was 89 in. from the fan rotational axis (about four fan diameters). A wallmounted microphone probe was placed at a reference location adjacent to the translating probe home position (134.6 $6^{\circ}$, maximum aft travel). The three fixed microphone assemblies were mounted at the home axial position to acquire aft acoustic data at geometric angles of $140^{\circ}, 150^{\circ}$, and $160^{\circ}$. The acoustic data were acquired through a digital computer system and stored for post-run analysis. 


\section{Experimental Procedure}

\section{Aerodynamic Performance}

Fan and stage aerodynamic performance maps were obtained for the baseline R4 fan and with the 54 vane Baseline OGVs installed. In addition, performance on fixed operating lines was obtained with each of the four fixed area fan exit nozzle configurations. A Mach number of 0.05 was set in the test section during testing in order to provide uniform temperature and pressure distributions into the fan, and also to prevent the fan from ingesting vortices from the test section surfaces. To eliminate the day-to-day variations in pressure and temperature that affect the performance calculations, the fan and stage performance parameters were corrected to standard day pressure and temperature conditions, where required. To insure that data was acquired at steady state conditions, a 30 second settling time interval was maintained after each new fan operating condition was reached. In addition, pressure and temperature information from the data system was time averaged over a 10 second sampling.

\section{Fan and Stage Mapping}

Fan and stage performance mapping was conducted with the bellmouth inlet and the VFEN installed on the fan module. A fan speed range from 50 to 100 percent of the fan design speed was investigated. At each speed condition, the maximum weight flow was achieved at the maximum nozzle area with the VFEN fully open. To determine stage adiabatic efficiency, it was assumed that there was no loss in total temperature across the OGVs; this permitted the total temperature data from the fan performance rakes to be used in the calculations. This method is a more accurate determination of stage adiabatic efficiency since variations in temperature measurements between the fan rakes and the stage rakes are eliminated, thereby also eliminating the accompanying errors in the stage adiabatic calculation. Overall values for the fan and stage performance were obtained by averaging the seven radial profile values for each performance parameter.

In order to minimize the risk of damaging the fan blades caused by an unintentional hard fan rub, the fan stall region located at the lower fan weight flow conditions was intentionally avoided. With this fan design, an approaching stall condition was indicated by an increase in the fan blade stress. Therefore, the minimum fan weight flow was established when the fan blade stress measured with blade mounted strain gauges reached a predetermined limit, typically 25 percent of the fan material yield strength. This limit, however, varied with fan speed. The 87.5 percent speed line was unusually sensitive (higher blade stress at higher weight flow conditions), so the minimum weight flow boundary at this speed was larger than the minimum weight flow at the other fan speed lines. The shape of the maps had a distinct bend, or knee, because of this sensitivity.

\section{Fixed Nozzle Operating Line}

Fan performance on the fixed area operating lines at sea level conditions was obtained using the bellmouth inlet and the fixed area, flight-type, nozzles. However, only the fan performance could be obtained with the fixed area nozzle installed since the stage performance rakes could only be installed with the VFEN installed. Therefore, once the fan weight flow and fan operating parameters were established for the fixed nozzle operating line, the corresponding stage performance was obtained with the VFEN installed by adjusting the nozzle exit area to match the fixed nozzle fan pressure and weight flow at each corresponding fan speed.

\section{Farfield Acoustics}

The farfield acoustic testing was conducted with only three different fixed area nozzles-BL, DP and HF. During aerodynamic performance testing, the data showed that the LF performance was not too different than the BL performance on the operating line. Therefore, the LF nozzle was not acoustically tested. All of the fan stage acoustic data were acquired at tunnel Mach number of 0.10 , which was sufficient to achieve acoustic flight effect (ref. 29). Sideline data are presented in terms of emission angles. The emission angles are related to the geometric or observed angles by the relationship:

$$
\Theta_{\mathrm{em}}=\Theta_{\text {geom }}-\sin ^{-1}\left(\mathrm{M}_{\mathrm{o}} \sin \Theta_{\text {geom }}\right),
$$

where $\Theta_{\mathrm{em}}$ and $\Theta_{\text {geom }}$ are, respectively, the emission and observed sideline angles, and $M_{o}$ is the test section Mach number. At Mach 0.10 then, the observed angles for the sideline translating microphone probe range from $25^{\circ}$ to $130^{\circ}$, and the three fixed microphones measure aft observed angles of $136^{\circ}, 147^{\circ}$, and $158^{\circ}$. This angular range was sufficient to define the sideline noise profile for this aftdominated fan stage for subsequent EPNL calculations.

Digital acoustic data were processed as constant bandwidth spectra. Spectra were acquired and averaged at each translating probe or fixed microphone position with 5.9 and $59 \mathrm{~Hz}$ bandwidths. These constant bandwidth spectra were electronically merged and used to generate $1 / 3$-octave spectra, using the $5.9 \mathrm{~Hz}$ bandwidth results for lower $1 / 3^{\text {rd }}$ octave frequencies, and the $59 \mathrm{~Hz}$ bandwidth results for the higher frequencies. Sound power level (PWL) spectra were calculated from the SPL spectra assuming spherical symmetry through the range of sideline data acquisition. Possible noise contributions outside the sideline range were ignored.

\section{Laser Doppler Velocimetry Surveys}

Figure 9 shows the location at which LDV wake measurements were made relative to the fan module hardware. The axial location was 3.12 in. downstream of the non-rotating position of the tip trailing edge. Wake data were 
acquired at four corrected rotor speeds, 6,329, 7,808, 11,074, and 12,657 (corresponding to $50,61.7,87.5$, and $100 \%$ of the fan design speed). The 7,808, 11,074, and 12,657 speeds correspond to nominal approach, cut-back, and take-off conditions for the R4 fan. The wake surveys were conducted to determine how the wake flows vary with rotor speed and axial location.

The tunnel flow was seeded with polystyrene latex (PSL) spheres that were manufactured at the NASA Glenn Research Center. The nominal size of the PSL spheres is estimated to be approximately $0.7 \mu \mathrm{m}$ in diameter. The polystyrene spheres are diluted with ethanol and sprayed into the wind tunnel using a set of nine spray nozzles located approximately $80 \mathrm{ft}$ upstream of the test section. The liquid solvent evaporates by the time it reaches the test section, leaving behind the solid spheres on which the LDV data is obtained.

The individual velocity measurements were sorted into circumferential bins around the rotor using shaft angle encoders fed with the once-per-revolution signal of the rotor. These encoders segmented the $360^{\circ}$ of rotor revolution occurring between two consecutive once-per-revolution pulses into 1100 bins of equal width (50 bins per blade passage). Each time a velocity measurement was made, the encoder output was sampled to determine the number of bins generated since the occurrence of the previous once-per-rev pulse. The velocity and corresponding bin number were then stored in the computer as a data pair.

Data were acquired at the survey measurement location over many rotor revolutions until either a preset number of measurements had been acquired on one of the two LDV channels, or until the maximum time allotted for the data acquisition had elapsed. On-line data plots were used to determine the number of measurements required to accurately resolve the flows occurring within the individual blade passages. In general, the higher the unsteadiness in the flow, the greater the number of measurements required to resolve the flow. On average, more than 40,000 velocity measurements per component were obtained at each combination of measurement location and operating condition. A more complete description of the LDV system and technique as used for flow diagnostics in turbofan simulators during wind tunnel tests at Glenn can be found in reference 12 .

\section{Results and Discussion}

\section{Aerodynamic Performance}

For the results presented in this section, the accuracy of the performance calculations is based on empirical observation and repeat data points. The accuracy of the data acquisition systems used during testing were \pm 0.002 psia for pressure and $\pm 0.25^{\circ} \mathrm{F}$ for temperature. However, the data systems were configured to provide time-averaged measurements at a high sample rate. For temperature and pressure, the data values are based on an average of ten, onesecond averages, with each one-second average based on the average of 20,000 samples. Therefore, the accuracy of the discrete performance points is higher than the results based on discrete data samples. For pressure ratio, the accuracy is \pm 0.0003 ; for temperature ratio, the accuracy of the results is \pm 0.001 ; and for adiabatic efficiency, the accuracy of the results is \pm 0.3 percent.

Fan performance maps are presented in figure 10. The corrected weight flow, fan total pressure ratio, total temperature ratio and adiabatic efficiency are shown in Figures 10a through d, respectively. Shown on each of the performance map plots is the operating line performance measured for the four fixed area nozzles-Low Flow, Baseline, Design Point and High Flow. As stated in an earlier section, the last data point on the far left on the plot does not represent the fan stall line. Instead, this minimum weight flow condition data was obtained at what was considered a safe operating distance away from the fan stall line in order to avoid a fan tip rub or any possible damage to the fan blades due to high blade stress caused by unintentionally entering a fan stall condition. The results show that opening the nozzle area allows more weight flow through the model on each fan speed line (fig. 10a), moving the operating lines toward where the engine cruise operating line would be at the right side of the plots in the figure. Consequently, the pressure and temperature ratios decrease along each fixed fan speed line (figs. 10b and c). The reverse is true as the nozzle exit area is closed. The weight flow decreases, the fixed operating line moves toward the left side or stall, and the fan pressure and temperature ratios increase on each fan speed line. Using the BL nozzle data as a reference, the changes in pressure ratio from $\mathrm{LF}$ to $\mathrm{HF}$ nozzle ranged from 1.1 to -7.3 percent at 50 percent speed and 1.1 to -11.4 percent at 100 percent speed. For the same LF to HF nozzle area range, the temperature ratio changed from 1.6 to -9.1 percent at 50 percent speed and 1.4 to -9.4 percent at 100 percent speed. The weight flow, meanwhile, changed from -1.4 to 7.9 percent at 50 percent speed and -1.1 to 5.7 percent at 100 percent speed. As can be seen, the pressure and temperature changes with nozzle area get larger as the fan speed increases, reflecting the spreading out of the fixed nozzle operating lines.

Interestingly, the fan adiabatic efficiency goes up as the nozzle area increases (fig. 10d), rising between 2.9 percent (50\% fan speed) and 1.9 percent (100\% fan speed). Peak efficiency ranged from 91.1 percent for the LF nozzle to 93.0 percent for the DP nozzle. The HF nozzle reached the same peak efficiency as the DP nozzle, but at 87.5 percent fan speed. At 100 percent corrected fan speed, the HF nozzle pressure ratio, temperature ratio and adiabatic efficiency rapidly fall off. The adiabatic efficiency quickly drops about 2 to 91.0 percent compared to the DP nozzle performance at the same speed. The HF nozzle area is too far open at this point, causing the performance fall-off. Since the fan tip is supersonic at this operating point (the fan tip reaches 
transonic at the 87.5 percent corrected fan speed, or cutback, condition), the drop in performance is most likely due to the low blade incidence angle experienced at this high axial velocity condition, a result of the high weight flow into the fan. Another possibility is separated flow on the fan blades, caused by the interaction of the strong passage shock with the boundary layer on the blade. The passage shock at this condition would be stronger compared with the shocks at the same speed for the other nozzle areas because of the higher relative velocity at the fan tip as a result of the higher weight flow into the fan. Also, the corrected weight flow appears to level out somewhat at 100 percent fan speed for the HF nozzle case (fig. 10a), suggesting that the presence of stronger shocks at the outer portions is limiting the amount of flow passing through the fan.

The stage performance plots are shown in figure 11. As discussed earlier, the assumption is made that there are minimal total temperature losses across the OGVs, so the fan exit total temperatures are used in the calculation of the stage adiabatic efficiency. The same performance trends observed for the fan can be seen in these results, indicating that there are no unusual flow phenomena that develop on the OGVs as a result of the changes brought on by increasing the fan nozzle exit area. As expected, the stage total pressure in figure $11 \mathrm{a}$ is lower compared with the fan pressure ratio because of the loss in pressure across the OGVs themselves. Again using the BL nozzle as the reference, the change in pressure ratio from LF to HF was from 0.9 to -6.9 percent at 50 percent speed and 0.9 to -12.0 percent at 100 percent speed. The stage adiabatic efficiency in figure $11 \mathrm{~b}$ went up about 2.1 percent at 50 percent fan speed to 1.7 percent at 100 percent speed, while the peak efficiency went from 88.0 percent for the LF nozzle to 89.7 percent for the DP nozzle. The difference in the stage adiabatic efficiency across the range in nozzle area is slightly less sensitive than the fan, with smaller differences between nozzles for the stage compared to the fan. The HF nozzle performance again fell off at the 100 percent speed line, dropping about 2 percent from its peak efficiency of 89.4 percent at a fan speed of 87.5 percent, which is the same drop as seen for the fan efficiency with the HF nozzle.

The change in OGV performance with the change in fan nozzle exit area can also be expressed in terms of a loss function. Figures $11 \mathrm{c}$ and $\mathrm{d}$, the total pressure and adiabatic efficiency losses, respectively, associated with the OGVs over the stage operating map are given. The total pressure loss across the OGVs in figure $11 \mathrm{c}$, expressed as a function of the upstream total pressure, is defined in percent as:

$$
\left(\mathrm{P}_{\mathrm{t}, \mathrm{f}}-\mathrm{P}_{\mathrm{t}, \mathrm{s}}\right) / \mathrm{P}_{\mathrm{t}, \mathrm{f}} \times 100
$$

In figure $11 \mathrm{~d}$, the loss in adiabatic efficiency across the OGVs is defined in percent as:

$$
\left(\eta_{\mathrm{f}}-\eta_{\mathrm{s}}\right) \times 100
$$

Figure 11c shows that the total pressure loss across the OGVs decreased as the nozzle area increased from the LF to the HF configuration. The improvement in pressure rise was anywhere from a minimum 0.05 percent ( $50 \%$ fan speed) to a maximum of 0.12 percent ( $95 \%$ fan speed) between the four fixed nozzle operating lines. Figure 11d shows similar results with an increase in the adiabatic efficiency as the nozzle area increased. The drop in HF nozzle efficiency previously seen in the total pressure results can readily be seen, showing the drop off starting at 87.5 percent fan speed. The efficiency difference between nozzle configurations was shown to get smaller as the fan speed increased. The DP nozzle showed the best performance overall, since the loss in efficiency is the smallest at all fan speeds. This was to be expected since the DP nozzle achieved the design point conditions for the fan stage and hence the best performance. The efficiency increases ranged from 0.43 percent (LF to DP nozzles) at 60 percent fan speed to 0.12 percent (LF to $\mathrm{BL}$ ) at 100 percent fan speed.

Figure 12 provides the spanwise radial profiles of fan pressure ratio (fig. 12a), temperature ratio (fig. 12b) and adiabatic efficiency (fig. 12c) downstream of the fan for several fan speeds comparing the four fan nozzle configurations. These figures are useful in determining what part of the fan blade is responsible for the change in performance as the nozzle exit area is changed. For the sake of clarity, the adiabatic efficiency plots have been separated into their respective fan speeds, instead of presenting all fan speeds on one plot. The results show that the fan loading increases outboard as the nozzle exit area is reduced, especially the outer 40 percent of the fan blade. In the pressure and temperature ratio plots (figs. 12a and b), the fall off in performance over the outer 40 percent span of the blade for the HF nozzle at 100 percent fan speed can readily be seen, especially at 70 percent span where a significant drop causes a bend or kink in the radial distributions. The adiabatic efficiency plot shows the drop-off in fan performance over the outer portion of the fan blade at 87.5 percent fan speed when the fan flow first becomes transonic, and a recovery in performance in this region at 100 percent fan speed once the tip flow has stabilized. The HF nozzle efficiency data, however, does not follow this trend. It shows a dramatic loss in performance outboard of about 50 percent span. This is especially the case at 70 percent span where the local efficiency drops 5.5 percent from 87.5 percent speed to 100 percent speed. This is possible evidence of a strong shock/flow interaction phenomenon occurring near 70 percent of the blade span. The data also suggest that the performance outboard of 70 percent span accounts for the difference in efficiency for the LF and BL nozzles compared with the DP nozzle - the DP nozzle performance is 4 to 5 percent better than the BL or LF nozzle performance at about 83 percent blade span at 100 percent fan speed.

In figure 13, swirl angle data obtained downstream of the fan from a traversing survey probe are shown for each of the 
four fan nozzle configurations at several fan speeds. These results demonstrate the difference in the capacity of the blade to do work, as well as a measure of blade loading radially between the four nozzles at each fan speed. Typically, as the blade loading goes up, the swirl angle increases. However, this is not necessarily true at the hub and the tip. Here, the plots demonstrate that the blade work capacity is reduced at the hub and the tip, and is most effective near the mid region. The plots show the shape of the loading distribution remains fairly constant between the fan nozzles at 61.7 and 75 percent fan speed, and that the fan performs best with the HF nozzle and worst with the LF nozzle. That trend is verified by the fan adiabatic efficiency plots shown in figure 12c. The loading begins to fall off near the hub at 10 percent span and near the tip at 85 percent span, with the peak loading occurring near 85 percent span. As the fan speed increases to 87.5 percent, the BL and LF nozzles develop small variations in the loading distribution, as evidenced by the wiggles near 60 and 85 percent span. These wiggles indicate loading changes and coincide with sharp changes in the efficiency profiles, appearing as losses, in figure 12. Also, the radial location of the fall off point in swirl seems to be moving inboard as nozzle area is decreased. For the LF nozzle, the peak loading moved from about 79 percent to about 75 percent span. At 100 percent fan speed, the results show that the peak loading on the fan blades is spread over a larger span of the blades for the LF and BL nozzles compared to the DP and HF nozzles. The difference in the swirl angle between the BL and LF nozzle cases compared to the DP and HF nozzles at the peak loading point on the blades also seems to be increasing at the higher speed. This indicates that the fan is not performing as well outboard for the BL and LF nozzles compared to the DP and HF nozzles. Finally, there is some indication in the swirl results from about 60 to 70 percent blade span of the fan performance loss for the HF nozzle at 100 percent speed, with a increase in the swirl angle at that point. The adiabatic efficiency results in figure 12c confirm this result, showing a large change in fan efficiency for the HF nozzle at the same blade span location.

The thrust generated by the fan and OGVs are important parameters for farfield acoustics since differences in acoustics associated with different hardware configurations can only be reasonably compared on an equal thrust basis. Figure 14 shows the corrected fan thrust and corrected stage total thrust results obtained for BL, DP and HF nozzle configurations across the fan speed range on their fixed operating lines. The stage or total thrust is the combined forces from the fan and the OGV assembly. Thrust data were not obtained with the LF nozzle, so that configuration is not shown. The fan thrust results show that as the nozzle exit area increases, the fan thrust decreases. This is expected since the pressure ratio for the fan decreases as well with increasing nozzle area. The significant drop in performance for the HF nozzle at 100 percent fan speed can be seen in the plot. The results obtained for the corrected total stage thrust, which includes the fan and the OGVs assembly forces, are also shown in figure 14. Interestingly, the results show that as the fan nozzle exit area increases, the total thrust increases as well. The exception again is the 100 percent speed condition for the HF nozzle.

In figure 15, plots of the percent differences in corrected fan and total or stage thrust with differences in nozzle exit area are shown for selected fan speeds. For this figure, the BL nozzle results were used as the zero reference point. The thrust results presented in this form clearly demonstrate the increase in corrected total thrust achieved by the OGVs across almost the entire fan speed range associated with increasing the nozzle area. It was shown in figure 14 that the fan thrust decreases with increasing nozzle area, and that result is shown in this figure. The increase in total thrust shown in figure 15 must therefore come from an increase in thrust produced by the OGVs. The results also indicate that as the fan speed increases, the total thrust advantage decreases slightly. The loss in fan thrust from figure 15 ranges between -0.2 percent at low speeds to -3.3 percent at high speeds for the DP nozzle, and between -3.8 and -7.7 percent for the HF nozzle, with the exception of the takeoff fan speed that shows a drop of -10.2 percent in thrust. The increase in total thrust ranges from around 2 percent at higher fan speeds to about 3.5 percent at lower fan speeds compared to the BL nozzle, depending on the fan speed. The results also show that the increase in total thrust produced is almost constant, or drops slightly, as the nozzle area increases from the DP nozzle to the HF nozzle, again except for 100 percent fan speed. The large loss in fan thrust that occurs for the HF nozzle at 100 percent fan speed produces an overall loss in total thrust compared to the $\mathrm{BL}$ nozzle, but that loss is significantly reduced by the increase in thrust from the OGVs. The reason for the increase in total thrust is most likely due to the increase in the lift force generated by the vanes in the direction of the thrust vector, as a result of the increase in the axial velocity that accompanies the increase in weight flow as the fan nozzle exit area increases.

\section{Farfield Acoustics}

Figure 16 shows the overall sound power level (OAPWL) as a function of stage thrust for three fixed area nozzle configurations. The OAPWL was calculated from the $59 \mathrm{~Hz}$ bandwidth (BW) spectra over a 1 to $50 \mathrm{~K}$ frequency range for sideline emission angles from 25 to $158^{\circ}$. The results show a significant noise decrease associated with increasing nozzle area and weight flow-especially at lower fan speeds. Figure 17 shows the change in OAPWL plotted for the DP and HF nozzles relative to the BL nozzle. These delta OAPWL were measured at constant thrust levels interpolated from the curves of figure 16. Increasing the nozzle area 5.4 percent and the weight flow by 5 percent with the DP nozzle resulted in a $2 \mathrm{~dB}$ noise reduction at rotor speeds up to cutback (87.5\% design speed), and around a $1 \mathrm{~dB}$ reduction at higher rotor speeds. Further increasing the nozzle area to 
10.9 percent and the weight flow to 7.5 percent of BL design values gave noise reductions of about $3 \mathrm{~dB}$ relative to the $\mathrm{BL}$ nozzle at lower rotor speeds (near approach at $61.7 \%$ design speed) and a $2 \mathrm{~dB}$ noise reduction at intermediate rotor speeds. However, the more open HF nozzle resulted in higher noise levels at the highest rotor speeds. This is the likely result of the degraded rotor performance with the HF nozzle shown earlier in the aerodynamic performance section near the 100 percent fan design speed.

Noise reductions associated with increased nozzle flow extend over a significant frequency range. Figure 18 shows the sound power level spectra (PWL) results obtained at the three fan stage acoustic rating conditions - approach, cutback and takeoff, corresponding to $61.7,87.5$, and 100 percent corrected fan speed. For the 61.7 percent fan speed presented in figure $18 \mathrm{a}$, the blade/vane ratio numbers for this fan stage design resulted in the fundamental rotor-stator interaction tone (ref. 30), or blade passing frequency (BPF), being essentially eliminated from the spectra, or cut off. This is true at fan speeds below where the relative velocity on the fan blade is below transonic, or for this fan at 87.5 percent speed (cutback). However the 2nd BPF tone is visible in the spectra and shows that there is a slight increase in tone level as the nozzle area and hence weight flow are increased. The 2 nd BPF is not present at the other two fan speeds shown in the figure because beyond $8 \mathrm{kHz}$ there is a significant artificial roll-off in the level of the data as a result of the bandwidth packets selected for data reduction to get higher data resolution for these plots. The reason for the increase in tone level between nozzle configurations may be that increasing the weight flow as the nozzle area increases also increased the axial velocity component of the flow. As a result, the fan relative velocity and fan tip speed also increase, and since tone level is partly a function of fan tip speed, the tone level increases with the larger nozzles. A significant change in the broadband noise levels between nozzles can be seen in the figure across the entire frequency range. The broadband noise levels are up to $3 \mathrm{~dB}$ lower for the DP nozzle and $6 \mathrm{~dB}$ lower for the HF nozzle relative to the noise levels observed for the BL nozzle. A possible explanation is the reduced loading on the fan blades in terms of lower fan pressure ratio (Figs. 10b and 12a), reduced fan swirl (fig. 13), and lower rotor thrust (fig. 14) that was shown in the aerodynamic performance results section.

At 87.5 percent corrected fan speed, there is a significant increase in the BPF tone level with increasing nozzle area (fig. 18b). This may be explained by the previous argument of increasing rotor relative velocity with increasing weight flow at larger nozzle areas. The higher fan tip velocity for the $\mathrm{HF}$ and DP nozzles is generating stronger shocks than for the BL case. As the flow tip reaches sonic flow conditions, rotoralone noise begins to dominate the rotor tone levels. In addition, the onset of supersonic flow on the fan initiates the generation of Multiple Pure Tones (MPTs). MPTs are tones which occur in the acoustic spectra at multiples of the rotor once per revolution frequency. They are thought to result from blade-to-blade differences in the shocks which propagate upstream of the rotor when the rotor is operated at transonic tip. The MPTs become more evident with increasing nozzle area and weight flow at this cutback fan speed, especially for the higher flow nozzles (This earlier onset of MPTs with increased nozzle flow is consistent with the OAPWL results shown in fig. 17). Apparently, opening the nozzle causes the shocks on the blades to become stronger and to extend over a larger spanwise extent of the blade. This, in turn, results in more shock associated noise. The spectra of figure $18 \mathrm{~b}$ show a modest reduction in broadband noise of about $2 \mathrm{~dB}$ with both larger area nozzles for this fan speed. The noise "hump" at about $1 / 2$ BPF for the BL nozzle is unexplained.

At takeoff conditions at 100 percent corrected fan speed, the MPT generation is well established (fig. 18c). At this speed the shocks extend over a large spanwise extent of the blades. There is a small increase in the BPF tone level with increasing nozzle flow, but the increase is smaller between the HF and DP nozzles. This relatively small increase may be associated with the location of the shocks on the blades. At these high flow conditions it is likely that the shocks in the tip region have been pushed downstream to the point where they bend around the leading edge of the adjacent blades (confirmed by LDV measurements presented in ref. 15). Once the shocks begin to bend around the adjacent blades, further increases in flow velocity cause the shocks to bend even more. This increased bending moves the shocks downstream toward the rotor face and away from the inlet throat. This is important since it is the amplitude of the disturbance created by the shocks at the inlet throat which dictates how much shock associated noise is radiated to the farfield. Consequently, the increase in flow velocity which results from opening the nozzle at the takeoff condition can be expected to lead to only modest increases (or perhaps even reductions) in shock associated noise (ref. 31). The broadband noise levels show a modest reduction at low frequencies with increasing nozzle area, but not nearly as dramatic as the previous two fan speeds. The broadband noise is also now dominated by the supersonic flow over the fan blades and the shock-fan blade interaction noise, so the modest changes in fan blade loading, which appears to be the main driver for broadband noise as previously shown in the figures $18 \mathrm{a}$ and $\mathrm{b}$, are not significant.

Finally, figure 19 provides a summary plot of the change in OASPL as a function of fan nozzle exit area change for various fan speeds tested from 50 to 100 percent. The Low Flow nozzle is not represented in the figure since no acoustic data was obtained with that nozzle. The figure provides a summary of the acoustic benefit which results from increasing the fan nozzle exit area has on the noise produced by the fan module. It can be seen that for most operating conditions a significant decrease in the OASPL is possible, the exception being the high speed conditions at cutback and takeoff for the HF nozzle. However, even for those conditions a modest decrease in noise was seen. 


\section{Laser Doppler Velocimetry}

The LDV data were obtained in order to determine how the wake flow generated by the fan changes as the nozzle area changes. These wake data can be used to explain some of the observations made above regarding how the acoustic spectra change as the nozzle area and weight flow are increased.

Figures 20 through 22 show how the rotor wake flow varies with changes in nozzle area as measured at the approach, cutback and takeoff fan operating conditions, respectively. Parts $a$ and $b$ of these figures show that the mean axial velocities increase and the mean tangential velocities decrease in the rotor wake as nozzle area increases. As a result, swirl angle also decreases, as was shown in figure 13. As was suggested then, the decreased swirl suggests that the loading on the rotor blades decreases as nozzle area increases. In general, this decreased blade loading should lead to a decrease in the amount of turbulence generated by each blade. The plots shown in parts c) and d) of each figure, which depict the axial and tangential turbulence components, confirm that this was the case- the measured turbulence level in the rotor wake decreased as nozzle area increased. This decreased rotor wake turbulence will result in the decreased levels of rotor/stator interaction broadband noise. This was evident in the acoustic spectra plots of figure $18 \mathrm{a}$ and $\mathrm{b}$. These plots showed a reduction in broadband noise with increasing nozzle area, as discussed earlier in the section on farfield acoustic results.

However, the broadband acoustic data presented for the takeoff condition in figure $18 \mathrm{c}$ show a different trend. These data are similar to the approach and cutback condition data in that they show a decrease in the broadband level as the nozzle area is increased from 0 (BL nozzle) to 5.4 percent open (DP nozzle), but they are unlike the other data in that they show an increase in high frequency broadband noise as the nozzle area is increased further to 10.9 percent open (HF nozzle). The LDV flow field data can also be used to explain this anomaly. Figure 22 shows the variation in rotor wake flow with increasing nozzle area as measured at the take off condition. Like the data obtained at the two lower fan speeds, the axial velocities (part a) increase while the tangential velocities (part b) decrease as nozzle area increases. Consequently, swirl angle also decreases at takeoff, as was shown in figure 13. The reduced swirl implies that the blade loading decreases with increasing nozzle area-a result that should lead to less turbulence generated by the blades. However, as indicated in parts $\mathrm{c}$ and $\mathrm{d}$ of figure 22, the turbulence generated by the blades actually increases over much of the blade span as the nozzle area and weight flow increase between the DP nozzle and the HF nozzle.

Figures 22c and d also indicate that the outer portions of the blade wakes get thicker and more turbulent as the nozzle area increases between the DP and HF nozzles at the takeoff speed. This increased blade wake thickness may be indicating a flow separation on the fan blades resulting, perhaps, from stronger shocks on the blades or from non-optimum inflow angles. In any event, this increase in blade wake turbulence seems to account for the increase in high frequency broadband noise illustrated in figure $18 \mathrm{c}$ for the takeoff condition. These thicker wakes are also consistent with the degraded aerodynamic performance measured at this test condition shown earlier. This was especially evident in the fan adiabatic efficiency plots shown in figures $10 \mathrm{~d}$ and $12 \mathrm{c}$, and in the changes in corrected total thrust shown in figure 15.

The trends indicated by the LDV data also support the explanation presented above in the farfield acoustics result section earlier for the increase in BPF and MPT noise which occurs when the nozzle is opened at the 87.5 percent cutback speed. Previous reports (refs. 4 and 5) have presented LDV data obtained within the rotor blade passages at a radial location 0.4 in. inboard of the tip during a test in which the baseline nozzle was installed. These data show that normal shocks exist on the suction side of the blades when the fan is operating at the cutback speed. The plot presented above in figure 21 a show that axial flow velocities increase as the area increases above that of the BL nozzle. The increased axial velocities would lead to higher relative flow velocities on the blades which, in turn, would be expected to lead to stronger passage shocks. The increased noise produced by these shocks is evident in the acoustic spectra of figures $18 \mathrm{~b}$ and $\mathrm{c}$, which show that both the BPF tone and the Multiple Pure Tones increase as the nozzle area increases.

\section{Summary and Conclusion}

The design of effective new technologies to reduce aircraft propulsion noise is dependent on identifying and understanding the noise sources and noise generation mechanisms in the modern turbofan engine, as well as determining their contribution to the overall aircraft noise signature. Therefore, a comprehensive aeroacoustic wind tunnel test program was conducted as part of the NASA Quiet Aircraft Technology program called the Fan Broadband Source Diagnostic Test. The test was performed in the anechoic NASA Glenn 9- by 15-Foot Low Speed Wind Tunnel using a $1 / 5$ scale model turbofan simulator that is representative of a current generation, medium pressure ratio high bypass turbofan engine. The investigation focused on the simulated bypass section of the turbofan engine. The technical objectives of the test were: 1) to identify the noise sources within the model and their contribution to the overall noise level; 2) to investigate several component design technologies by evaluating their impact on the aerodynamic and acoustic performance; and 3) to conduct detailed flow diagnostics within the research model to help in understanding the physics of the flowfield.

Details were presented in this report on the aerodynamic performance, farfield acoustics and fan wake flow diagnostic results obtained during an investigation of the effect of the bypass nozzle exit area on the bypass stage performance, 
specifically the fan and outlet guide vanes (OGVs). Four different fixed-area bypass nozzles were investigated in combination with a baseline fan and set of OGVs-Low Flow (LF), Baseline (BL), Design Point (DP) and High Flow (HF). They represented fixed engine operating lines encompassing the operating envelope of the turbofan engine from near stall to cruise, with a total change in area from the smallest to the largest nozzle of 12.9 percent. The BL nozzle was selected as the reference nozzle area. Its area was 2 percent larger than the LF nozzle, 5.4 percent smaller than the DP nozzle and 10.9 percent smaller than the HF nozzle.

The results demonstrate that there are significant changes in aerodynamic performance and farfield acoustics as the nozzle area is increased:

1) Fan and stage pressure and temperature ratios decrease as nozzle area increases. The maximum loss in total pressure from LF to HF was 12.5 percent at takeoff condition $(100 \%$ fan design speed). However, the HF nozzle performance was seriously degraded at the 100 percent speed point most likely due to shock losses on the blades. At 95 percent speed, just below takeoff, the overall pressure loss was only 9.7 percent. The maximum temperature loss between LF and HF remained fairly constant with fan speed, between 10.7 and 11.3 percent. For the stage, the maximum loss in pressure was 12.9 percent at 100 percent speed and 10.1 percent at 95 percent fan speed.

2) Fan and stage adiabatic efficiency increase as the nozzle area increase, the fan and stage efficiency increased as well. The overall change in fan efficiency from LF to HF nozzle varied slightly with fan speed. The overall change was generally from 2.5 to 3 percent, except at the 100 percent point, where the maximum difference was only 1.1 percent. For the stage adiabatic efficiency, the overall change between the LF and HF nozzles was between 2.4 and 3.1 percent up to 87.5 percent fan speed. At higher fan speeds, the increase in stage efficiency associated with larger nozzle area still occur but was smaller, a 1.8 percent increase at 100 percent fan speed. The smaller increase is a result of increased losses on the OGVs at the higher weight flow and axial velocity.

3) Radial profile results show that the HF nozzle provided the lightest blade loading and the highest adiabatic efficiency. The shock induced losses on the blade at 100 percent fan speed for the HF nozzle could easily be seen in the efficiency profile near 70 percent blade span. The swirl angle survey results showed the drop in blade loading near 70 percent span at 100 percent fan speed, the location which showed the large drop in local efficiency and the area where flow separation on the fan blade due shock interactions might have occurred. The swirl angle results also showed that the BL and LF nozzles produced highly loaded blades above 70 percent span which caused the fan efficiency to drop near the tip.

4) Corrected fan thrust decreases with increasing nozzle area, but corrected stage thrust - the combination of fan and OGV thrust - increases with increasing nozzle area up to area increases of about 5 percent. Beyond that, as the nozzle exit area continues to increase, the stage thrust advantage levels off and remains constant or even drops at very low or very high fan speeds. Compared to the BL nozzle, the overall fan thrust loss for the DP nozzle was from 0.3 percent at approach $(61.7 \%$ fan speed) to 2.3 percent at takeoff (100\% fan speed), while the fan thrust loss for the HF nozzle ranged from about 3.8 percent at approach to 6.7 percent at 95 percent fan speed. A jump in losses to 10.3 percent occurred at 100 percent fan speed as the shock losses on the fan blade dramatically reduce the blade performance. The stage total thrust increases compared with the BL nozzle reference from 3.6 percent at approach to 2.1 percent at takeoff for the DP nozzle. As the nozzle area increases for the HF nozzle, the gain in total thrust remains fairly constant or decreases slightly by about 0.2 percent, except at 100 percent fan speed. Here, the stage thrust drops compared with the BL nozzle stage thrust, losing 1.9 percent in thrust.

5) As the nozzle area increases, the overall sound power level decreases anywhere from $3.5 \mathrm{~dB}$ at approach speed (61.7\% fan speed) to $1 \mathrm{~dB}$ at takeoff (100\% fan speed). The HF nozzle showed a slight $1 \mathrm{~dB}$ advantage over the DP nozzle at lower speeds (up to about $75 \%$ fan speed), but the advantage disappears at the higher speeds, except around 90 percent speed where the HF again had the $1 \mathrm{~dB}$ advantage. At 95 percent speed and above, the HF nozzle was noisier than the DP or BL nozzles due, presumably, to shockinduced flow separation and losses. The reductions in overall noise level associated with increasing the nozzle area were primarily a result of decreased broadband noise. The fan tone levels actually increased with increasing nozzle area, most likely due to the higher relative speed on the fan blades because of the increase in weight flow and hence axial velocity as the nozzle area increased.

6) Laser Doppler velocimeter results show that mean axial velocities increase and mean tangential velocities decrease with increasing nozzle area at a given fan speed. Consequently, the swirl in the wake flow also decreases-a result which indicates that the fan blade loading decreases with increasing nozzle area. At the approach and cutback speeds, wake turbulence levels decrease and the blade wakes get thinner as the nozzle area is increased. These trends explain the drop in broadband noise level measured as the nozzle area increased. At 100 percent speed, the results showed an increase in wake turbulence when the HF nozzle was installed. This is thought to result from shock losses in the outboard region of the fan blade. Again, this correlates with the acoustic results which showed the broadband level increasing at high frequencies for the HF nozzle at takeoff.

In summary, the results provided in this report suggest that a variable area bypass exhaust nozzle for a typical turbofan engine may be an effective way to further decrease engine fan stage noise and possibly realize a concurrent slight thrust increase. Turbofan engine bypass exhaust nozzles are normally sized for maximum performance at the portion of the aircraft flight profile where most of the flight time is spent-typically at the cruise condition. Increasing the nozzle 
flow within the envelope defined by desirable engine performance reduced the fan stage noise in this scale model test. Thus, it may be desirable to employ a variable area engine bypass exhaust nozzle as a technique to reduce fan stage noise levels at all rotor operating speeds. Even the addition of a limited position variable area bypass nozzle, in order to reduce mechanical complexity and weight, might be an effective retrofit to existing turbofan engines to control fan stage noise and realize additional noise reduction without sacrificing aerodynamic performance.

\section{References}

1. Groeneweg, J.F., and Rice, E.J., "Aircraft Turbofan Noise," vol. 109, Journal of Turbomachinery, January 1987.

2. Groeneweg, J.F., "Fan Noise Research at NASA," NASA TM$106512,1994$.

3. Envia, E., "Fan Noise Reduction: An Overview," NASA/TM2001-210699, AIAA-2001-0661, 2001.

4. Bridges, J., Envia, E., and Huff, D., "Recent Developments in U.S. Engine Noise Reduction Research," NASA/TM-2001211083, ISABE-2001-1017, 2001.

5. Dittmar, J.H. and Elliott, D.M., and Bock, L.A., "Some Acoustic Results From the Pratt \& Whitney Advanced Ducted Propulsor-Fan 1," NASA/TM-1999-209049; March 1999.

6. Dittmar, J.H. and Hughes, C.E., Bock, L.A., and Hall, D.G., "Cruise Noise Measurements of a Scale Model Advanced Ducted Propulsor," 15th AIAA Aeroacoustics Conference, Long Beach, CA; AIAA-93-4400, October 25-27, 1993.

7. Envia, E., and Nallasamy, M., "Design Selection and Analysis of a Swept and Leaned Stator Concept," NASA/TM-1998208662, December 1998.

8. Hoyniak, D. and Fleeter, S., "Effect of Aerodynamic Detuning on Supersonic Rotor Discrete Frequency Noise Generation," NOISE-CON 88, Purdue University, West Lafayette, IN; June 20-22, 1988

9. Woodward, R.P., Elliott, D.M., Hughes, C.E., and Berton, J.J., "Benefits of Swept and Leaned Stators for Fan Noise Reduction," NASA/TM-1998-208661; AIAA-99-0479; November 1998.

10. Podboy, G.G., "Further Analysis of Fan Wake Data Obtained Downstream of the Allison Low Noise Fan and the Pratt \& Whitney ADP "Fan 1' Models," AST Engine Noise Workshop, vol. IV, pp. 131-160, April 1998.

11. Hughes, C.E., "Aerodynamic Performance of Scale-Model Turbofan Outlet Guide Vanes Designed for Low Noise," AIAA-2002-0374, January 2002.

12. Podboy, G.G., Krupar, M.J., Helland, S.M., and Hughes, C.E., "Steady and Unsteady Flow Field Measurements Within a NASA 22 Inch Fan Model," AIAA-2002-1033, January 2002.

13. Woodward, R.P., Hughes, C.E., Jeracki, R.J., and Miller, C.J., "Fan Noise Source Diagnostic Test-Far-field Acoustic Results," AIAA-2002-2427, June, 2002.
14. Hughes, C.E., Jeracki, R.J., and Miller, C.J., "Fan Noise Source Diagnostic Test-Rotor Alone Aerodynamic Performance Results," AIAA-2002-2426, June 2002.

15. Podboy, G.G., Krupar, M.J., Hughes, C.E., and Woodward, R.P., "Fan Source Diagnostic Test-LDV Measured Flow Field Results," AIAA-2002-2431, June 2002.

16. Heidelberg, L.J., "Fan Noise Source Diagnostic Test-Tone Model Structure Results," AIAA-2002-2428, June 2002.

17. Woodward, R.P., Lucas, J.G., and Stakolilch, E.G., "Acoustic and Aerodynamic Performance of a 1.83-Meter- (6-Ft-) Diameter 1.2-Pressure-Ratio Fan (QF-6)," NASA TN D-7809, December, 1974.

18. Woodward, R.P., Lucas, J.G., and Balombin, J.G., "Acoustic and Aerodynamic Performance of a 1.5-Pressure-Ratio, 1.83Meter (6 Ft.-) Diameter Fan Stage for Turbofan Engines (QF2)," NASA TM X-3521, April, 1977.

19. Woodward, R.P., and Glaser, F.W., "Effect of Inflow Control on Inlet Noise of a Cut-on Fan," AIAA Journal, vol. 19, no. 3, March 1981, pp. 387-392.

20. Gliebe, P.R., "The Effect of Throttling on Forward Radiated Fan Noise," AIAA-79-0640, March, 1979.

21. Ginder, R.B. and Newby, D.R., "An Improved Correlation for the Broadband Noise of High-Speed Fans," AIAA Journal of Aircraft, vol. 14, no. 9, September, 1977, pp. 844-849.

22. Yuska, J.A., Diedrich, J.H., and Nestor, C., "Lewis 9- by 15Foot V/STOL Wind Tunnel," NASA TM X-2305, 1971.

23. Arrington, A.E., and Gonsalez, J.C., "Flow Quality Improvements in the NASA Lewis Research Center 9- by 15Foot Low Speed Wind Tunnel," NASA CR-195439, 1995.

24. Dahl, M.D., and Woodward, R.P., "Comparison Between Design and Installed Acoustic Characteristics of the NASA Lewis 9- by 15-Foot Low Speed Wind Tunnel Acoustic Treatment," NASA TP-2996, April 1990.

25. Dahl, M.D., and Woodward, R.P., "Background Noise Levels Measured I the NASA Lewis 9- by 15 -Foot Low Speed Wind Tunnel," NASA TP-3274, November 1992.

26. Woodward, R.P., and Dittmar, J.H., "Background Noise Levels Measured in the NASA Lewis 9- by 15-Foot Low-Speed Wind Tunnel," NASA TM-106817, AIAA-95-0720, January 1995.

27. Balan, C. and Hoff, G.E., "Propulsion Simulator for High Bypass Turbofan Performance Evaluation," SAE 931410, 1993.

28. Jeracki, R.J., "Model Engine Performance Measurement from Force Balance Instrumentation," NASA/TM-1998-208486, AIAA-98-3112, July 1998.

29. Chestnutt, D., "Flight Effects of Fan Noise," NASA CP-2242, January 1982.

30. Tyler, J.M. and Sofrin, T.G., "Axial Flow Compressor Noise Studies," SAE Trans, vol. 70, 1962, pp. 309-332.

31. Podboy, G.G. and Krupar, M.K., "Blade-to-Blade Variations in Shocks Upstream of Both a Forward-Swept and an Aft-Swept Fan," NASA/TM-2005-213445, 2005. 
TABLE 1.-FAN DESIGN PARAMETERS

\begin{tabular}{|l|c|}
\hline No. of Blades & 22 \\
\hline Tip Diameter, in. & 22 \\
\hline Inlet Radius Ratio & 0.30 \\
\hline Corrected Design Speed, $\mathrm{rpm}$ & 12,657 \\
\hline Design Tip Speed, $\mathrm{ft} / \mathrm{s}$ & 1,215 \\
\hline Corrected Weight Flow, $\mathrm{lb} / \mathrm{s}$ & 100.5 \\
\hline Specific Flow, $\mathrm{lb}_{\mathrm{m}} / \mathrm{s}-\mathrm{ft}^{2}$ & 41.8 \\
\hline Stage Pressure Ratio & 1.47 \\
\hline
\end{tabular}

TABLE 2.-OUTLET GUIDE VANE DESIGN PARAMETERS

\begin{tabular}{|c|c|c|}
\hline & Span Location & \\
\hline No. Vanes & & 54 \\
\hline Aft Sweep, deg & & 0 \\
\hline Aspect Ratio & Pitchline & 3.51 \\
\hline Chord, in & Pitchline & 1.57 \\
\hline \multirow[t]{3}{*}{ Solidity } & Hub & 2.25 \\
\hline & Pitchline & 1.52 \\
\hline & Tip & 1.23 \\
\hline \multirow[t]{3}{*}{ Stagger, deg ${ }^{1,2}$} & Hub & 12.56 \\
\hline & Pitchline & 10.29 \\
\hline & Tip & 10.65 \\
\hline \multirow[t]{3}{*}{ Vane Camber, deg } & $\mathrm{Hub}$ & 38.40 \\
\hline & Pitchline & 34.56 \\
\hline & Tip & 40.49 \\
\hline \multirow[t]{3}{*}{$\mathrm{t}_{\max } / \mathrm{c}$} & Hub & 0.0707 \\
\hline & Pitchline & 0.0702 \\
\hline & Tip & 0.0698 \\
\hline
\end{tabular}

${ }^{1}$ Defined from axial plane; positive angle in direction of fan rotation.

${ }^{2}$ Positive angle in opposite direction of fan rotation for OGVs.

TABLE 3.-FAN EXIT NOZZLE DESIGN PARAMETERS

\begin{tabular}{|l|c|c|c|}
\hline Nozzle & $\begin{array}{c}\text { Weight Flow, } \\
\mathrm{lb}_{\mathrm{m}} / \mathrm{sec}\end{array}$ & $\begin{array}{c}\text { Diameter, } \\
\text { in }\end{array}$ & $\begin{array}{c}\text { Area, } \\
\mathrm{in}^{2}\end{array}$ \\
\hline Baseline & 97.2 & 21.340 & 217.38 \\
\hline Low Flow & 96.1 & 21.210 & 213.04 \\
\hline Design Point & 101.4 & 21.684 & 229.01 \\
\hline High Flow & 102.7 & 22.034 & 241.02 \\
\hline
\end{tabular}




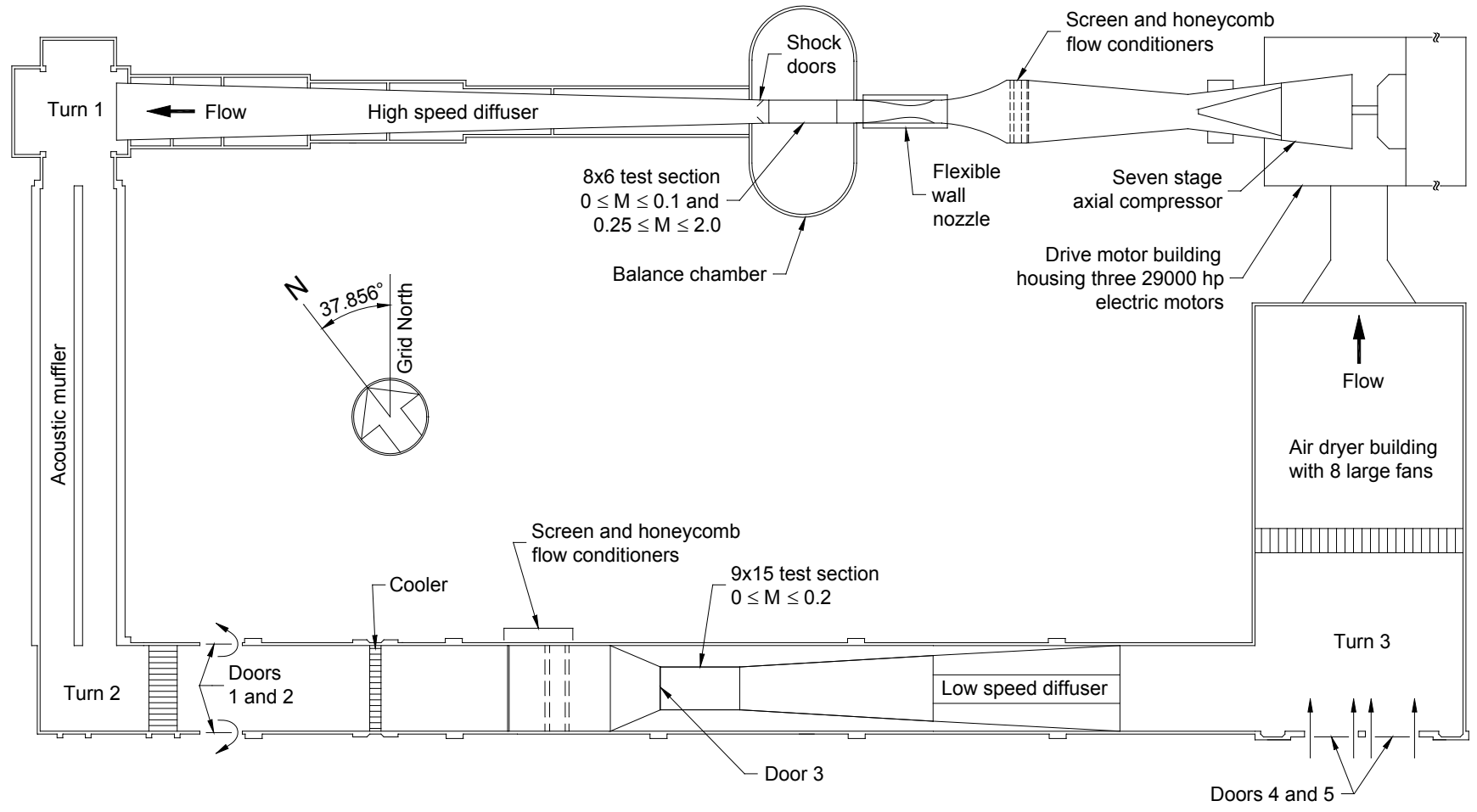

Figure 1.-NASA Glenn Research Center 8- by 6-Foot Supersonic Wind Tunnel/ 9- by 15 -Foot Low Speed Wind Tunnel Complex. 


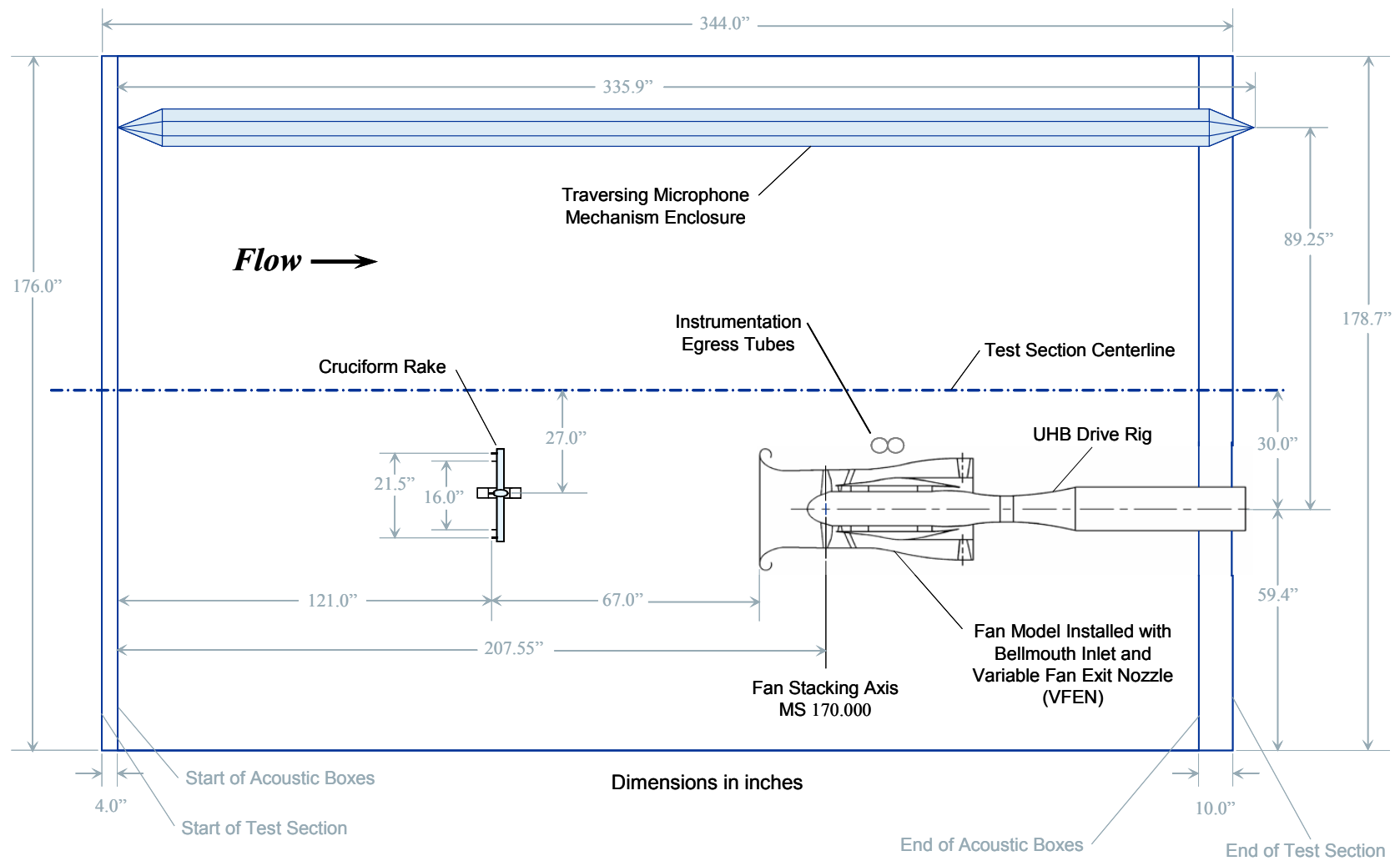

a) Aerodynamic Performance configuration

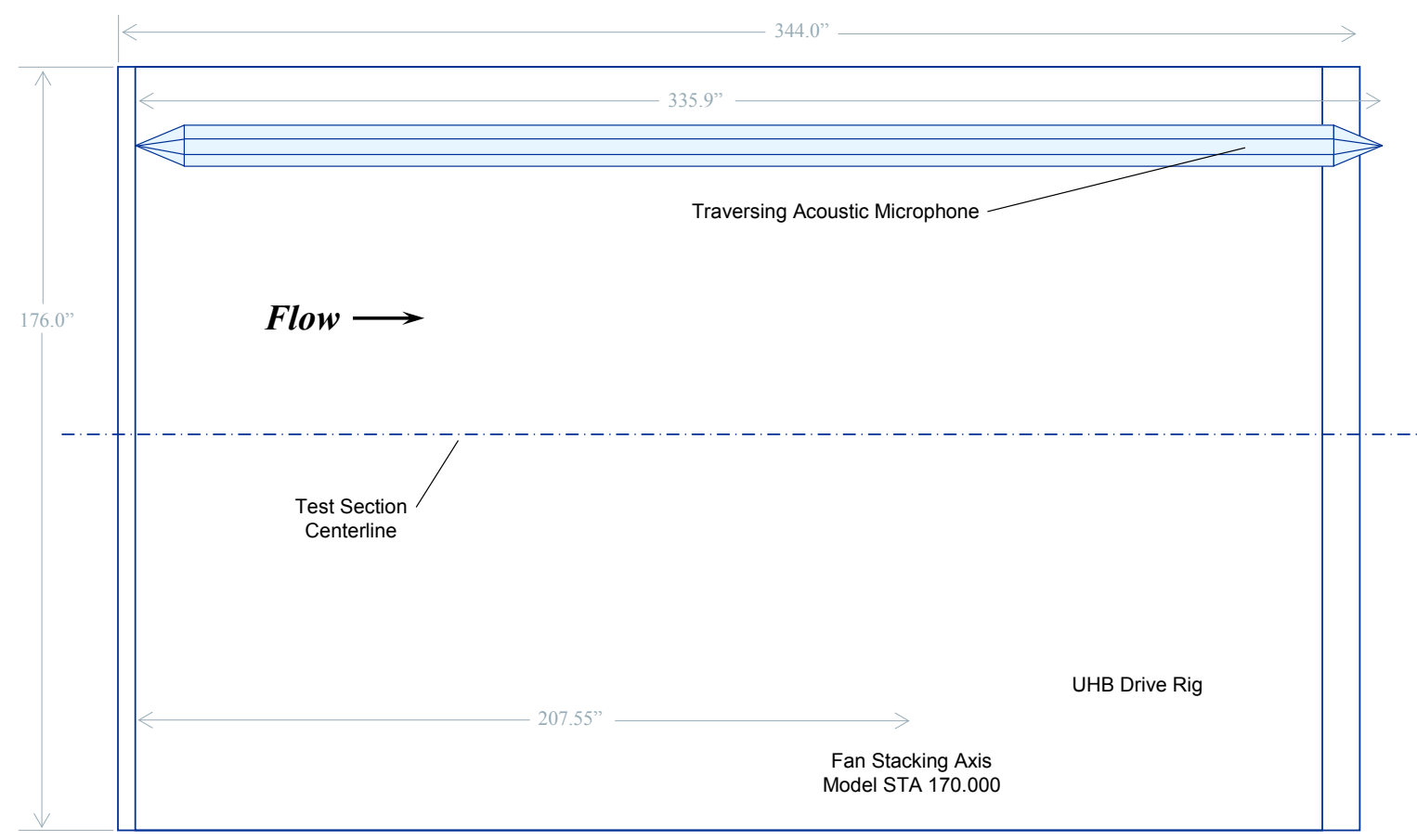

b) Farfield Acoustics configuration

Figure 2.- Top views showing test hardware locations in Glenn 9- by 15-Foot Low Speed Wind Tunnel. 


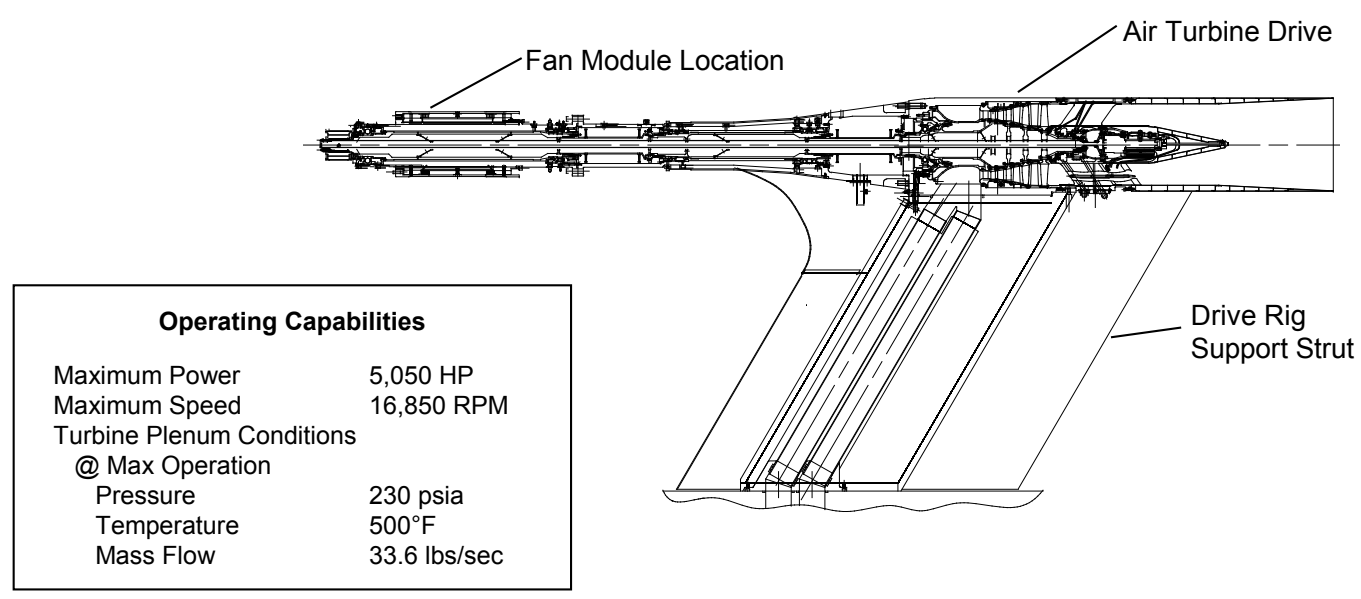

Figure 3.-NASA Glenn Research Center Ultra High Bypass (UHB) Drive Rig propulsion simulator.

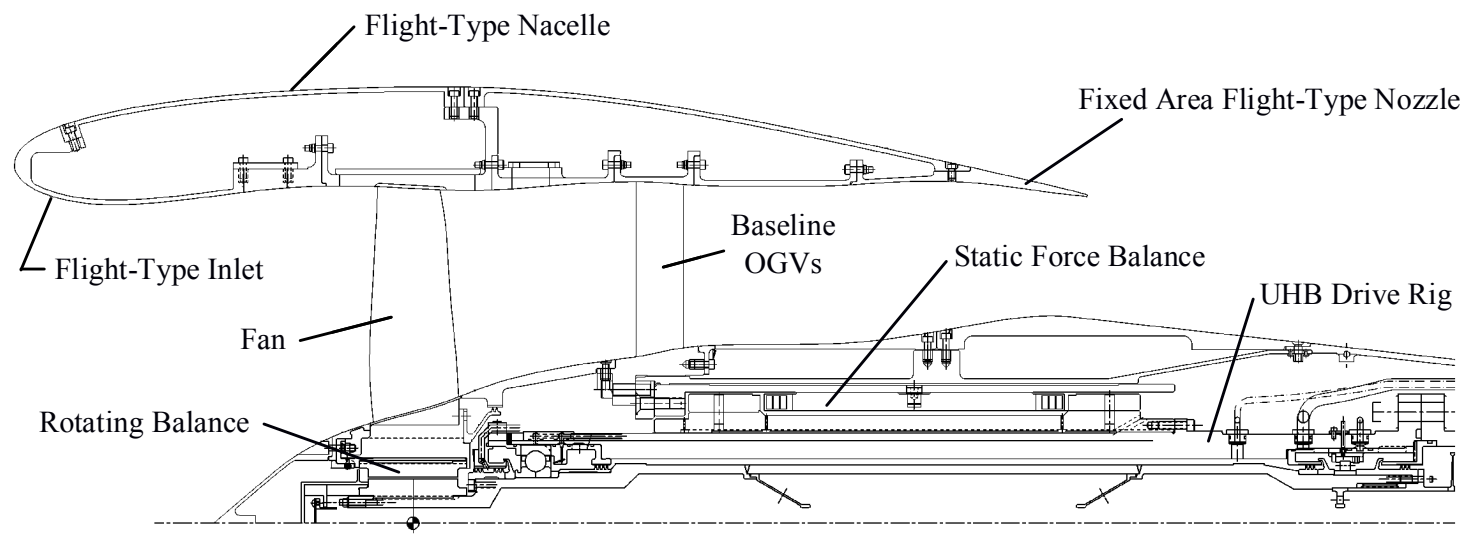

Figure 4.-Schematic diagram of the Fan Model and Baseline OGVs installed on the UHB Drive Rig. 


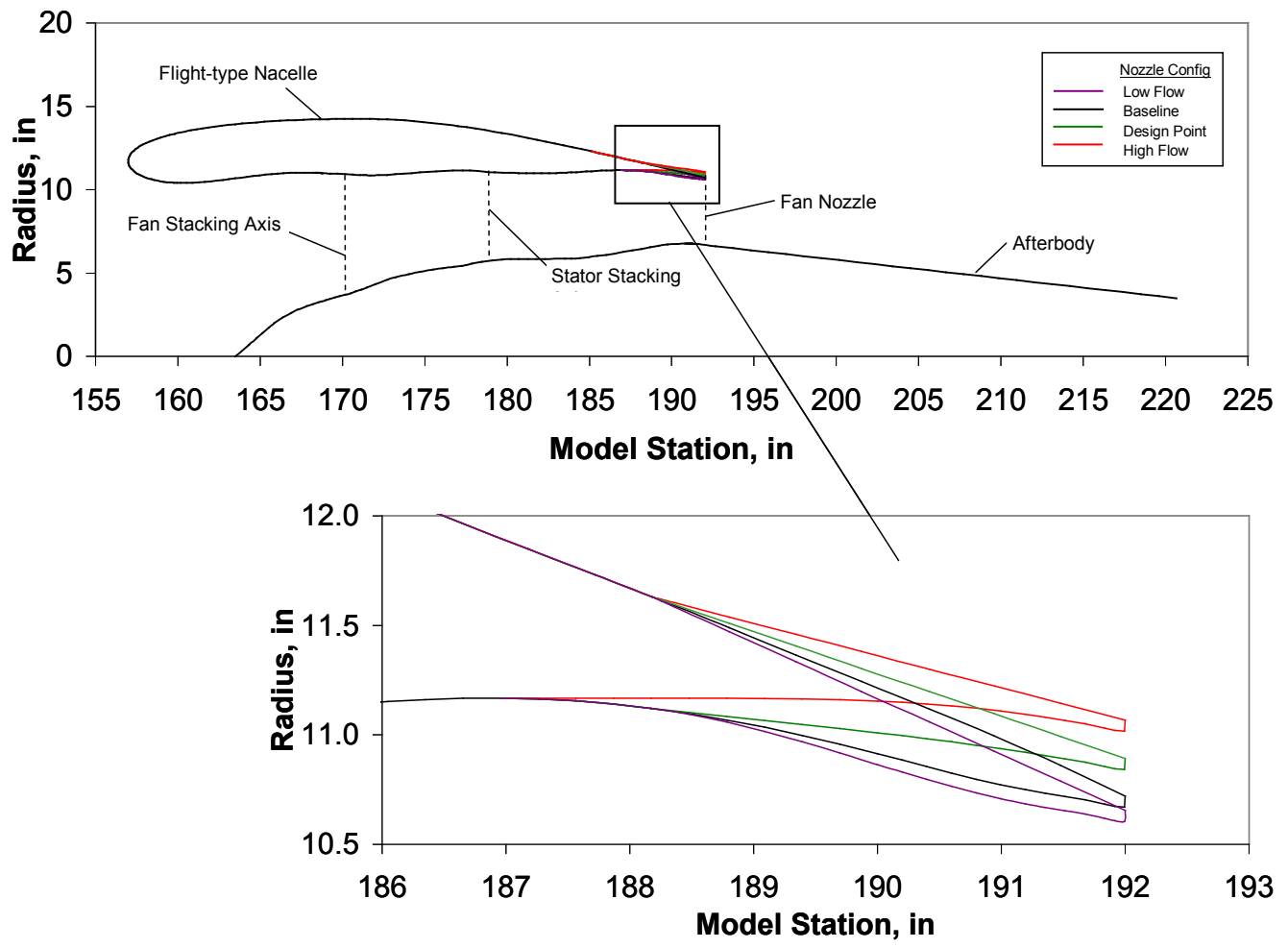

Figure 5.- Schematic diagram of fan module hardware and variation in fan nozzle exit area. 


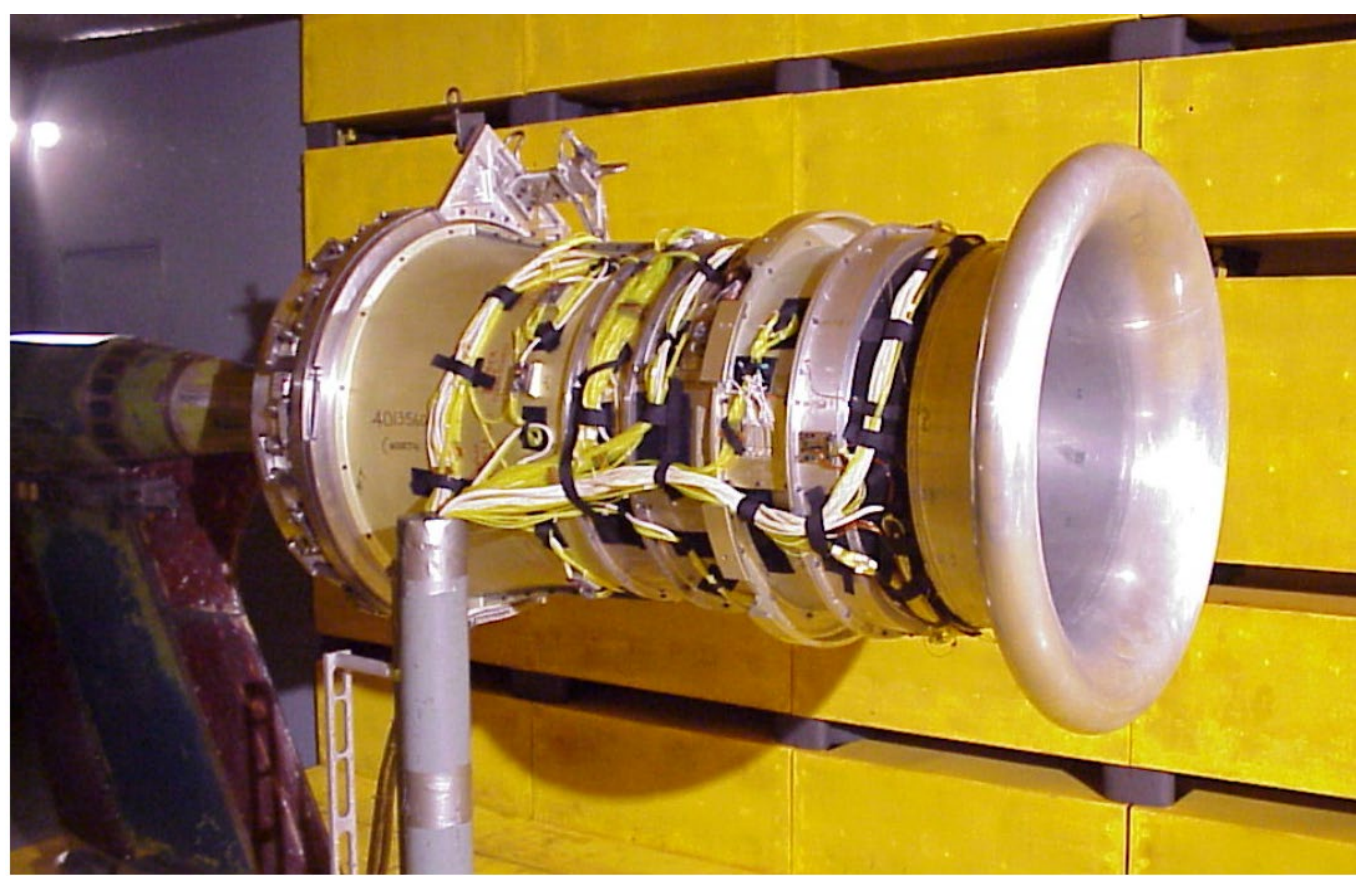

a) Fan module with bellmouth inlet and variable area fan exit nozzle

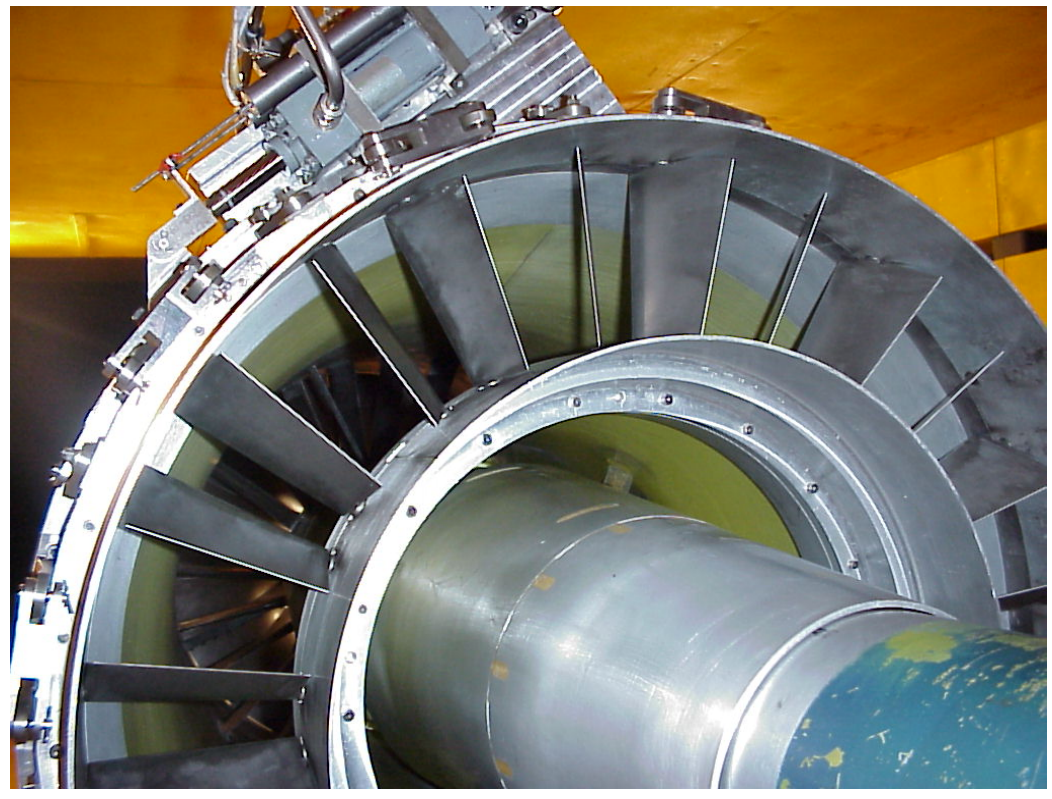

b) Close-up view of variable fan exit nozzle hardware arrangement

Figure 6.-Photographs of fan module installed in the Glenn 9- by 15-Foot Low Speed Wind Tunnel in the aerodynamic performance configuration. 


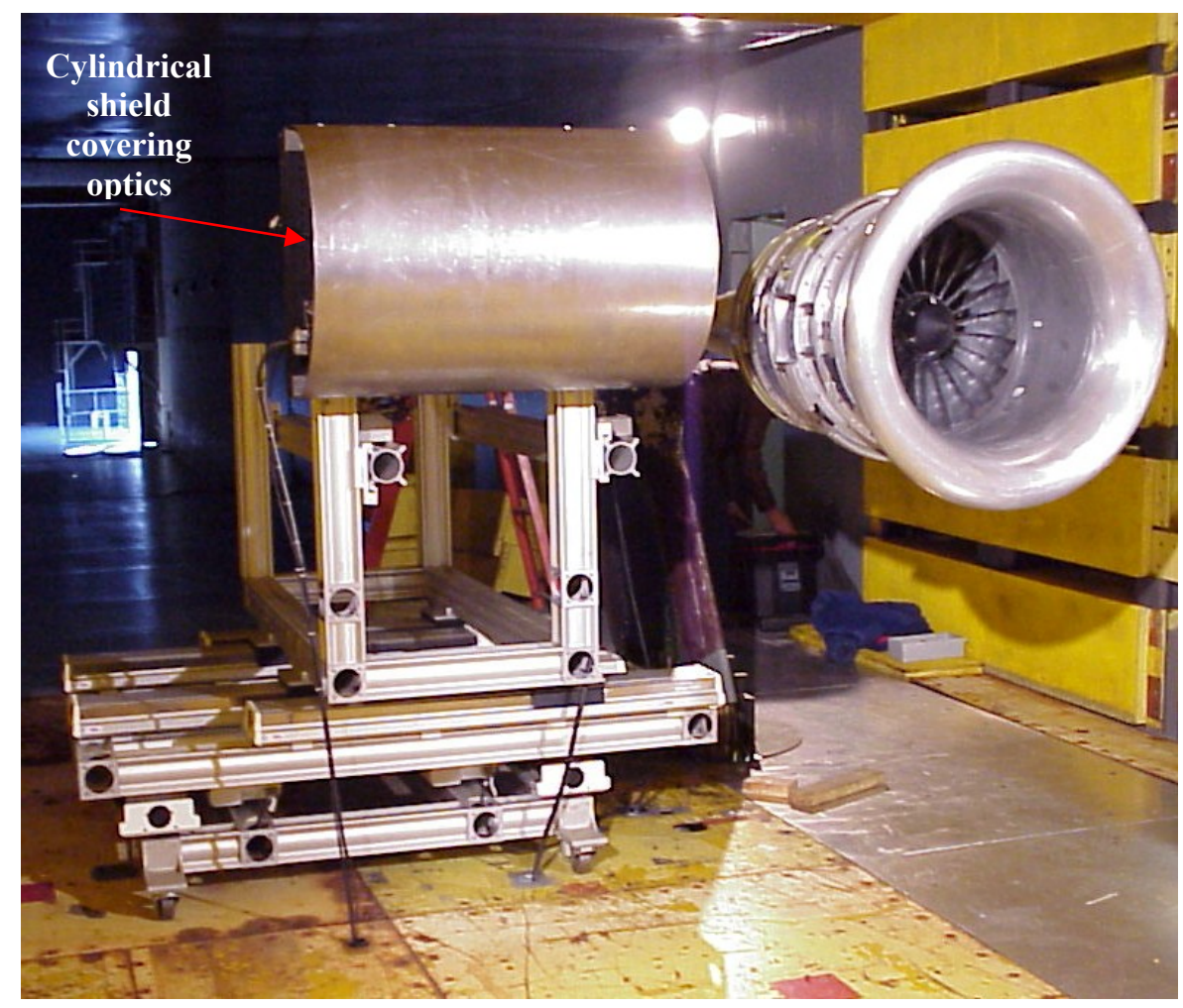

a) LDV system hardware installed next to the research fan model in the wind tunnel

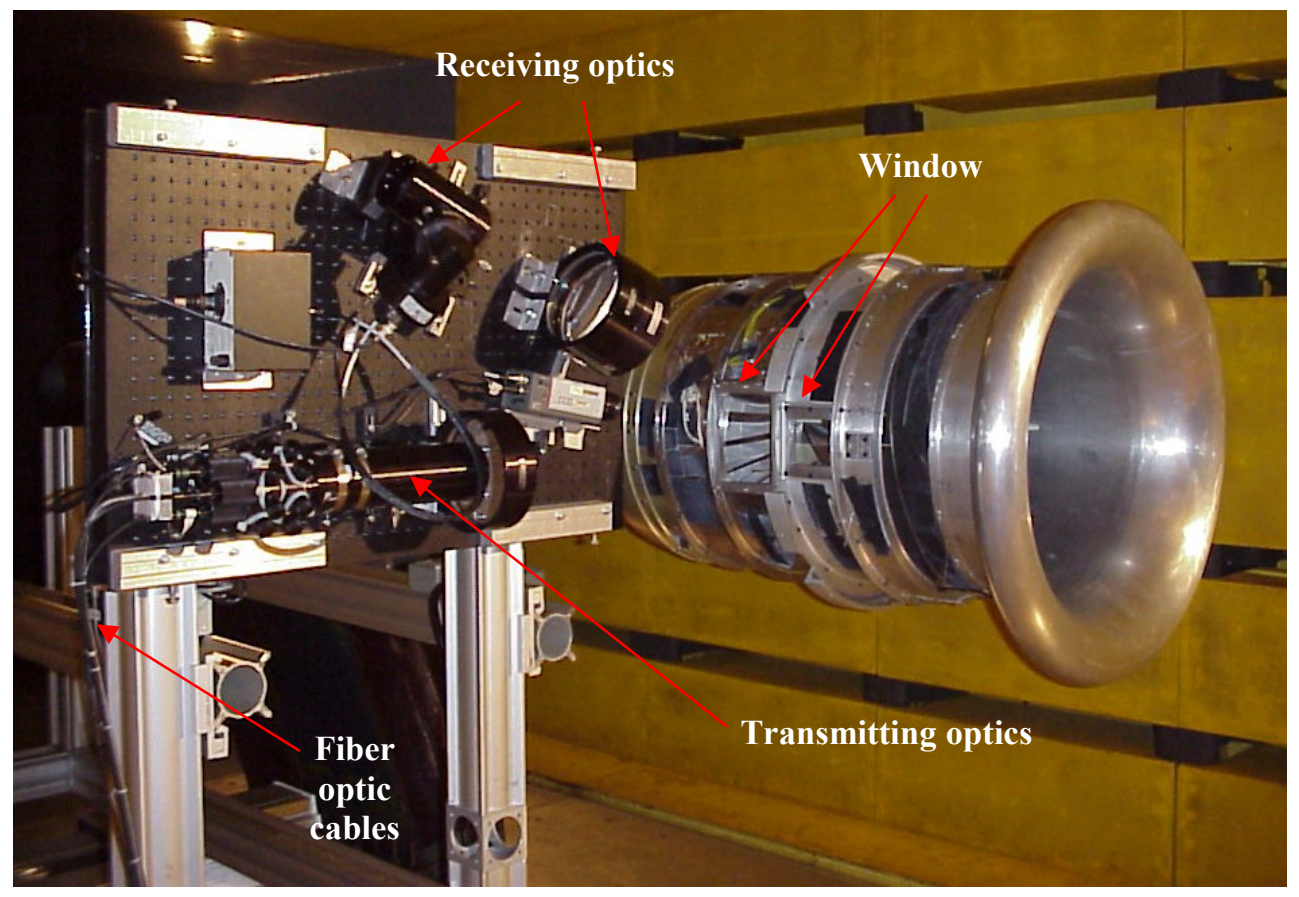

b) LDV system components with optics protective shield removed

Figure 7.-LDV system components and installation setup with the fan module in Glenn 9- by 15-Foot Low Speed Wind Tunnel. 


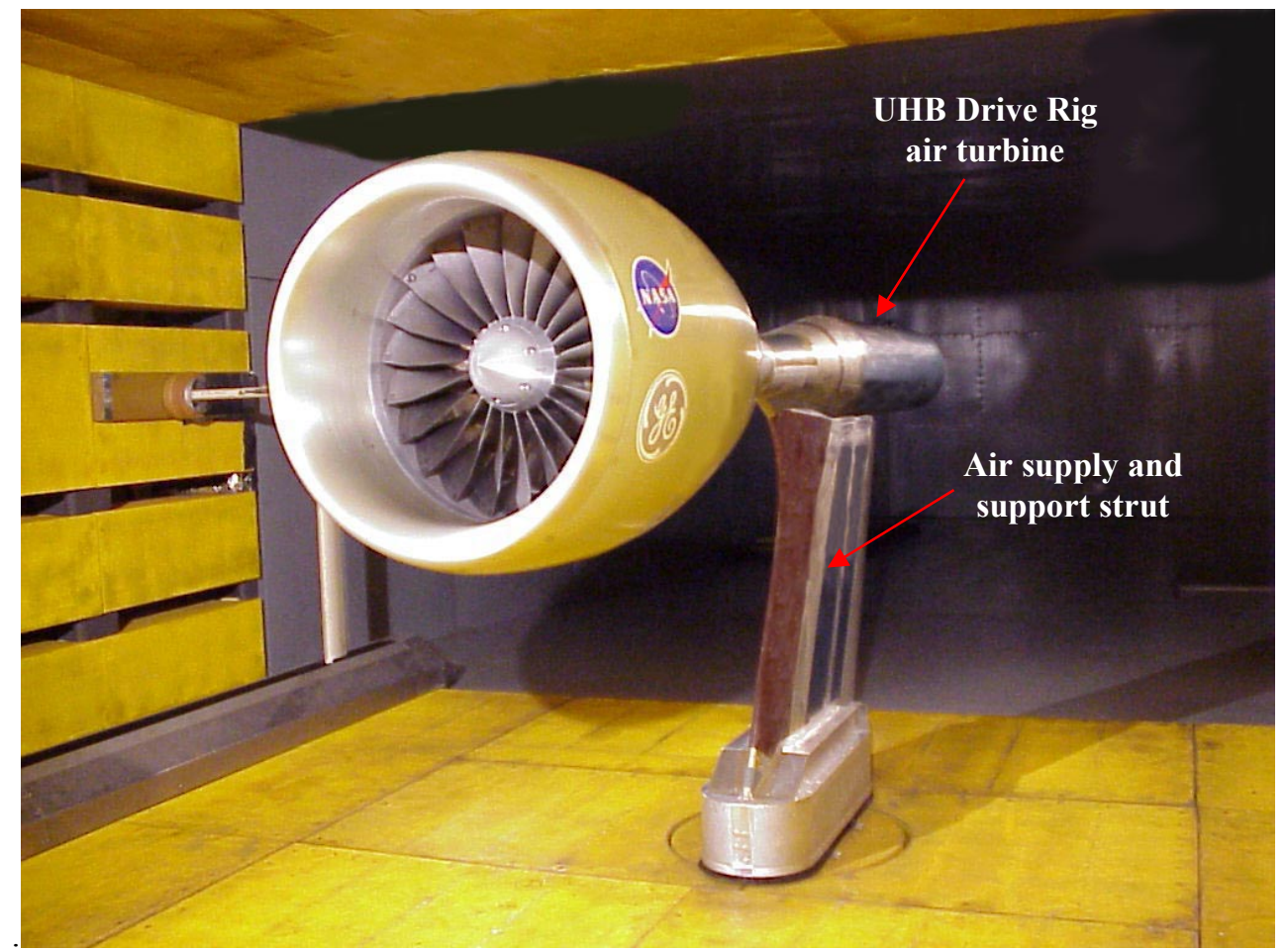

a) Fan module with flight-type inlet, nacelle and fixed area fan nozzle

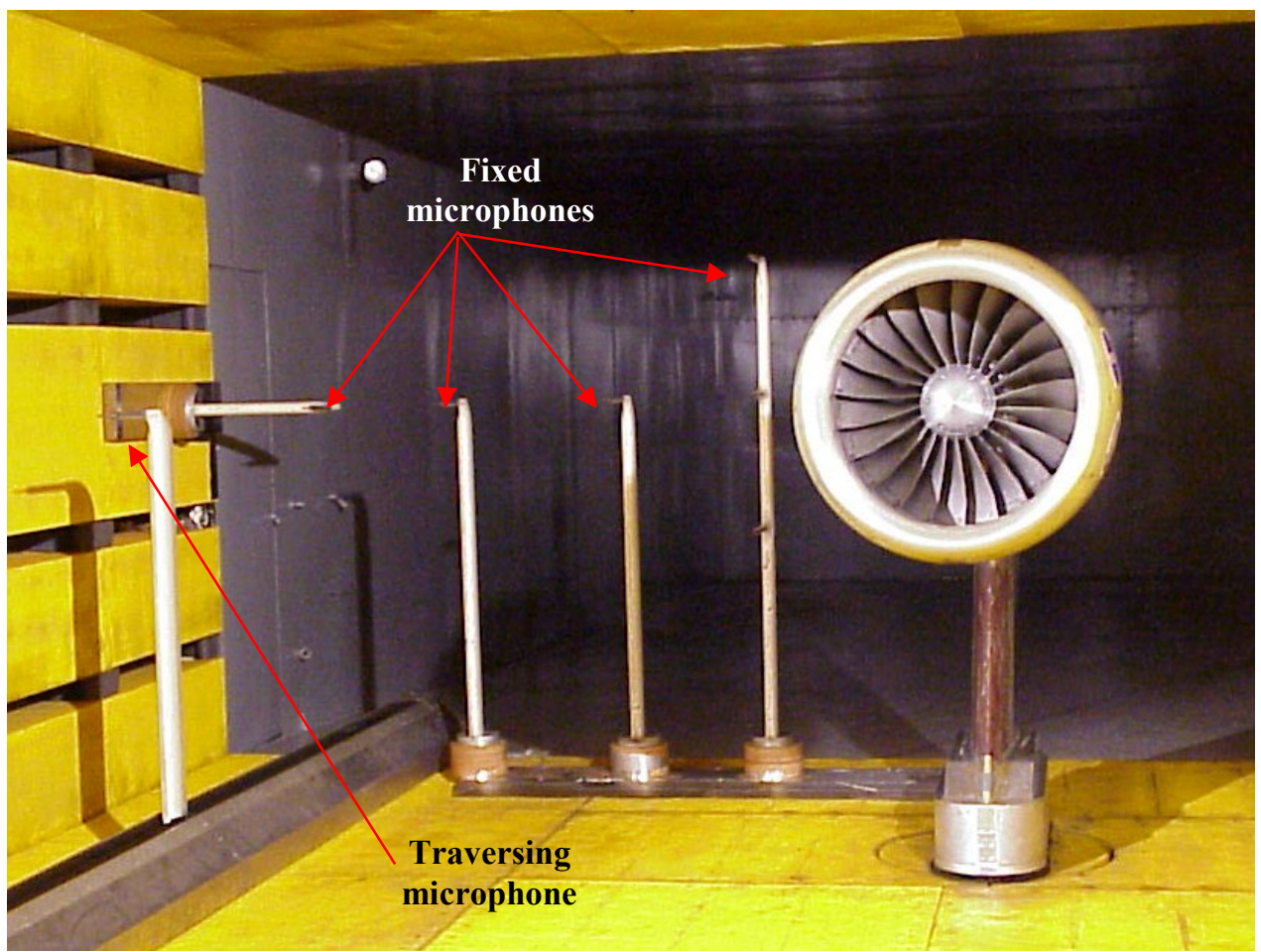

b) View of acoustic microphone orientation in the wind tunnel

Figure 8.-Photographs of fan module installed in the Glenn 9- by 15-Foot Low Speed Wind Tunnel in the farfield acoustic configuration. 


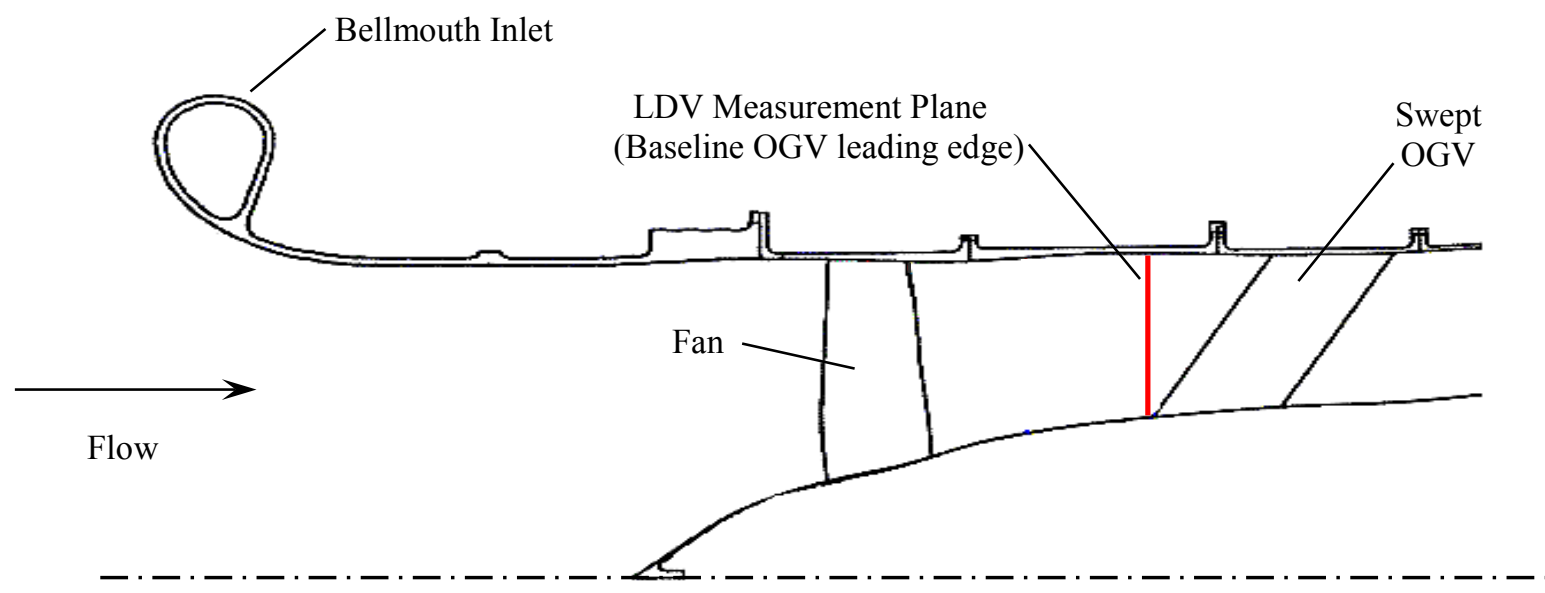

Figure 9.-Schematic diagram of the LDV fan wake measurement plane axial location within the fan module. 


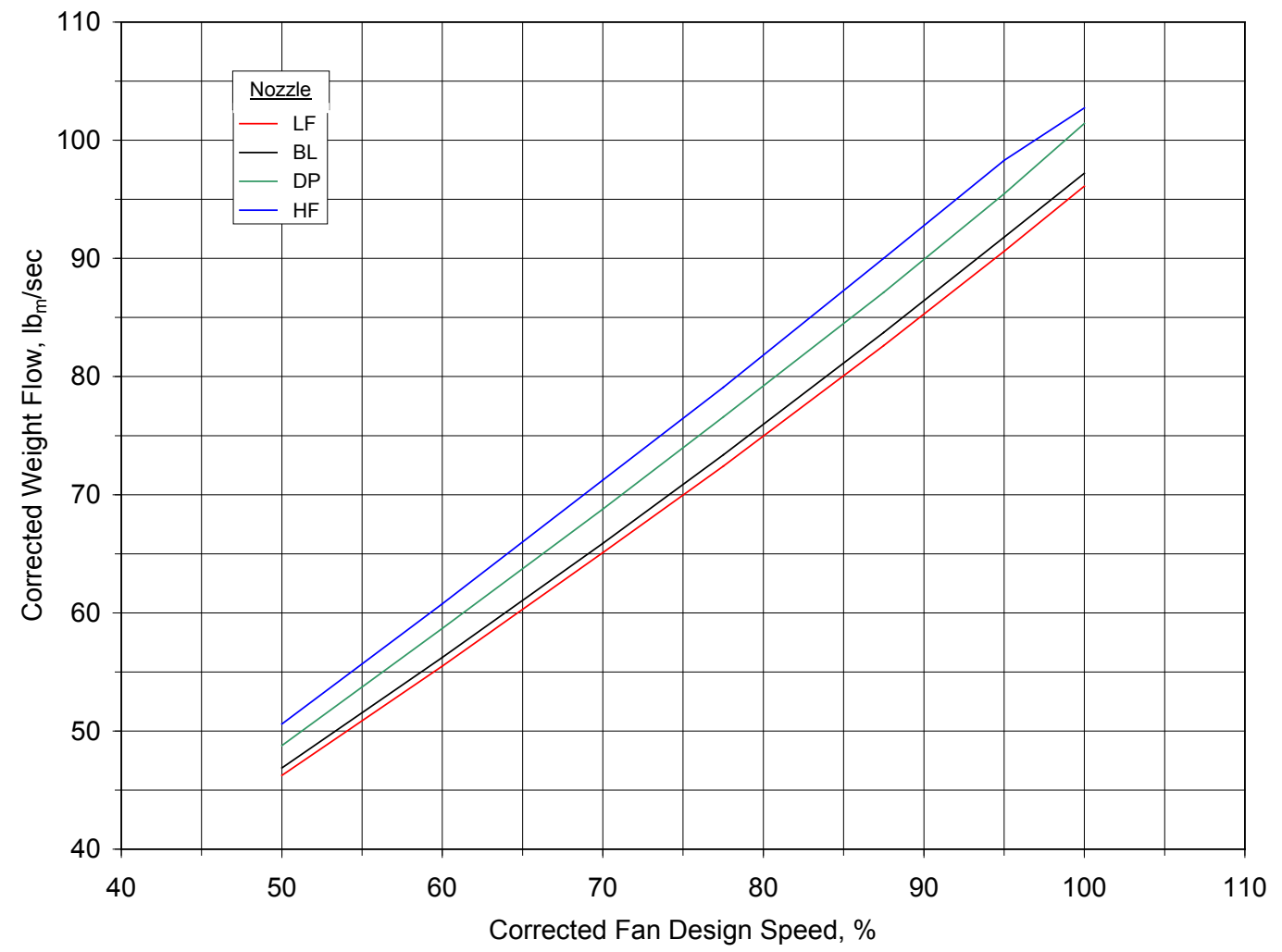

a) Corrected weight flow map on the fixed area nozzle operating lines

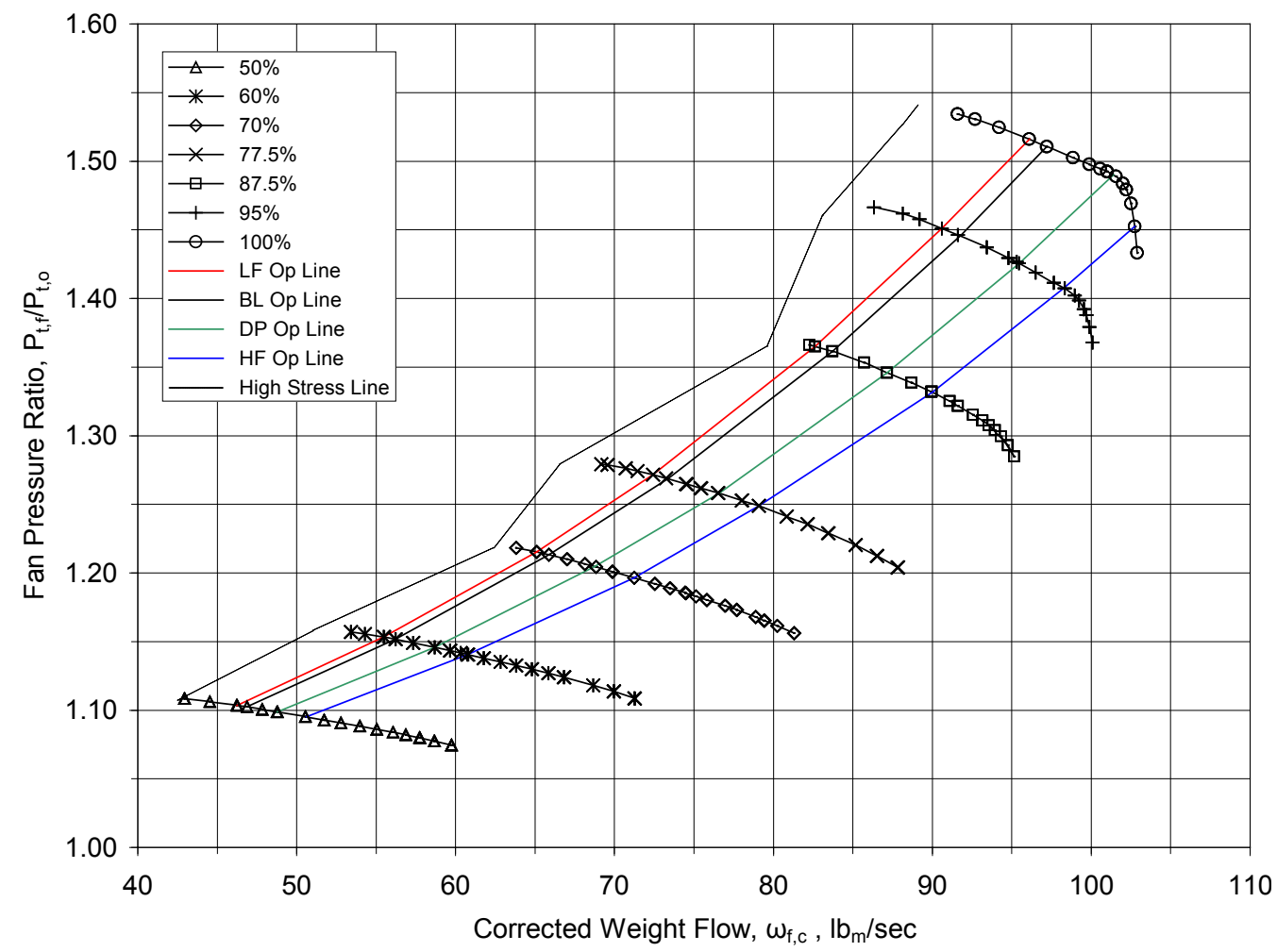

b) Total pressure ratio map

Figure 10.-Fan performance maps (continued). 


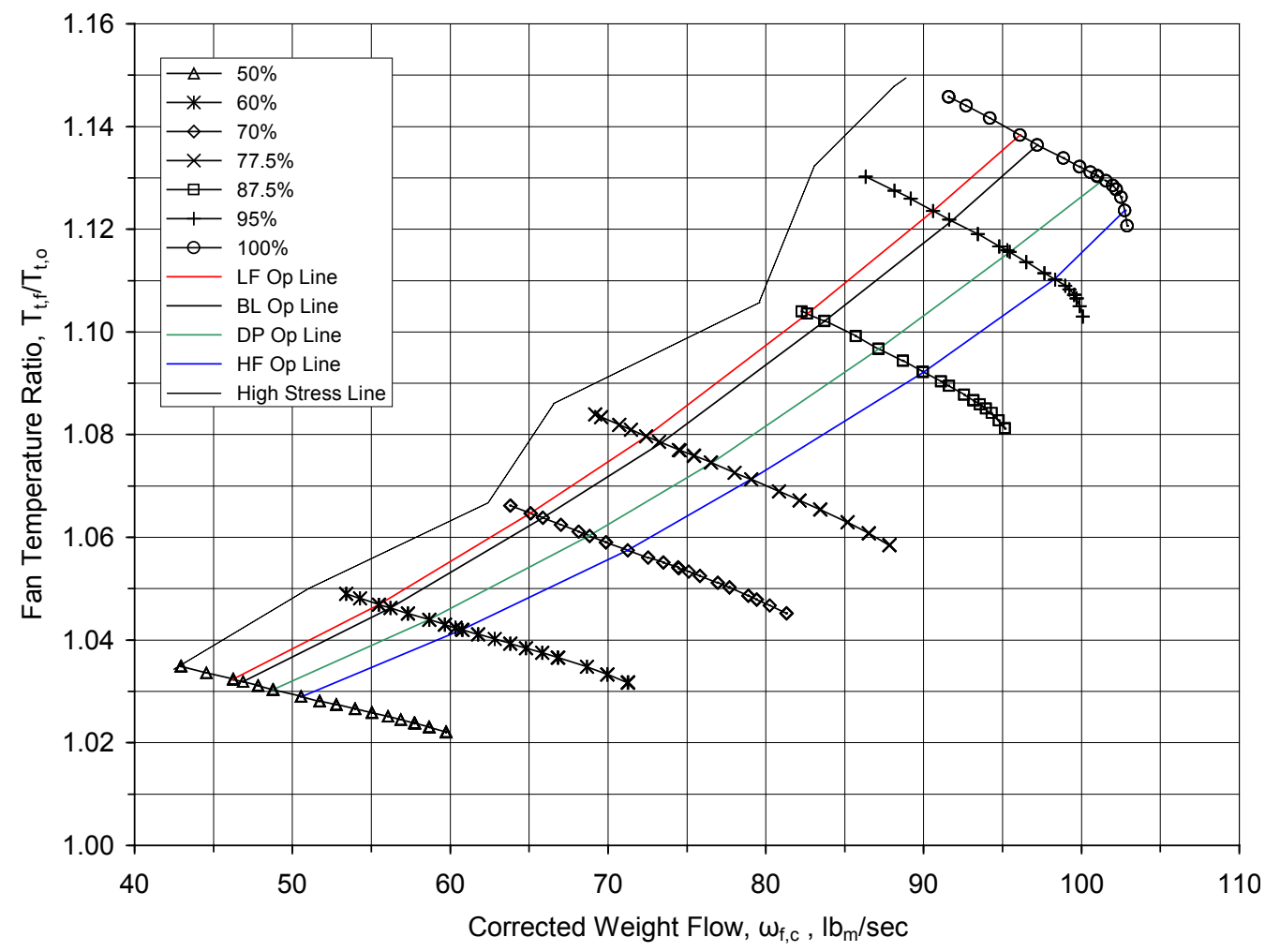

c) Total temperature ratio map

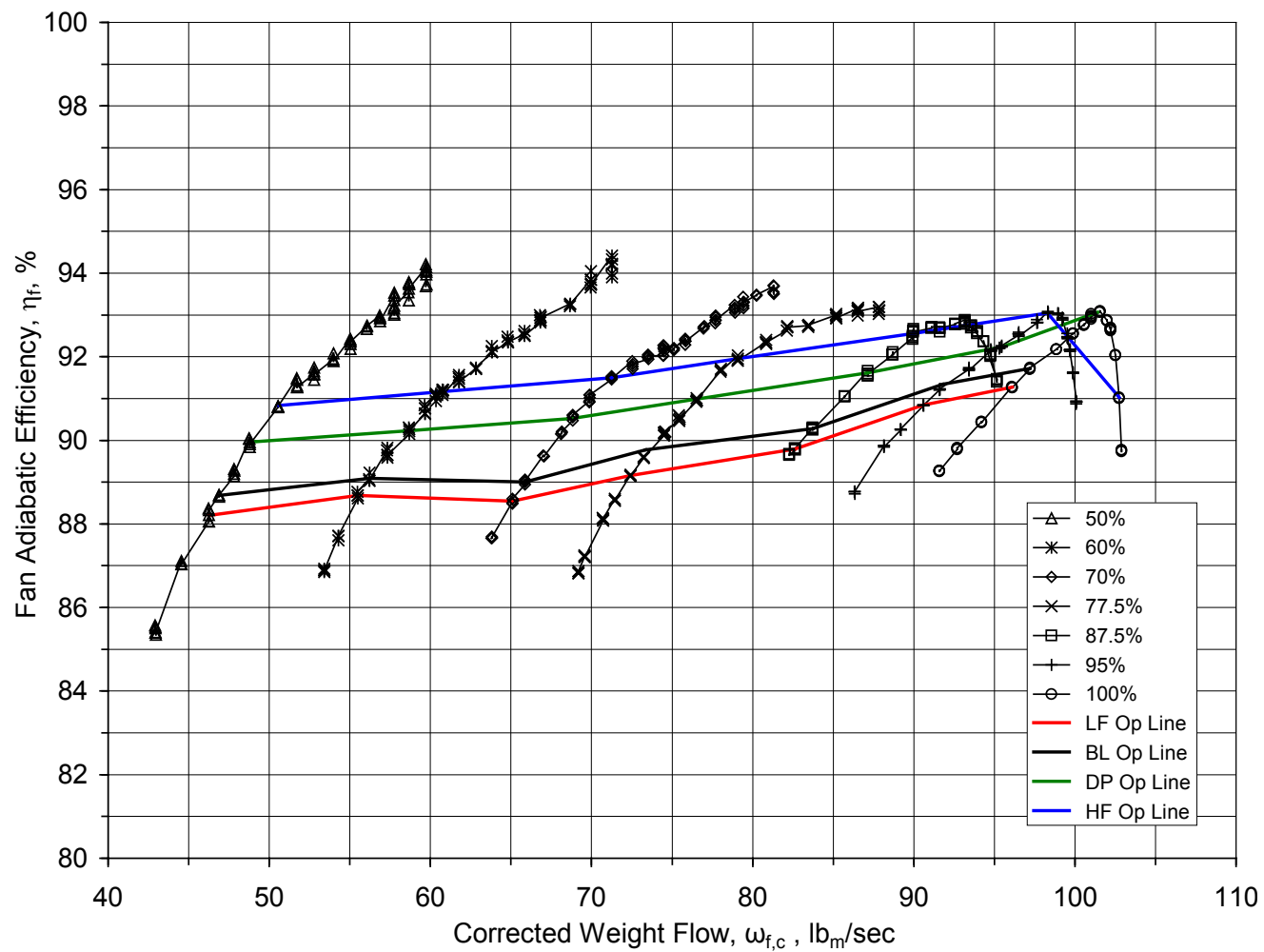

d) Adiabatic efficiency map

Figure 10.-Fan performance maps (concluded). 


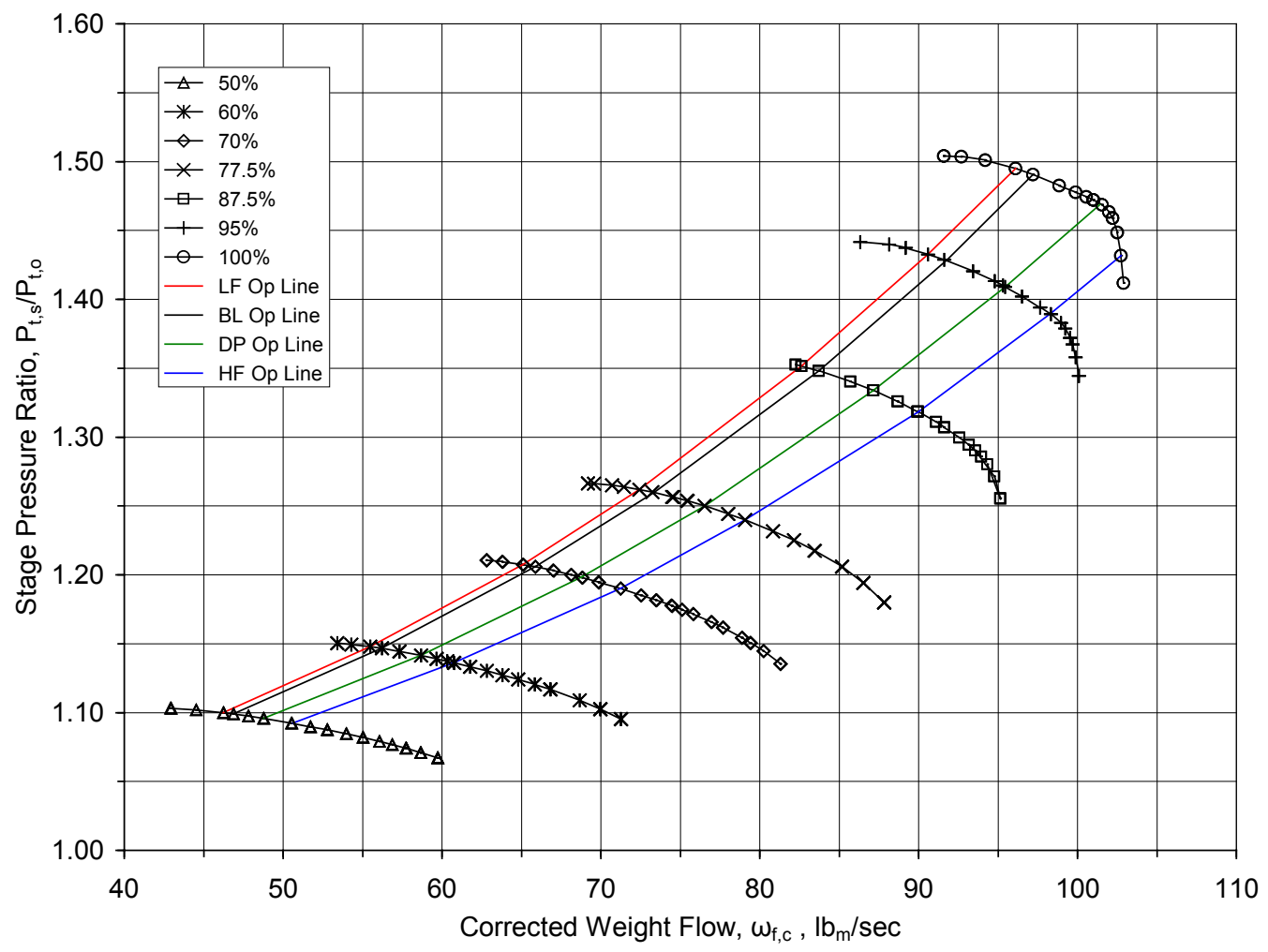

a) Total pressure ratio map

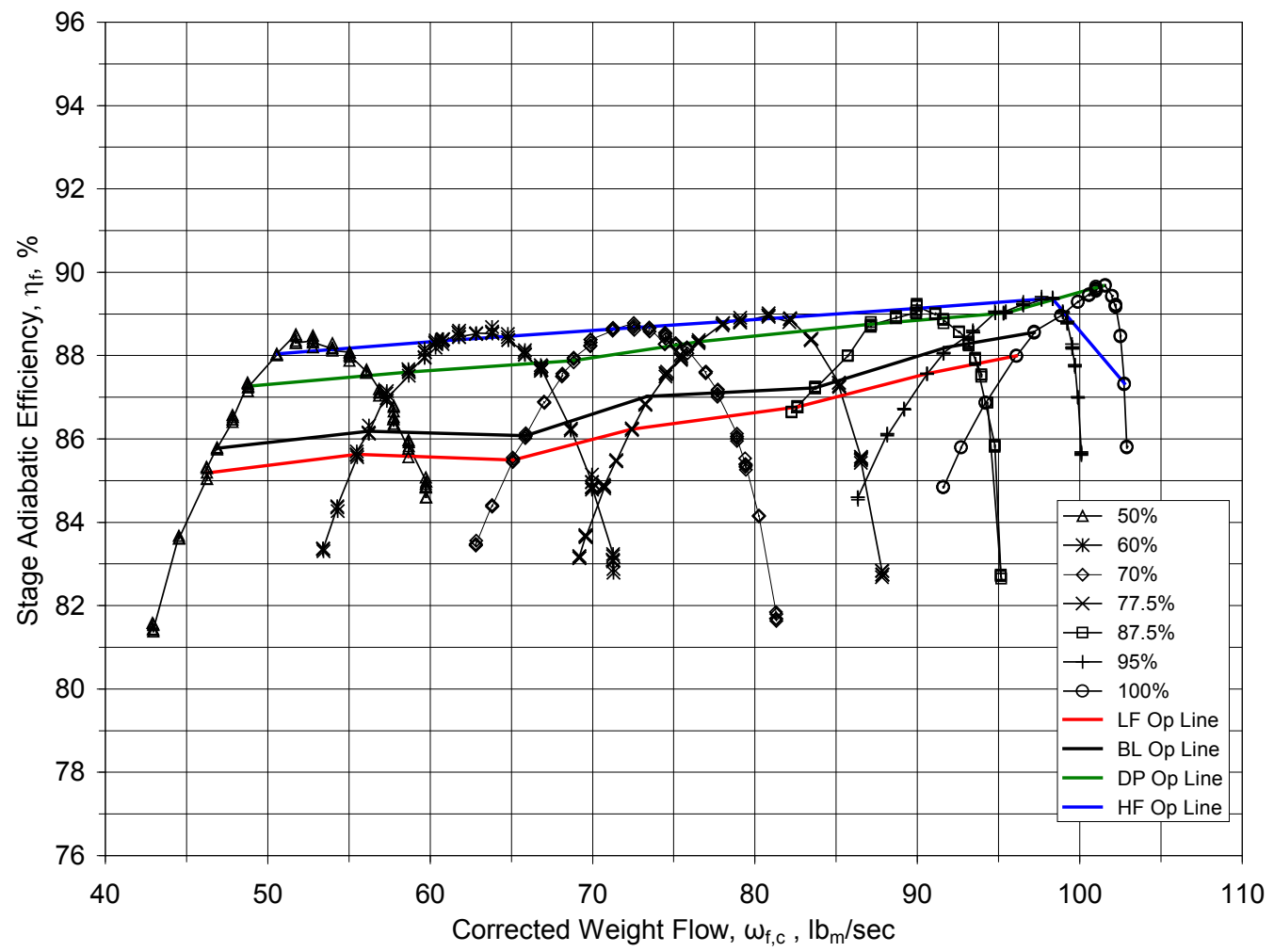

b) Adiabatic efficiency map

Figure 11.- Stage performance maps (continued). 


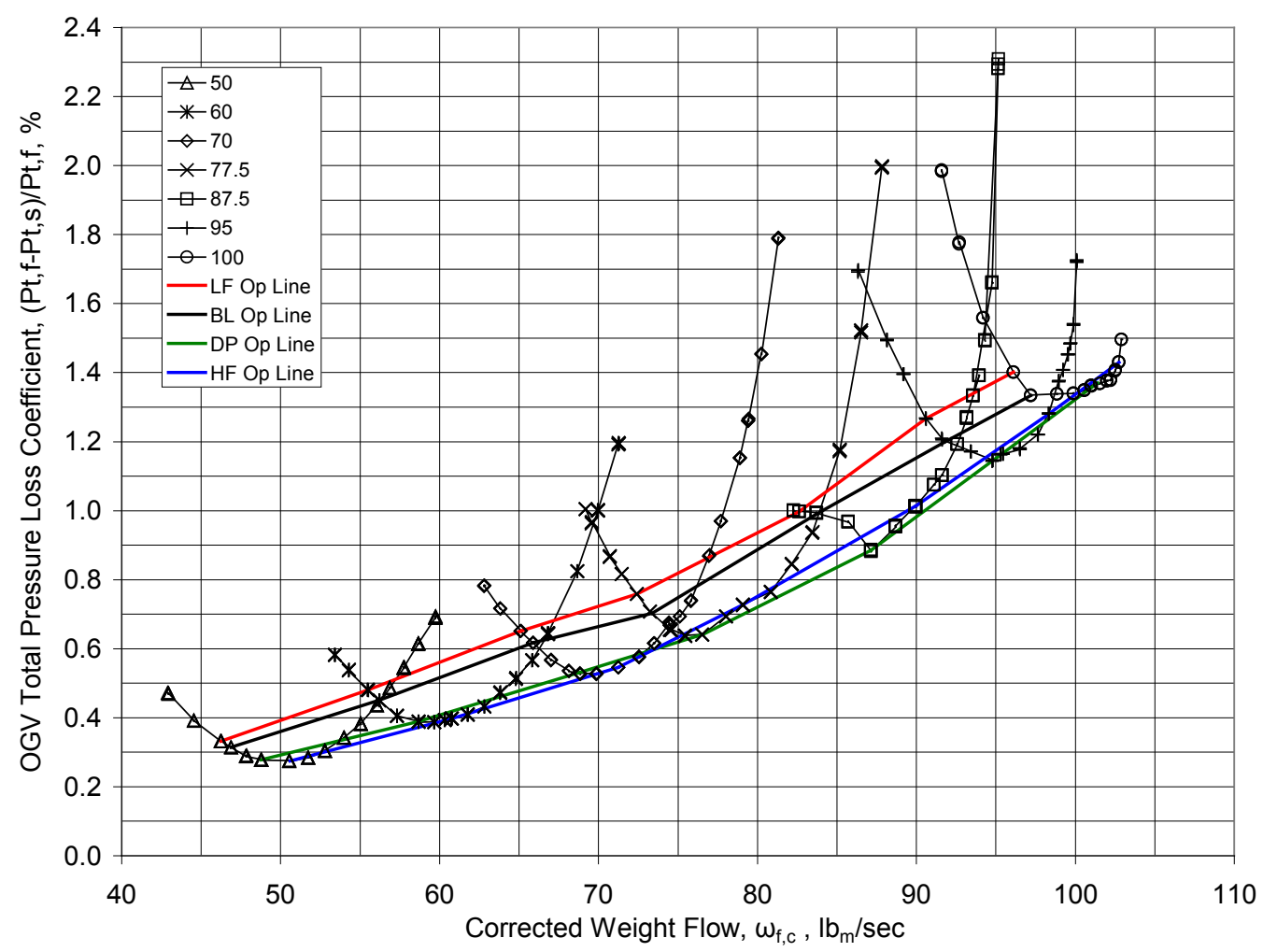

c) Total pressure loss across the OGVs

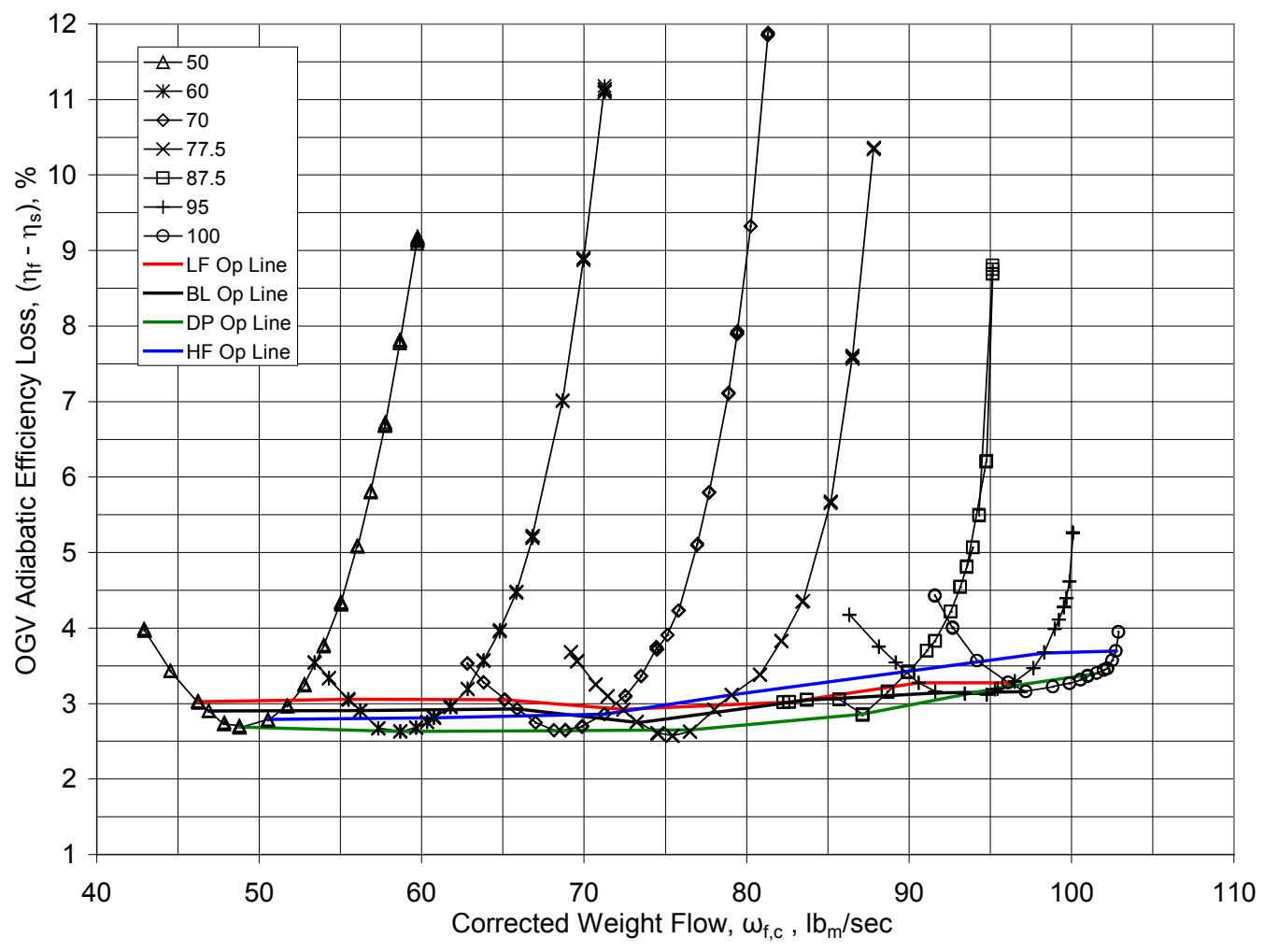

d) Adiabatic efficiency loss across the OGVs

Figure 11.—Stage performance maps (concluded). 


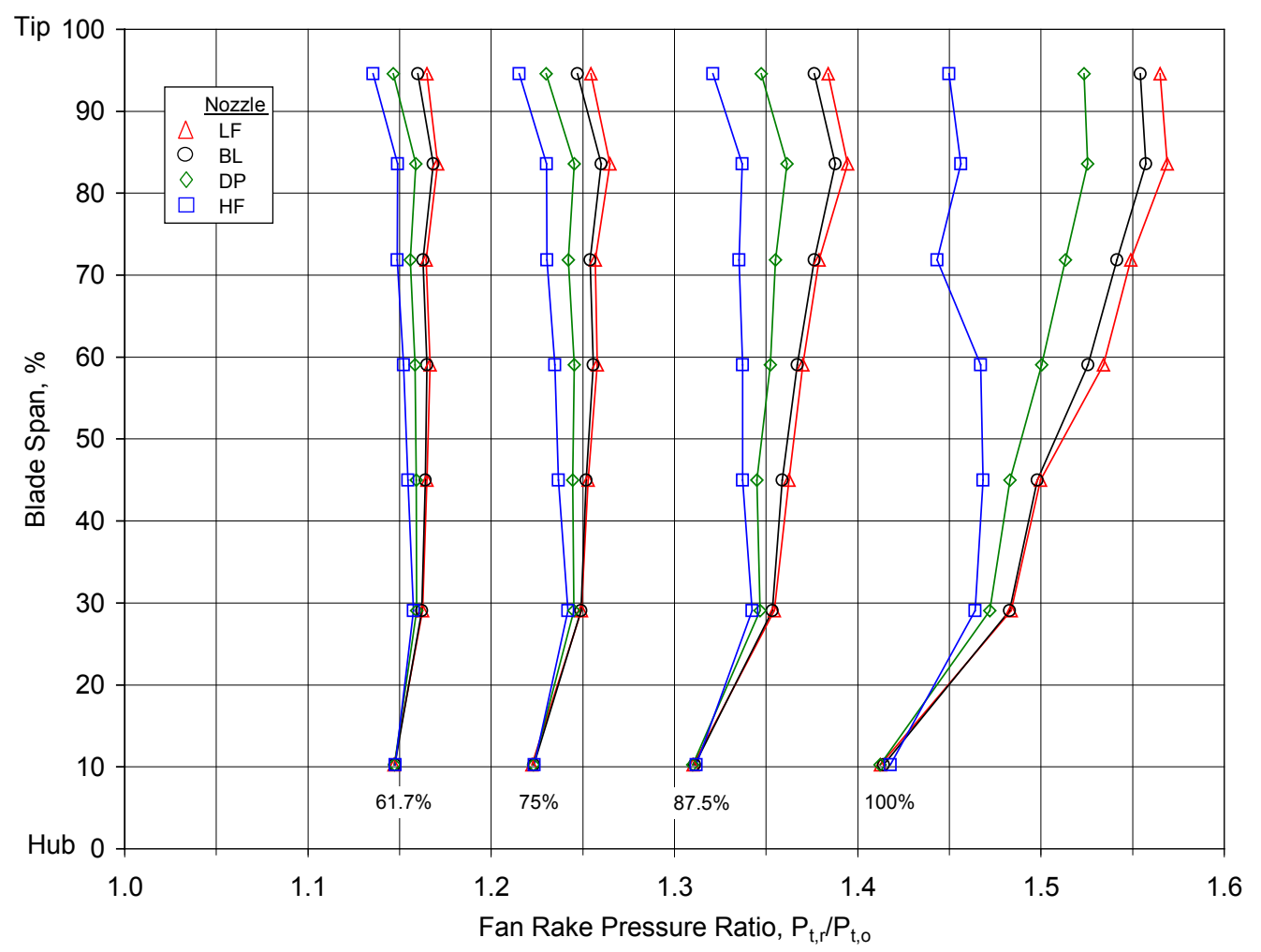

a) Total pressure ratio profiles

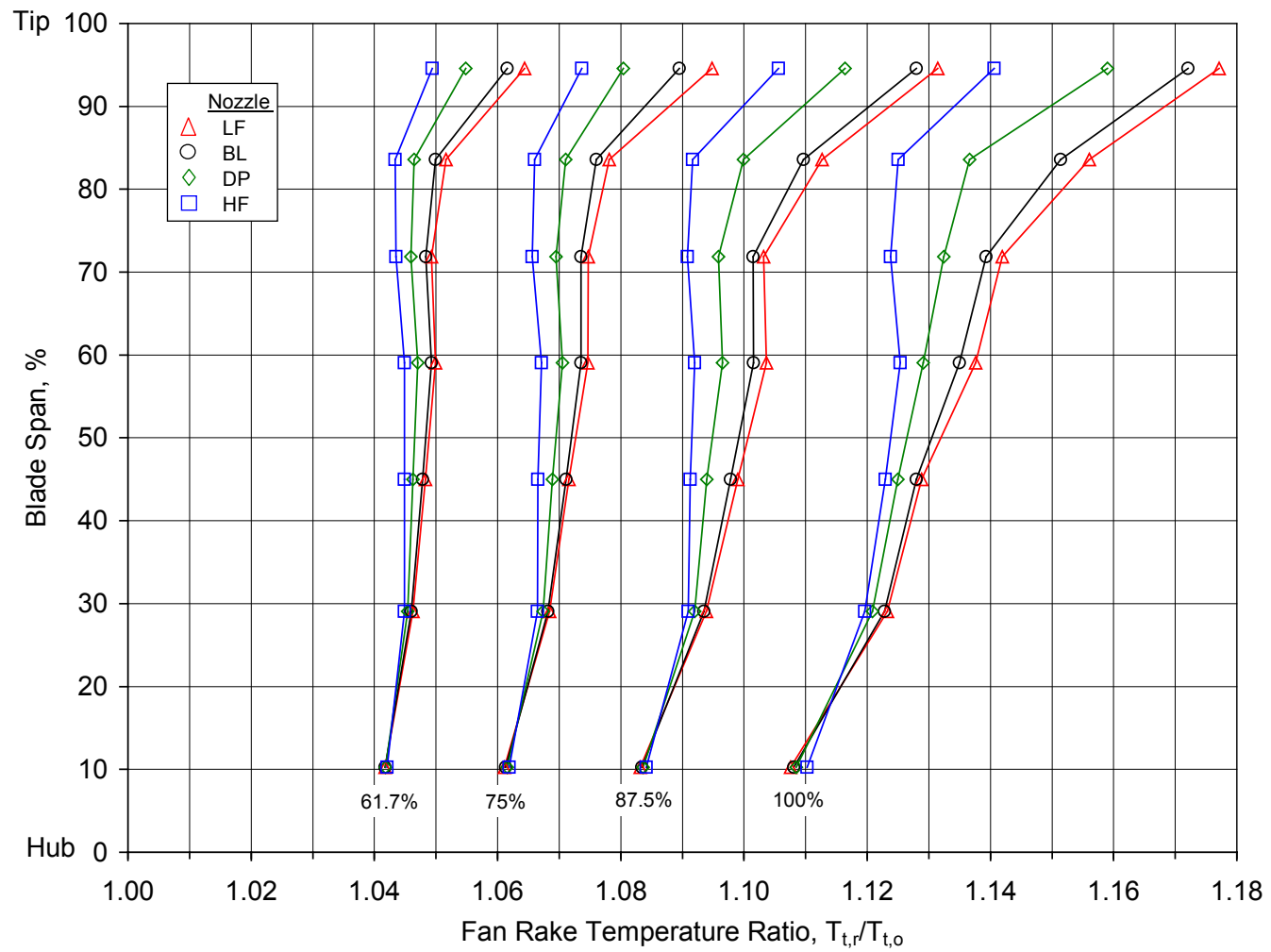

b) Total temperature ratio profiles

Figure 12.-Comparison of fan wake radial profiles with nozzle area at selected fan speeds (continued). 


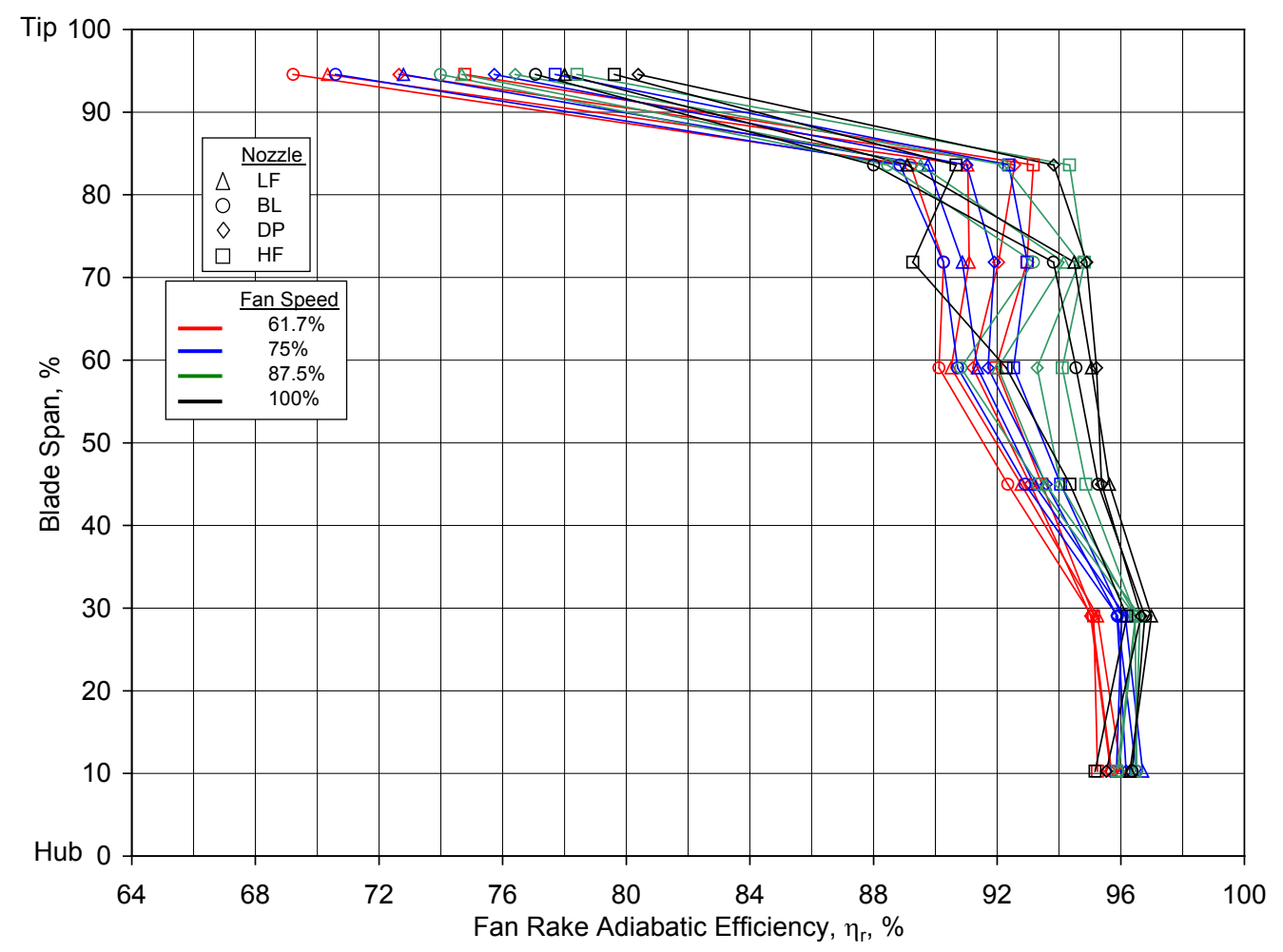

c) Adiabatic efficiency profiles

Figure 12.-Comparison of fan wake radial profiles with nozzle area at selected fan speeds (concluded).

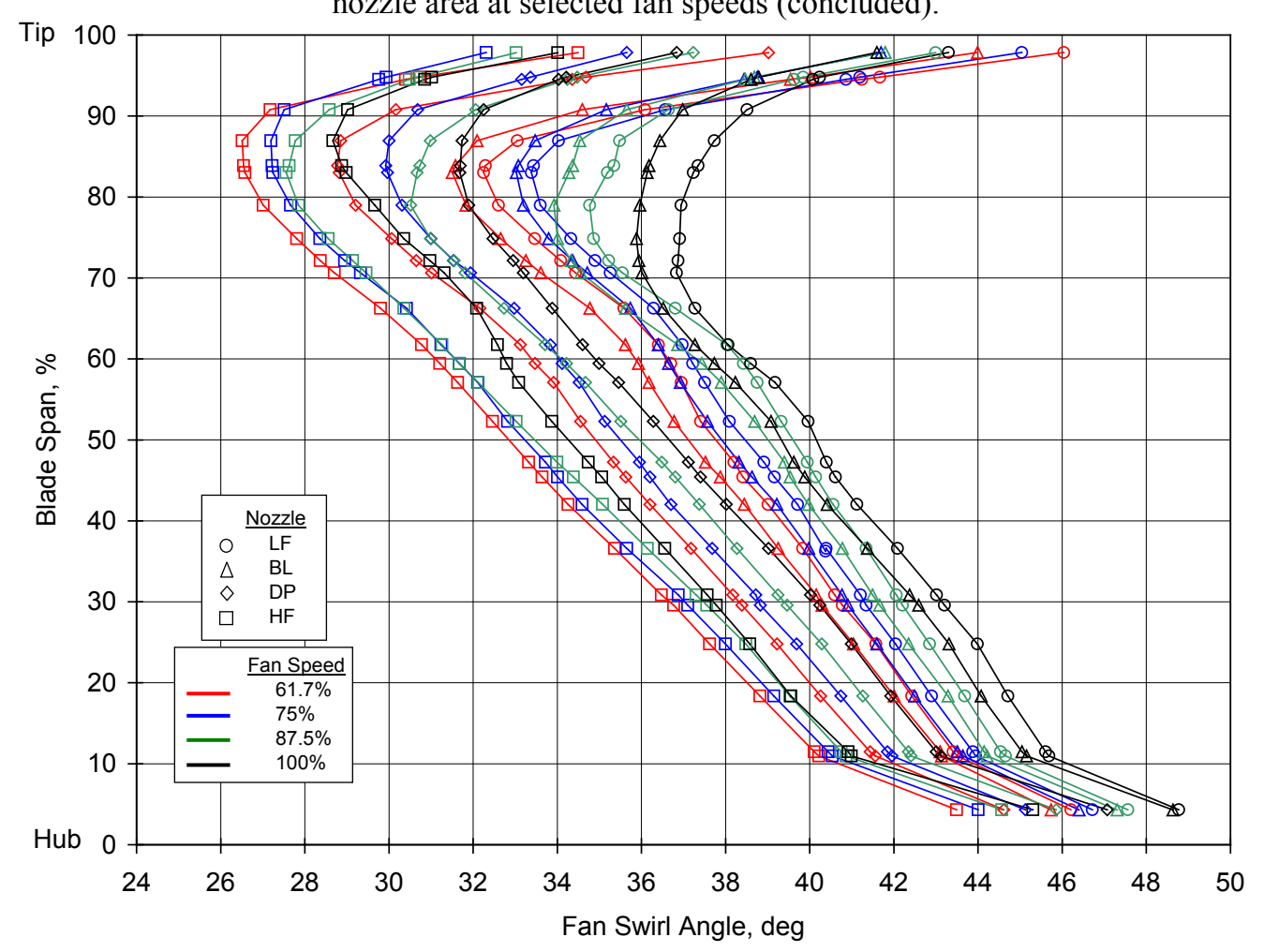

Figure 13. - Comparison of fan wake radial swirl angle profiles with nozzle area at selected fan speeds. 


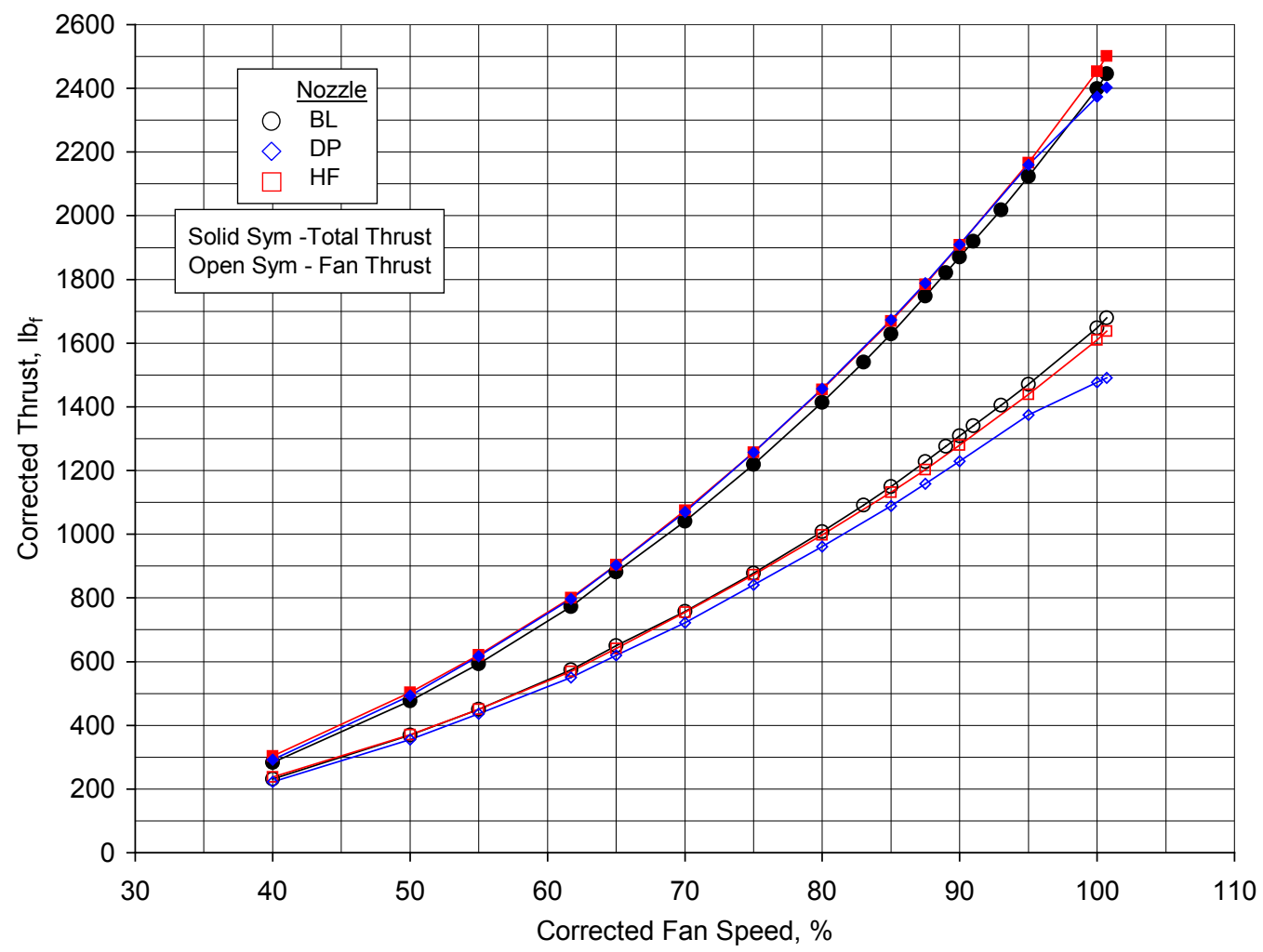

Figure 14.- Comparison of corrected thrust with fan nozzle area on fixed operating lines as measured with force balances.

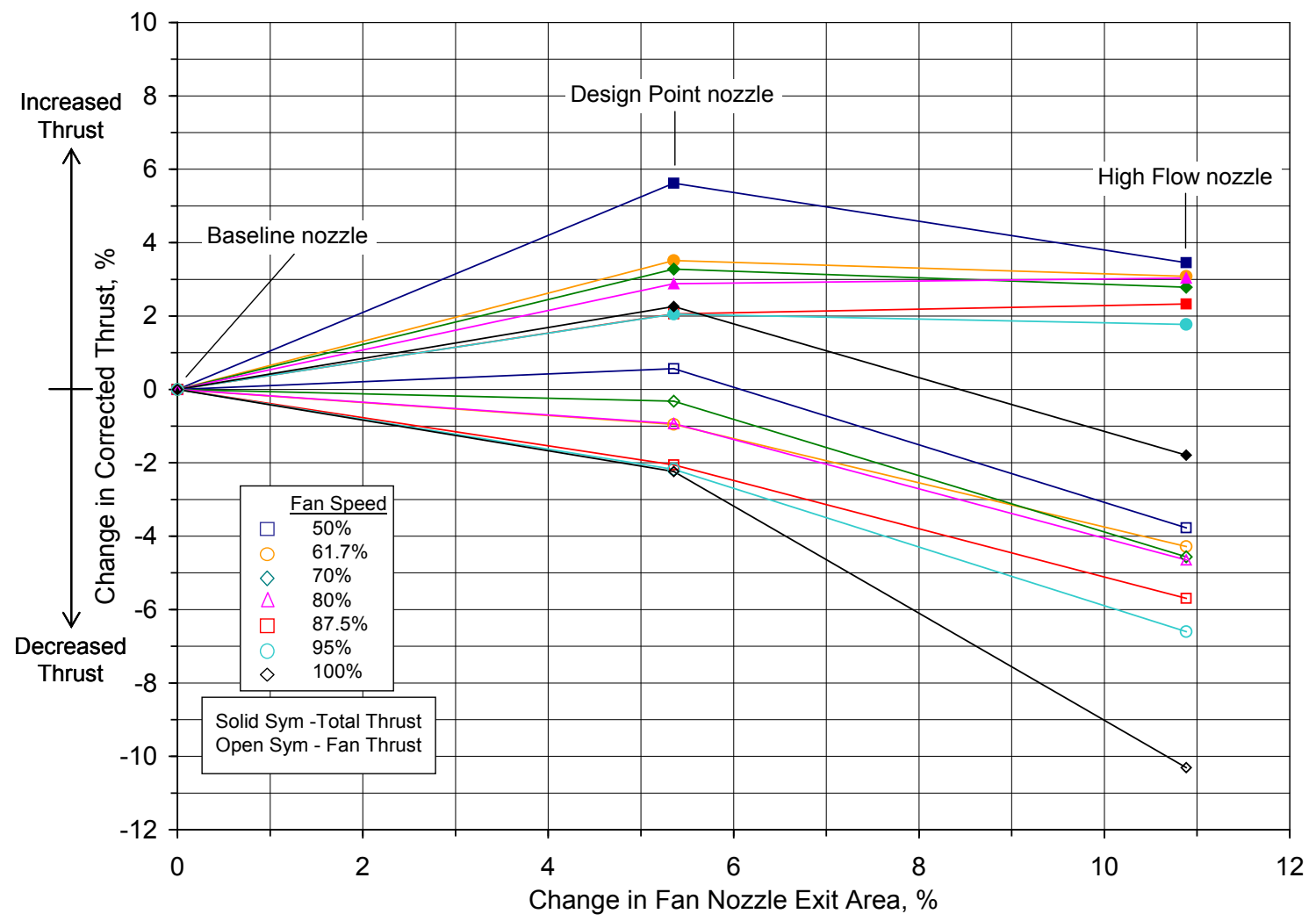

Figure 15.-Change in corrected thrust with difference in fan nozzle area for several corrected fan speeds. 


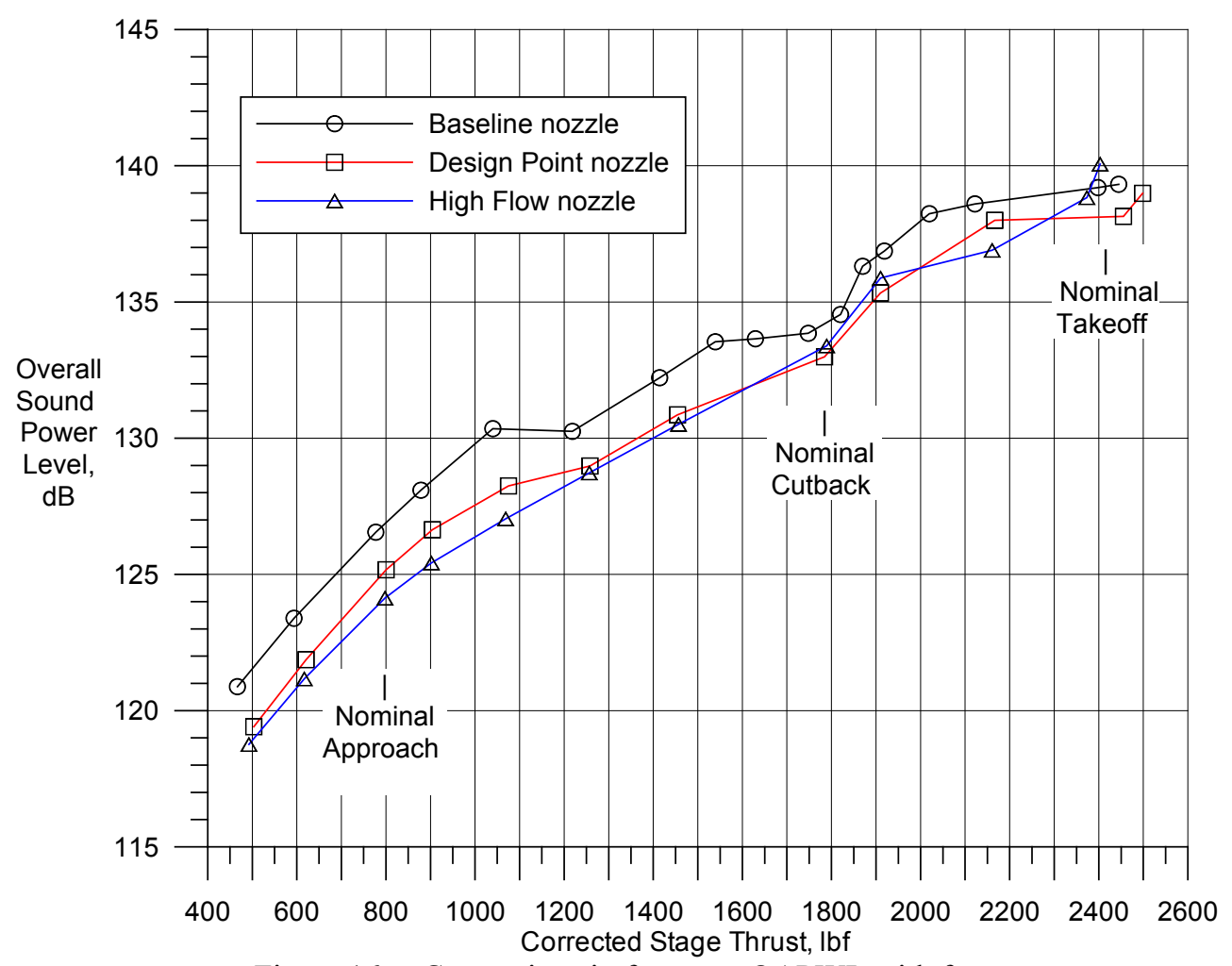

Figure 16.-Comparison in fan stage OAPWL with fan nozzle area as a function of corrected total thrust.

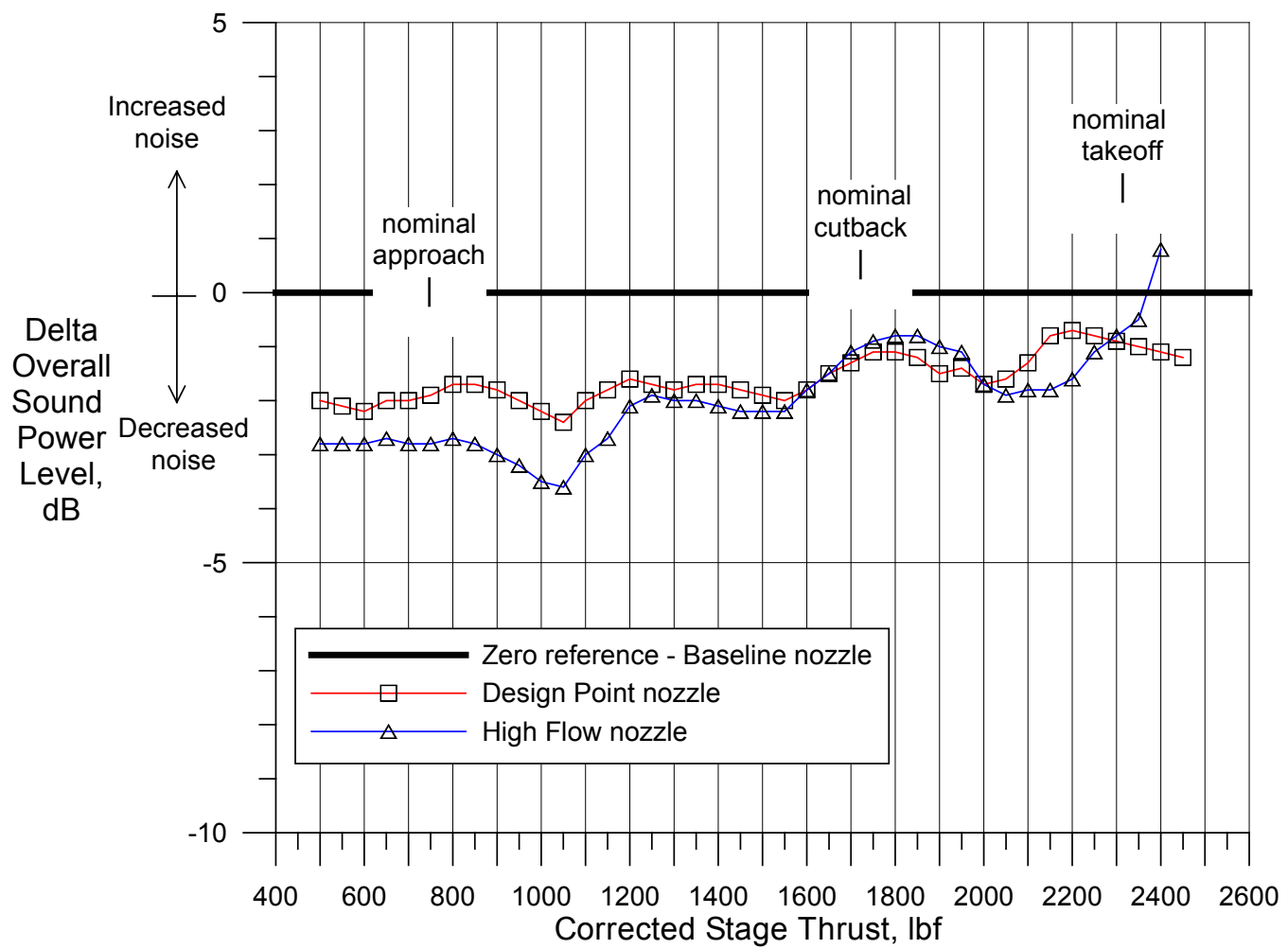

Figure 17.-Difference in OAPWL relative to the baseline fan nozzle as a function of corrected total thrust. 


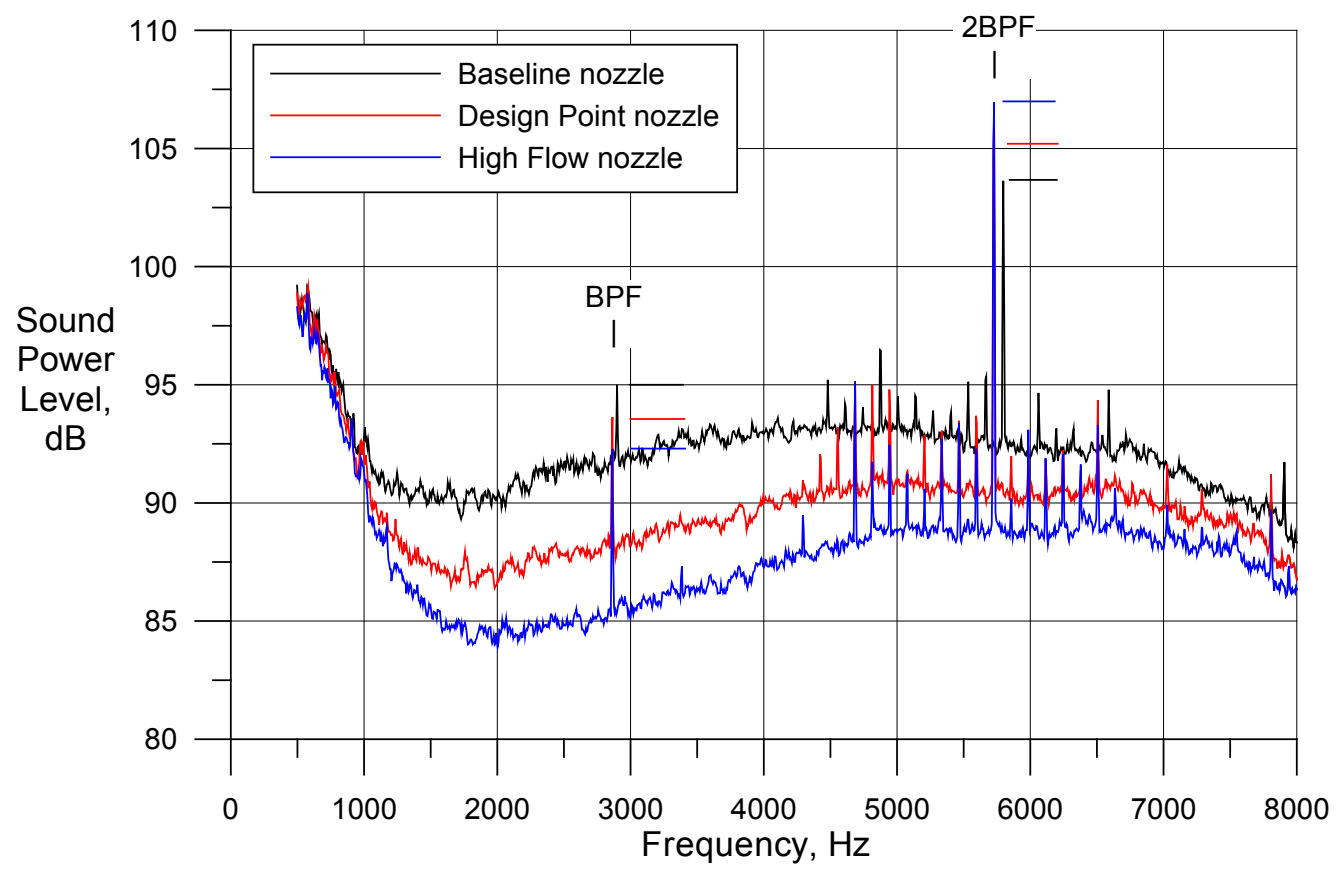

a) 61.7 percent fan design speed (designated approach speed)

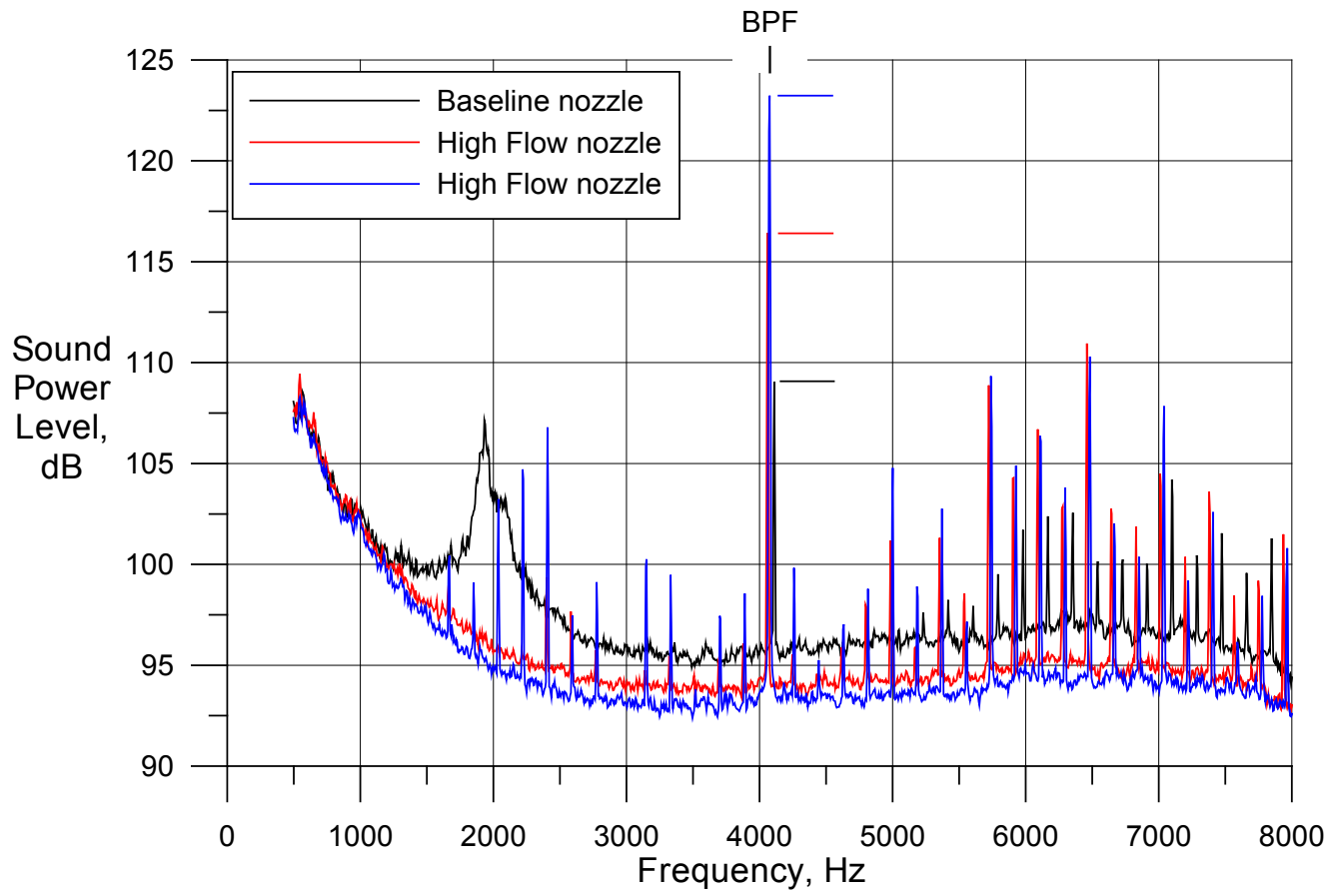

b) 87.5 percent fan design speed (designated cutback speed)

Figure 18.- Sound power level spectra for acoustic rating speeds (5.9 Hz bandwidth) (continued). 


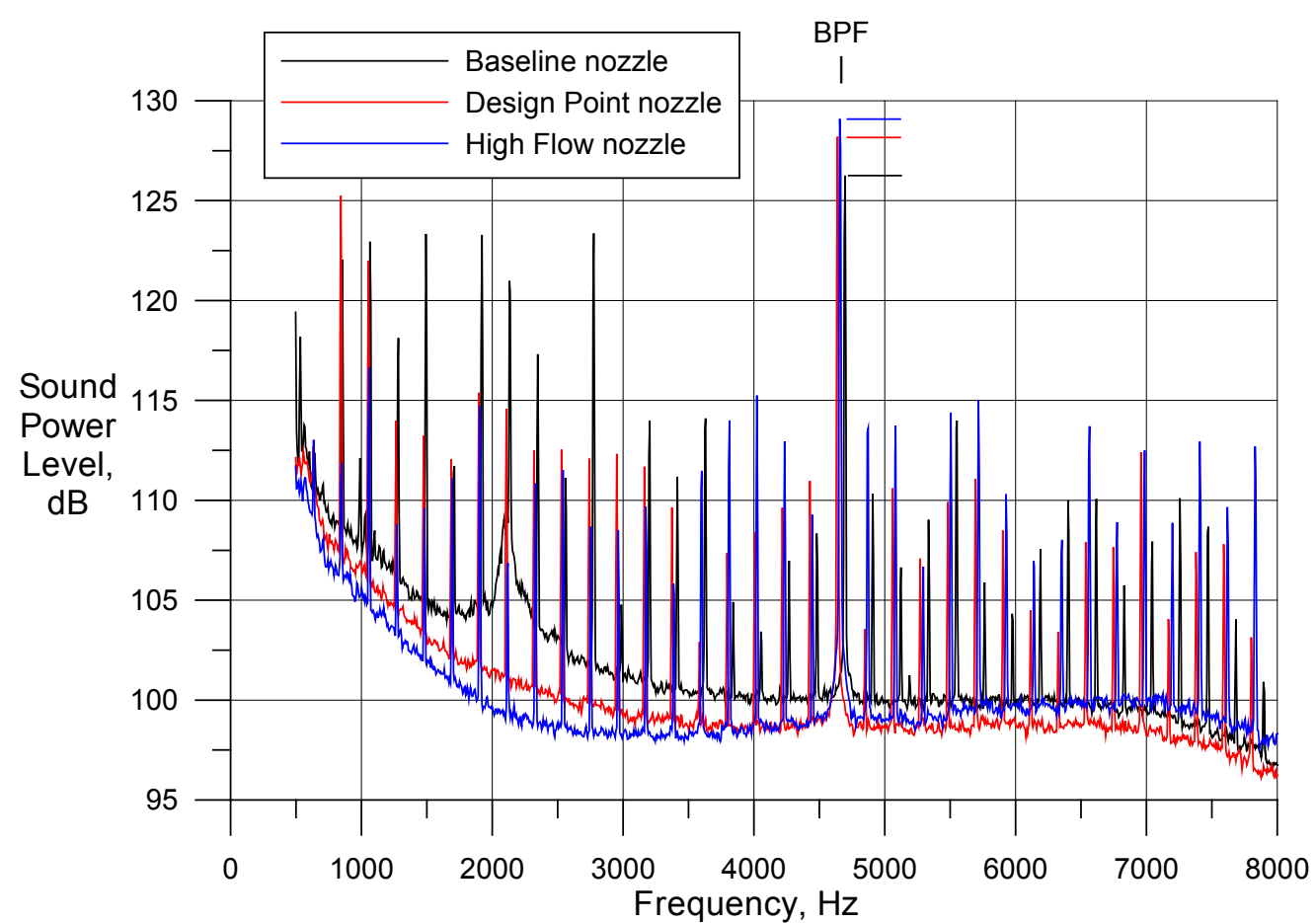

c) 100 percent fan design speed (designated takeoff speed)

Figure 18.- Sound power level spectra for acoustic rating speeds (5.9 Hz bandwidth) (concluded).

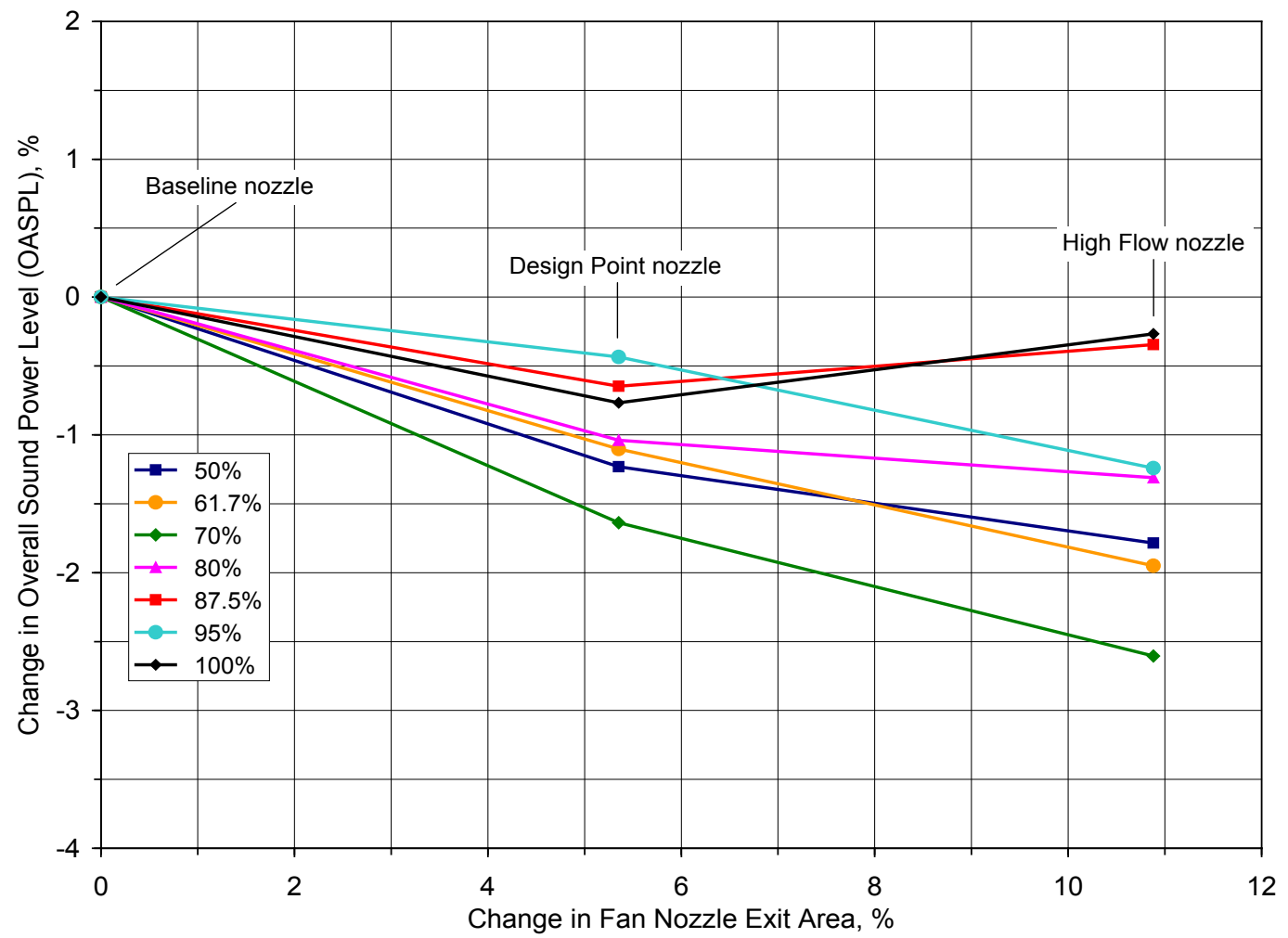

Figure 19.-Percent change in fan stage OAPWL as a function of percent change in fan nozzle area. 
Baseline

Nozzle

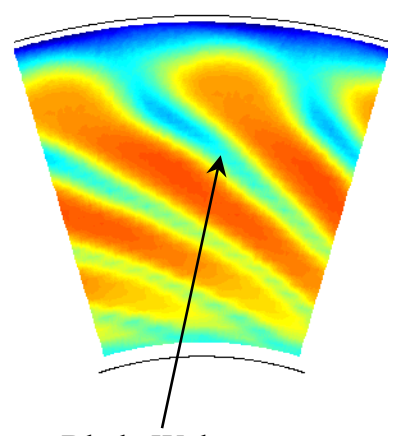

Blade Wake
Design Point

Nozzle

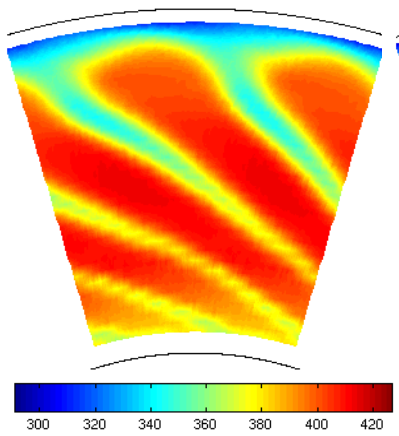

a) Axial mean velocity

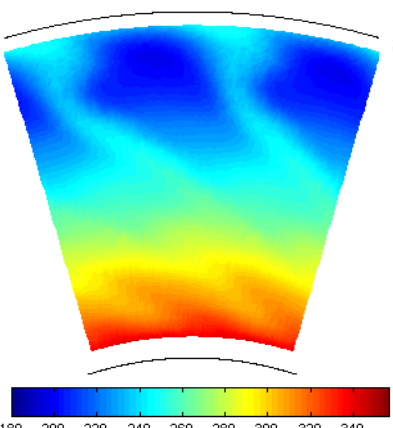

b) Tangential mean velocity

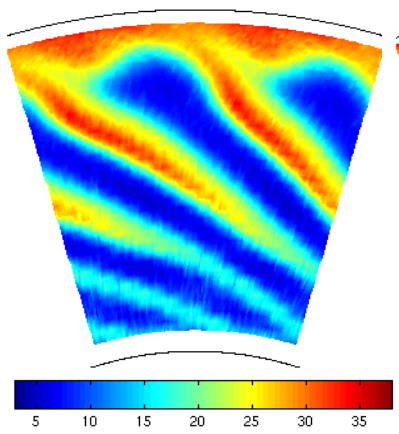

c) Axial turbulent velocity

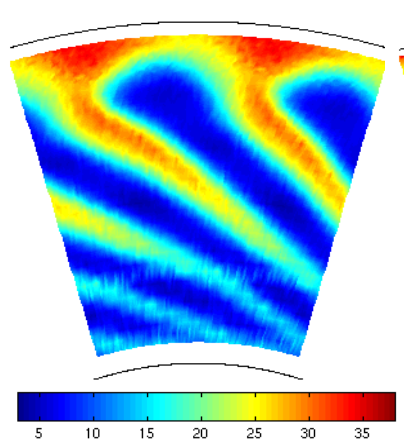

d) Tangential turbulent velocity
High Flow

Nozzle
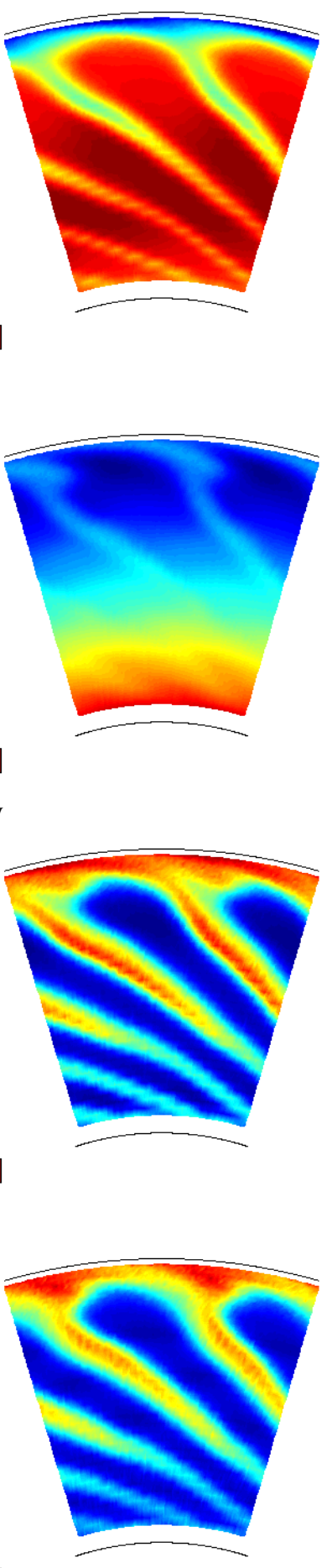

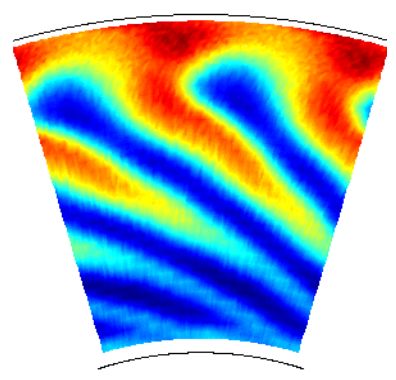

Figure 20.-LDV mean velocity and turbulence measurements at 61.7 percent corrected fan speed (approach conditions) for three fan nozzle configurations. 

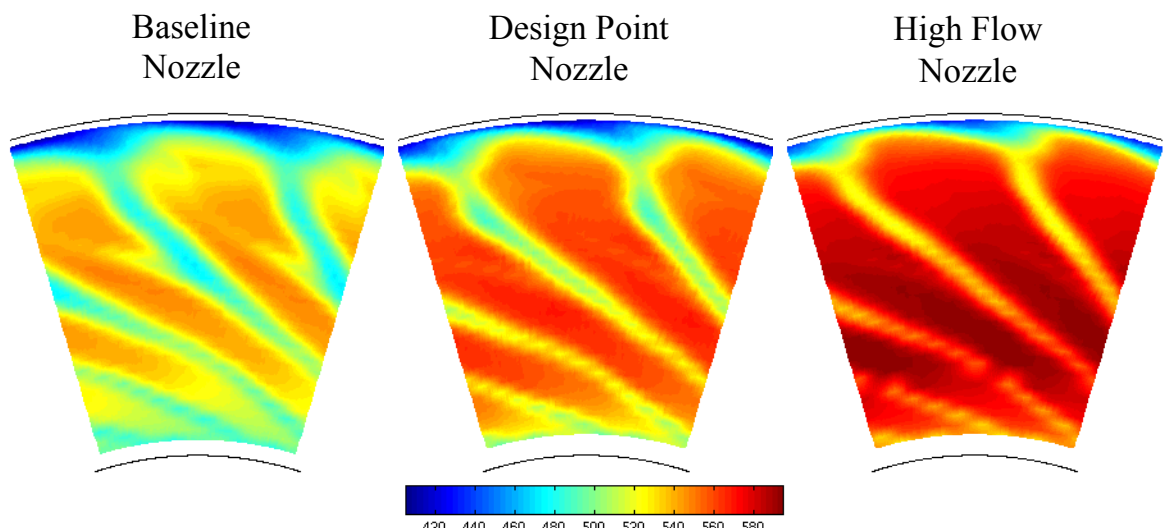

a) Axial mean velocity
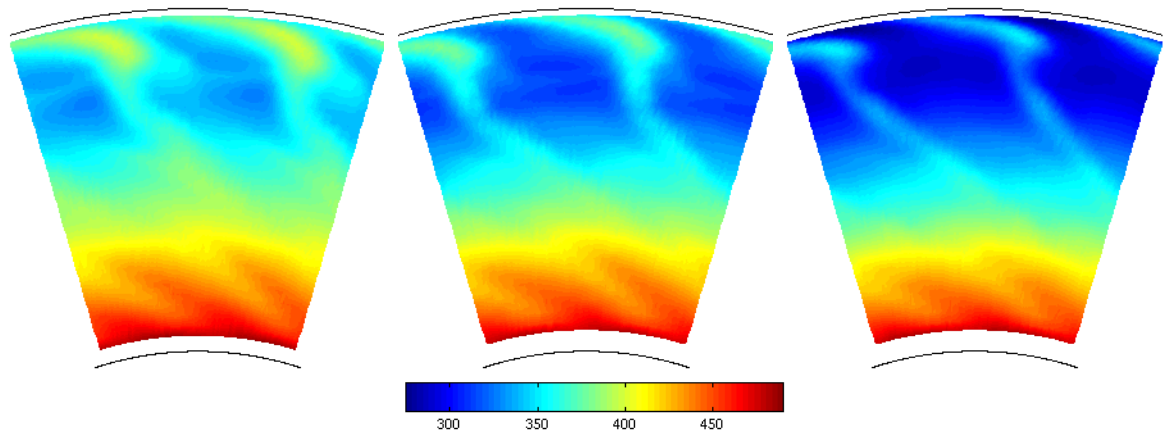

b) Tangential mean velocity
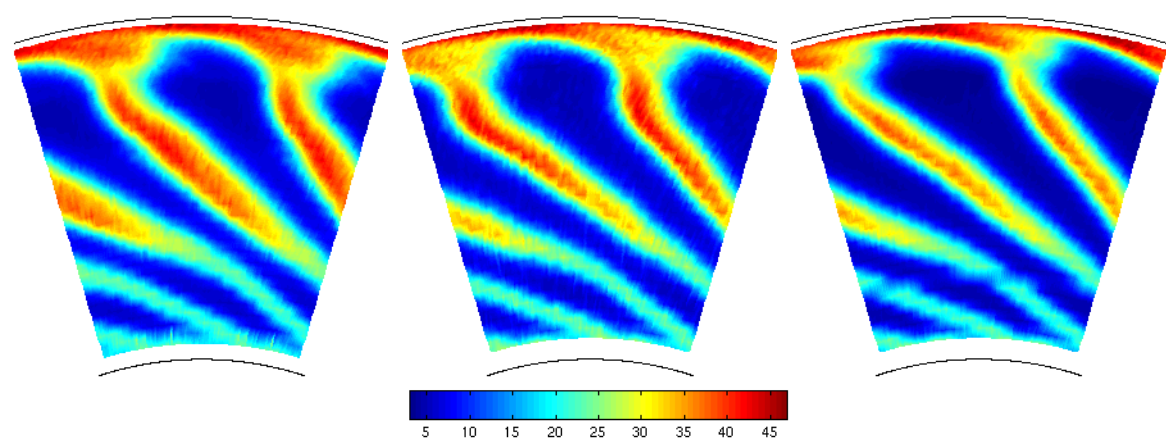

c) Axial turbulent velocity
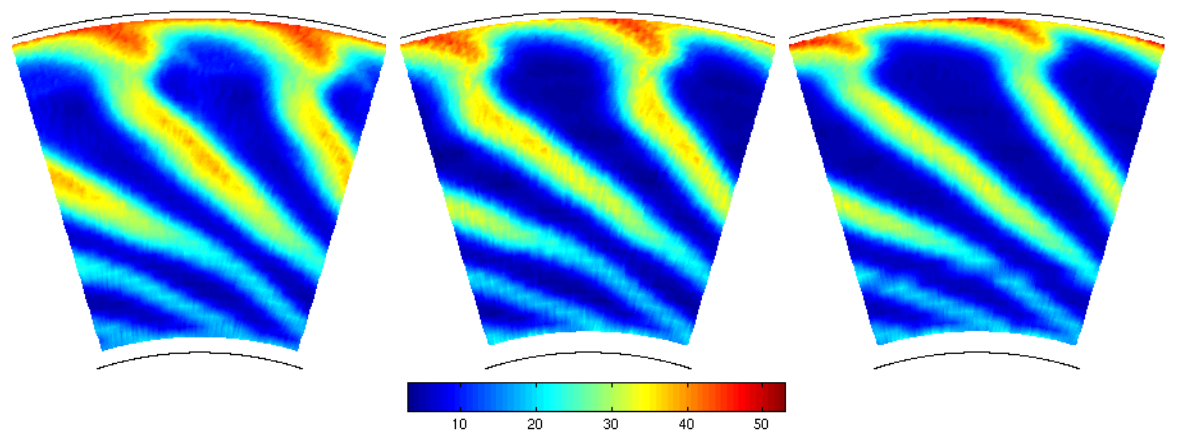

d) Tangential turbulent velocity

Figure 21.-LDV mean velocity and turbulence measurements at 87.5 percent corrected fan speed (cutback condition) for three fan nozzle configurations. 

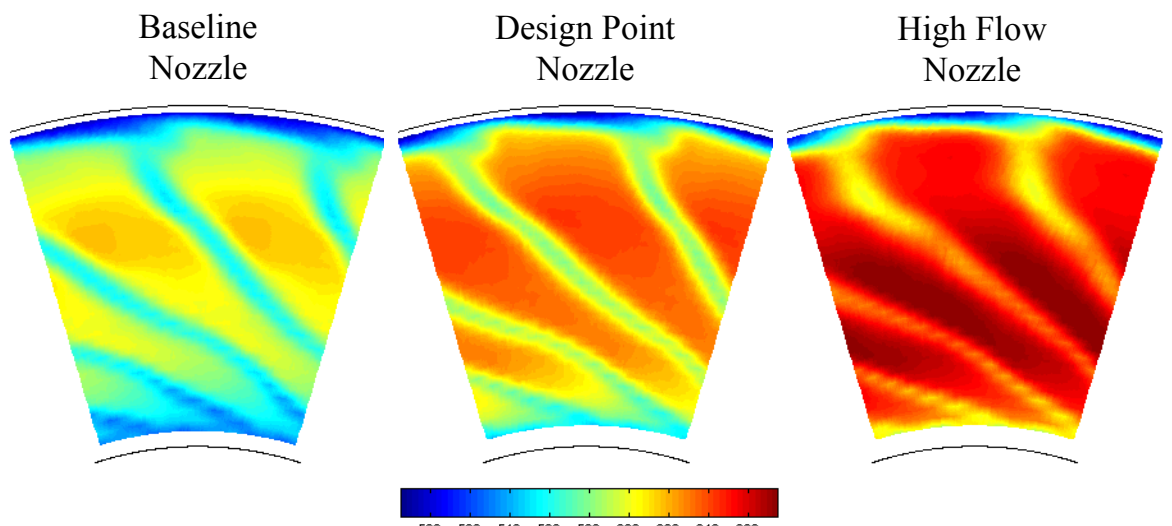

$500 \quad 520 \quad 540 \quad 560 \quad 580 \quad 600 \quad 620 \quad 640 \quad 660$
a) Axial mean velocity
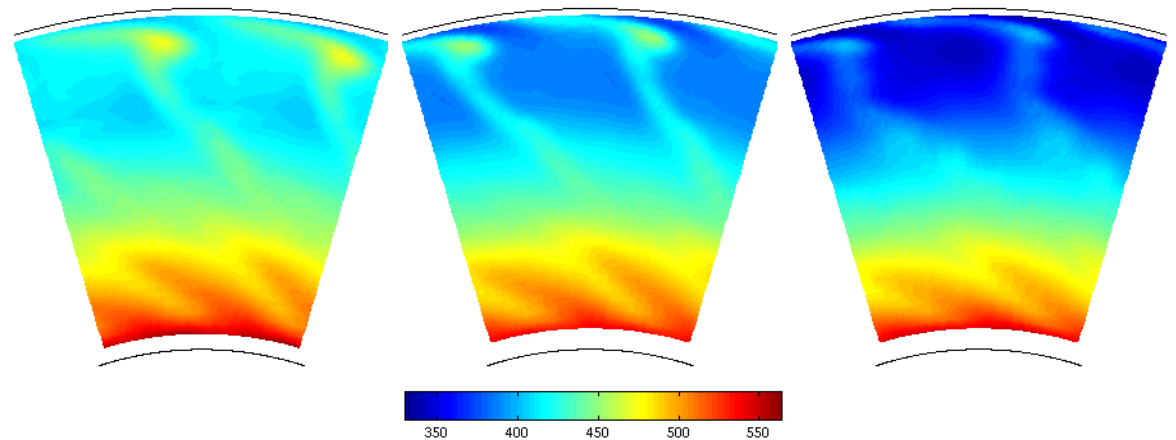

b) Tangential mean velocity
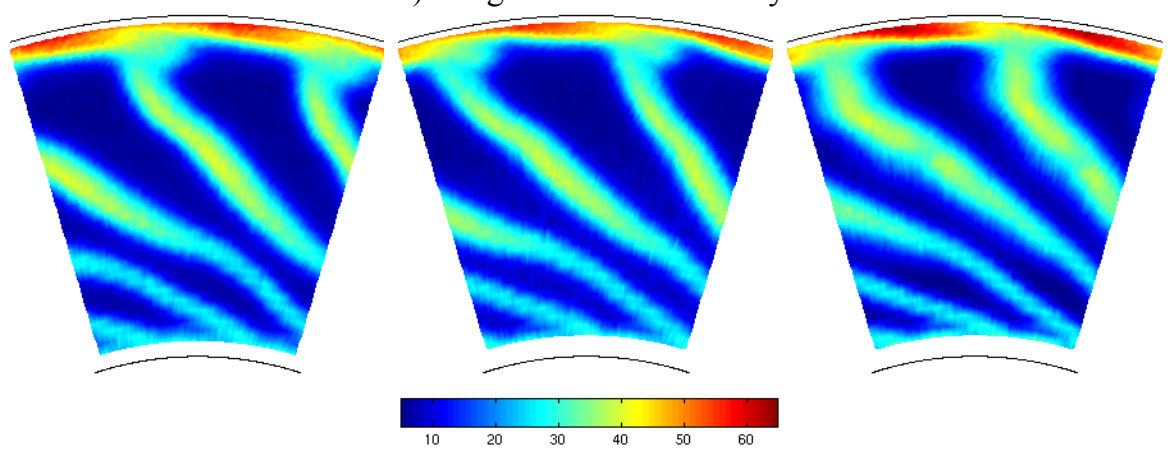

c) Axial turbulent velocity
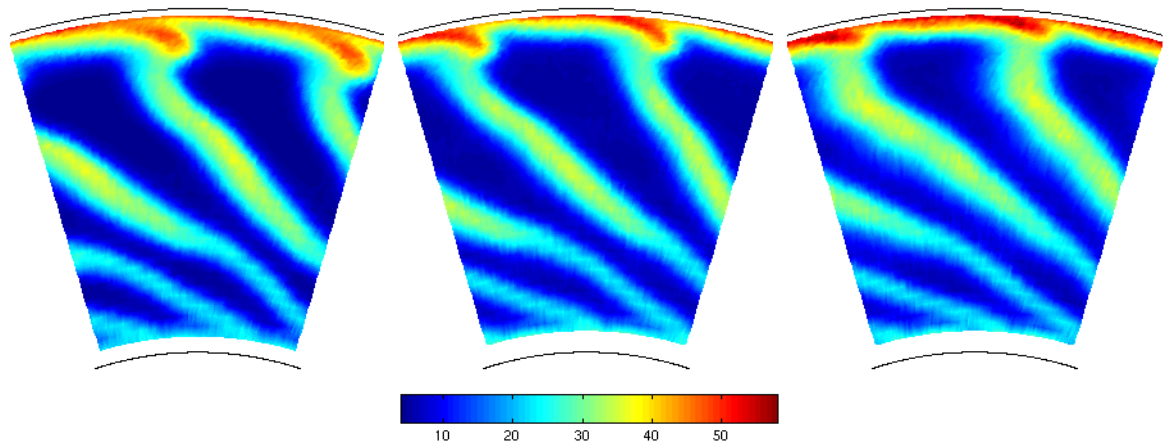

d) Tangential turbulent velocity

Figure 22.-LDV mean velocity and turbulence measurements at 100 percent corrected fan speed (takeoff condition) for three fan nozzle configurations. 


\begin{tabular}{|c|c|c|}
\hline \multicolumn{2}{|c|}{ REPORT DOCUMENTATION PAGE } & $\begin{array}{l}\text { Form Approved } \\
\text { OMB No. 0704-0188 }\end{array}$ \\
\hline \multicolumn{3}{|c|}{ 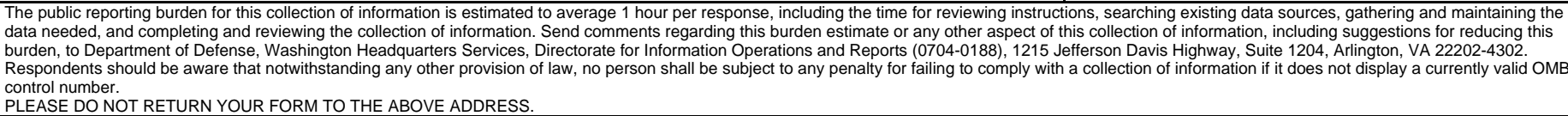 } \\
\hline $\begin{array}{l}\text { 1. REPORT DATE (DD-MM-YYYY) } \\
01-12-2013\end{array}$ & $\begin{array}{l}\text { 2. REPORT TYPE } \\
\text { Technical Memorandum }\end{array}$ & 3. DATES COVERED (From - To) \\
\hline \multirow{3}{*}{\multicolumn{2}{|c|}{$\begin{array}{l}\text { 4. TITLE AND SUBTITLE } \\
\text { The Effect of Bypass Nozzle Exit Area on Fan Aerodynamic Performance and Noise in a } \\
\text { Model Turbofan Simulator }\end{array}$}} & 5a. CONTRACT NUMBER \\
\hline & & 5b. GRANT NUMBER \\
\hline & & 5c. PROGRAM ELEMENT NUMBER \\
\hline \multirow{3}{*}{\multicolumn{2}{|c|}{$\begin{array}{l}\text { 6. AUTHOR(S) } \\
\text { Hughes, Christopher, E.; Podboy, Gary, G.; Woodward, Richard, P.; Jeracki, Robert, J. }\end{array}$}} & 5d. PROJECT NUMBER \\
\hline & & 5e. TASK NUMBER \\
\hline & & $\begin{array}{l}\text { 5f. WORK UNIT NUMBER } \\
\text { WBS-22-781-30-75 }\end{array}$ \\
\hline \multicolumn{2}{|c|}{$\begin{array}{l}\text { 7. PERFORMING ORGANIZATION NAME(S) AND ADDRESS(ES) } \\
\text { National Aeronautics and Space Administration } \\
\text { John H. Glenn Research Center at Lewis Field } \\
\text { Cleveland, Ohio 44135-3191 }\end{array}$} & $\begin{array}{l}\text { 8. PERFORMING ORGANIZATION } \\
\text { REPORT NUMBER } \\
\text { E-15384 }\end{array}$ \\
\hline \multirow{2}{*}{\multicolumn{2}{|c|}{$\begin{array}{l}\text { 9. SPONSORING/MONITORING AGENCY NAME(S) AND ADDRESS(ES) } \\
\text { National Aeronautics and Space Administration } \\
\text { Washington, DC 20546-0001 }\end{array}$}} & $\begin{array}{l}\text { 10. SPONSORING/MONITOR'S } \\
\text { ACRONYM(S) } \\
\text { NASA }\end{array}$ \\
\hline & & $\begin{array}{l}\text { 11. SPONSORING/MONITORING } \\
\text { REPORT NUMBER } \\
\text { NASA/TM-2013-214029 }\end{array}$ \\
\hline \multicolumn{3}{|c|}{$\begin{array}{l}\text { 12. DISTRIBUTION/AVAILABILITY STATEMENT } \\
\text { Unclassified-Unlimited } \\
\text { Subject Category: } 02 \\
\text { Available electronically at http://www.sti.nasa.gov } \\
\text { This publication is available from the NASA Center for AeroSpace Information, 443-757-5802 }\end{array}$} \\
\hline
\end{tabular}

\section{SUPPLEMENTARY NOTES}

\section{ABSTRACT}

The design of effective new technologies to reduce aircraft propulsion noise is dependent on identifying and understanding the noise sources and noise generation mechanisms in the modern turbofan engine, as well as determining their contribution to the overall aircraft noise signature. Therefore, as part of the NASA Quiet Aircraft Technology program, a comprehensive aeroacoustic wind tunnel test program was conducted called the Fan Broadband Source Diagnostic Test. Performed in the NASA Glenn 9- by 15-Foot Low Speed Wind Tunnel, a 1/5 scale model was used to simulate the bypass section of a current generation high bypass turbofan engine. The test objectives were to: identify the noise sources within the model and determine their noise contribution; investigate the impact of component design technology on noise level and aerodynamic performance; and conduct detailed flow diagnostics to characterize the physics of the noise generation mechanisms. This report discusses the results obtained investigating the effect of the bypass nozzle exit area on fan farfield noise and aerodynamic performance. The results will show that there were significant changes in aerodynamic performance and farfield acoustics as the fan nozzle area is increased: weight flow through the fan model increased between 7 and 9 percent; the combined fan stage adiabatic efficiency increased between 2 and 3 percent; total net thrust produced by the fan model increased between 2 and 3.5 percent; and the overall sound power farfield noise level dropped nearly linearly between 1 and $3.5 \mathrm{~dB}$.

\section{SUBJECT TERMS}

Rotors; Fan blades; Noise reduction; Broadband; Wakes; Thrust; Turbofans; Acoustic properties; Aerodynamic characteristics; Nozzle flow; Turbulence; Simulators; Guide vanes; Stator; Microphones; Wind tunnel tests; Engine noise; Scale models

\begin{tabular}{|c|c|c|c|c|c|}
\hline \multicolumn{3}{|c|}{ 16. SECURITY CLASSIFICATION OF: } & \multirow{2}{*}{$\begin{array}{l}\text { 17. LIMITATION OF } \\
\text { ABSTRACT } \\
\text { UU }\end{array}$} & \multirow{2}{*}{$\begin{array}{l}\text { 18. NUMBER } \\
\text { OF } \\
\text { PAGES } \\
42\end{array}$} & \multirow{2}{*}{$\begin{array}{l}\text { 19a. NAME OF RESPONSIBLE PERSON } \\
\text { STI Help Desk (email:help@sti.nasa.gov) } \\
\text { 19b. TELEPHONE NUMBER (include area code) } \\
\text { 443-757-5802 }\end{array}$} \\
\hline $\begin{array}{l}\text { a. REPORT } \\
\text { U }\end{array}$ & $\begin{array}{l}\text { b. ABSTRACT } \\
\text { U }\end{array}$ & $\begin{array}{l}\text { c. THIS } \\
\text { PAGE } \\
\text { U }\end{array}$ & & & \\
\hline
\end{tabular}



